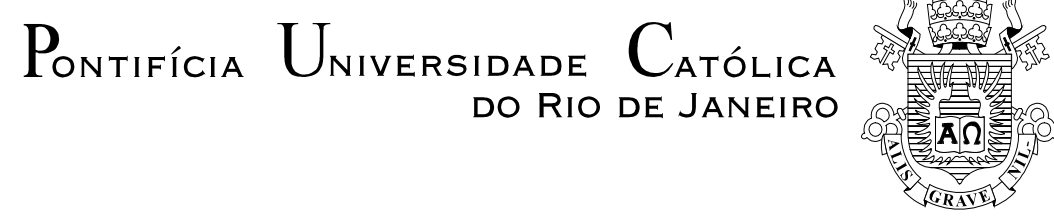

Jerson Erasmo León Almeida

\begin{abstract}
Planejamento da Expansão da Transmissão Considerando a Intermitência da Geração Eólica
\end{abstract}

Dissertação de Mestrado

Dissertação apresentada ao Programa de Pós-graduação em Engenharia Elétrica da PUC-Rio como requisito parcial para obtenção do grau de Mestre em Engenharia de Elétrica.

Orientador: Prof. Armando Martins Leite da Silva Coorientador: Prof. Luiz Antônio da Fonseca Manso 


$$
\begin{array}{r}
\text { Pontifícia } \\
U_{\text {niversidade }} \text { Católica }_{\text {do Rio de Janeiro }}
\end{array}
$$

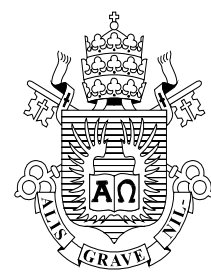

Jerson Erasmo León Almeida

\title{
Planejamento da Expansão da Transmissão Considerando a Intermitência da Geração Eólica
}

\begin{abstract}
Dissertação apresentada como requisito parcial para obtenção do grau de Mestre pelo Programa de Pós-Graduação em Engenharia Elétrica da PUC-Rio. Aprovada pela Comissão Examinadora abaixo assinada.
\end{abstract}

Prof. Armando Martins Leite da Silva Orientador Departamento de Engenharia Elétrica - PUC-Rio

Prof. Luiz Antônio da Fonseca Manso Co-Orientador Universidade Federal de São João Del-Rei

Prof. João Guilherme de Carvalho Costa UNIFEI

Prof. Leonidas Chaves de Resende Universidade Federal de São João Del-Rei

Prof. Márcio da Silveira Carvalho

Coordenador Setorial do Centro Técnico Científico - PUC-Rio 
Todos os direitos reservados. É proibida a reprodução total ou parcial do trabalho sem autorização da universidade, do autor e do orientador.

Jerson Erasmo Leon Almeida

Nasceu em Bucaramanga, Colômbia, no ano 1990. No 2014 se graduou na Universidad Industrial de Santander do programa de Engenharia Elétrica. Atualmente esta fazendo o mestrado no programa de Engenharia Elétrica da PUC-Rio na área de Sistemas de Energia Elétrica. Suas principais áreas de interesse são o planejamento e confiabilidade de sistemas elétricos de potência.

Ficha Catalográfica

Leon, Jerson Erasmo

Planejamento da Expansão da Transmissão Considerando a Intermitência da Geração Eólica / Jerson Erasmo Leon Almeida; orientador: Armando Martins Leite da Silva; coorientador: Luiz Antônio da Fonseca Manso - 2017.

$128 \mathrm{f.} \mathrm{;} 30 \mathrm{~cm}$

Dissertação de Mestrado - Pontifícia Universidade Católica do Rio de Janeiro, Departamento de Engenharia Elétrica.

Inclui bibliografia

1. Engenharia Elétrica - Teses. 2. Algoritmo metaheurístico construtivo 3. Critério de segurança "N-1"; 4. Fontes renováveis; 5. Geração eólica; 6. Planejamento da expansão da transmissão. I. Pontifícia Universidade Católica do Rio de Janeiro. Departamento de Engenharia Elétrica.

CDD: 621.3 


\section{A Deus,}

por me permitir despertar cada dia e olhar o milagre da sua criação.

A meus pais, Erasmo e Martha, pelo seu exemplo, apoio e amor incondicional.

A meus irmãos, Aidee e Didier, por estarem sempre próximos a mim.

A Camila, amiga, confidente e suporte ... minha companheira de vida. 


\section{Agradecimentos}

Aos meus orientadores Armando Martins Leite da Silva e Luiz Antônio da Fonseca Manso pela oportunidade, apoio, compreensão, motivação, orientação e paciência neste árduo e gratificante processo acadêmico.

Aos professores e amigos Fernando Aparecido de Assis, Silvan Antônio Flávio, Ricardo Santos e Diego Celis por todo seu apoio, tempo, colaboração e orientação. Sem vossa ajuda e comentários teria sido mais difícil realizar este trabalho.

À PUC-Rio e aos seus professores do Departamento de Engenharia Elétrica.

Ao CNPq, pelos auxílios fornecidos.

Novamente faço grata menção ao professor Armando, estou muito obrigado por sua imensa ajuda e por ter sido mais que um orientador. Grande exemplo como professor e pessoa.

À minha noiva, por seu apoio constante e incondicional nos bons e maus momentos do transcorrer do meu dia a dia.

Aos meus amigos e colegas da PUC-Rio e UFSJ, pela amizade, apoio e alegrias. 


\section{Resumo}

Leon, Jerson Erasmo; Leite da Silva, Armando Martins (Orientador); Manso; Luiz Antônio da Fonseca (Coorientador). Planejamento da Expansão da Transmissão Considerando a Intermitência da Geração Eólica. Rio de Janeiro, 2017. 128p. Dissertação de Mestrado - Departamento de Engenharia Elétrica, Pontifícia Universidade Católica do Rio de Janeiro.

O planejamento da expansão da transmissão (PET) visa identificar os novos reforços a serem implementados na rede do sistema elétrico de potência, necessários para assegurar uma adequada interligação entre a demanda e a geração do sistema, ambas previstas para o horizonte de planejamento. Um bom plano de expansão deve garantir o equilíbrio entre os custos de investimento e operação, mantendo um nível satisfatório de continuidade no fornecimento de energia. Entretanto, a identificação de boas soluções para o PET tem se tornado uma tarefa cada vez mais difícil. Isso se deve, principalmente, às características e dimensões dos sistemas atuais, incluindo o aumento na dependência de fontes renováveis, e à não linearidade e natureza combinatória do problema de otimização.

Nesta dissertação é proposta uma nova metodologia para resolver o problema PET com alta penetração de energia renovável, em particular a eólica. A metodologia é baseada na aplicação de uma nova ferramenta de otimização para solução do PET estático, a qual é classificada como metaheurística construtiva, onde soluções viáveis de boa qualidade são paralelamente construídas a partir da topologia inicial, por meio de adições graduais de reforços mais atrativos para a rede. Outras heurísticas são também utilizadas. Ênfase é dada à modelagem de cenários de geração eólica, que representam a energia renovável da rede a ser planejada, a qual deverá permitir uma operação flexível e adaptada à intermitência destas fontes. São utilizados o critério de segurança “ $N-1$ ” e o modelo linear DC de rede, com a consideração de perdas ôhmicas. Uma variante do sistema IEEE RTS, com inserção de fontes eólicas, é utilizada para testar a metodologia proposta.

\section{Palavras-chave}

Algoritmo metaheurístico construtivo; Critério de segurança "N-1"; Fontes renováveis; Geração eólica; Planejamento da expansão da transmissão. 


\section{Abstract}

Leon, Jerson Erasmo; Leite da Silva, Armando Martins (Advisor); Manso, Luiz Antônio da Fonseca (Co-advisor). Transmission Expansion Planning Considering the Intermittency of Wind Generation. Rio de Janeiro, 2017. 128p. Dissertação de Mestrado - Departamento de Engenharia Elétrica, Pontifícia Universidade Católica do Rio de Janeiro.

Transmission expansion planning (TEP) aims to identify the new reinforcements to be installed in the electric power system, necessary to ensure an adequate interconnection between demand and generation of the system, both foreseen for the planning horizon. A good expansion plan should ensure a balance between investment and operating costs, while maintaining a satisfactory level of continuity in the energy supply. However, identifying good expansion solutions for TEP has become an increasingly difficult task. This is mainly due to the characteristics and dimensions of the current systems, including the increase in the dependence of renewable sources, and the nonlinearity and combinatorial nature of the optimization problem.

In this dissertation, a new methodology is proposed to solve the TEP problem with high penetration of renewable energy, in particular wind power. The methodology is based on the application of a new optimization tool for static TEP solution, which is classified as a constructive metaheuristic, where feasible solutions of good quality are simultaneously constructed from the initial topology of the network, through incremental additions of reinforcements more attractive to the grid. Other heuristics are also used. Emphasis is given to the modeling of wind power scenarios, which represent the renewable energy of the network to be planned, which should allow a flexible operation and adapted to the intermittency of these sources. The security criterion "N-1" and the linear DC network model are used, with the consideration of ohmic losses. A variant of the IEEE RTS system, with insertion of wind sources, is used to test the proposed methodology.

\section{Keywords}

Constructive metaheuristic tool; Renewable sources, Security criteria "N-1"; Transmission expansion planning; Wind generation. 


\section{Sumário}

1 Introdução 16

$\begin{array}{ll}\text { 1.1. Considerações Gerais } & 17\end{array}$

1.2. Desenvolvimento Histórico - Estado da Arte 20

1.3. Estrutura da Dissertação 24

2 PLANEJAMENTO DA EXPANSÃO DA TRANSMISSÃO 26

2.1. Modelagem do Problema 26

2.2. Abordagens Disponíveis para Resolver o Problema PET 28

2.2.1. Otimização clássica matemática 29

2.2.2. Técnicas Heurísticas 29

2.2.3. Técnicas Metaheurísticas 30

2.3. Consideração de incertezas 36

2.3.1. Abordagem Determinística 36

2.3.2. Abordagem Não Determinística 37

2.4. Conclusão 38

3 METODOLOGIA 39

3.1. Introdução 39

3.2. Formulação do Problema PET com Critério de Segurança 39

3.2.1. Subproblema de Investimento 40

3.2.2. Subproblema de Operação 41

3.3. Algoritmo Metaheurístico Construtivo [1] 42

3.3.1. Conceitos Básicos 43

3.3.2. Mecanismos Construtivos $\quad 45$

3.3.3. Algoritmo Descritivo 48

3.4. Algoritmo Proposto para o PET Considerando a Intermitência da Geração Eólica 51

3.4.1. Estabelecimento dos Cenários de Geração Eólica 52

3.4.2. Ajuste do Conjunto de Parâmetros da Ferramenta AMC-PET 53

3.4.3. Tabela Decisão 53 
3.4.4. Etapa Iterativa para a Convergência dos Planos de Expansão

55

3.4.5. Etapa Combinatória para a Convergência dos Planos de Expansão

57

3.4.6. Algoritmo Descritivo 58

3.5. Conclusão 61

4 APLICAÇÃO $\quad 62$

4.1. Introdução 62

4.2. Sistema Teste 62

4.2.1. Informação das Barras 63

4.2.2. Rede de Transmissão Inicial 65

4.2.3. Dados dos Ramos Candidatos 66

4.3. Obtenção dos Cenários de Geração Eólica - Passo I 67

4.4. Ajuste dos Parâmetros do AMC-PET - Passo II 69

4.5. Obtenção do melhor plano de expansão para cada cenário e construção da Tabela Decisão - Passos III e IV

4.6. Etapa Iterativa para Convergência dos Planos de Expansão -

Passo V

4.6.1. Iteração 1

4.6.2. Iteração 2

4.6.3. Iteração 3

4.6.4. Iterações 4 a 10

4.7. Etapa Combinatória Para a Convergência dos Planos de

Expansão - Passo VI 83

4.8. Comparação com planos adicionais 86

4.8.1. Desconsideração inicial dos cenários menos prováveis $\quad 86$

4.8.2. Relaxamento na análise de contingências "N-1" 89

4.8.3. Análise comparativa dos planos obtidos 92

4.9. Esforço Computacional 93

4.10. Conclusão 94

5 CONCLUSÃO 96

$\begin{array}{ll}\text { Trabalhos futuros } & 97\end{array}$ 
REFERÊNCIAS BIBLIOGRÁFICAS

APÊNDICE A - "Tabelas Decisão" Complementares 


\section{Lista de Figuras}

Figura 1.1 - Capacidade global instalada de fontes eólicas e adições

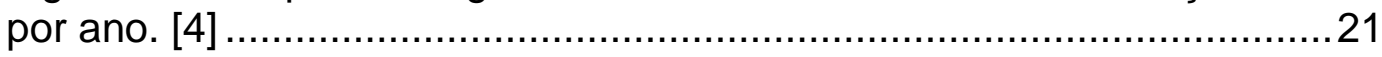

Figura 1.2 - Capacidade eólica instalada - Top 10 países [4]..................21

Figura 3.1 - Fluxograma representativo do AMC-PET [44] .....................50

Figura 3.2 Dinâmica entre conjuntos e mecanismos na evolução

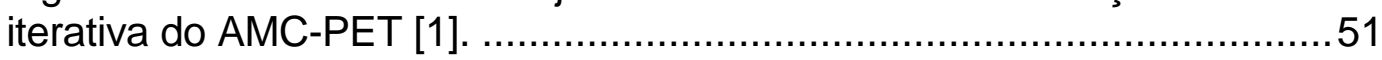

Figura 3.3 - Fluxograma da metodologia proposta para o PET considerando a intermitência da geração eólica. .......................................6

Figura 4.1 - Esquema representativo do sistema IEEE-RTS ...................63

Figura 4.2 - Média móvel mensal das séries de capacidade eólica por

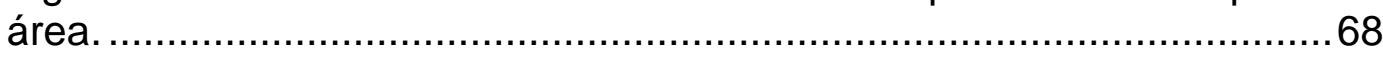




\section{Lista de Tabelas}

Tabela 3.1 - Exemplo para a estrutura da Tabela Decisão. .....................55

Tabela 4.1 - Geração Eólica para o Sistema IEEE RTS_Wind ................64

Tabela 4.2 - Informação das barras do sistema IEEE RTS_Wind...........66

Tabela 4.3 - Dados de circuitos existentes do sistema IEEE RTS Wind.

Tabela 4.4 - Dados dos Ramos Candidatos do sistema IEEE RTS_Wind.

Tabela 4.5 - Resumo dos cenários estabelecidos.

Tabela 4.6 - Conjuntos de Ajustes para configurar a ferramenta AMC-PET

Tabela 4.7 - Número de execuções definidas para a ferramenta AMC-PET segundo cada cenário.

Tabela 4.8 - Tabela Decisão Inicial. ............................................. 72

Tabela 4.9 - Reforços consolidados na Tabela Decisão Inicial. ..............73

Tabela 4.10 - Tabela Decisão da Iteração 1........................................74

Tabela 4.11 - Reforços consolidados até a Tabela Decisão da Iteração 1.

Tabela 4.12 - Tabela Decisão da Iteração 2

Tabela 4.13 - Reforços consolidados até a Tabela Decisão da Iteração 2 77

Tabela 4.14 - Tabela Decisão da Iteração 3 - Alternativa 1. .78

Tabela 4.15 - Tabela Decisão da Iteração 3 - Alternativa 2 79

Tabela 4.16 - Reforços consolidados até a Tabela Decisão da Iteração 3

Tabela 4.17 - Resumo das Iterações 4 a 10 81

Tabela 4.18 - Tabela Decisão da Iteração 10 82

Tabela 4.19 - Reforços consolidados até a Tabela Decisão da Iteração 10.

Tabela 4.20 - Combinações possíveis com 2 dos 4 reforços exclusivos remanescentes.

Tabela 4.21 - Plano Final - Resultado da aplicação da metodologia proposta. 85

Tabela 4.22 - Tabela Decisão Inicial - Cenários mais Prováveis. 87

Tabela 4.23 - Plano Final - Cenários mais Prováveis. 88 
Tabela 4.24 - Tabela Decisão Inicial - Relaxamento no "N-1" ................90

Tabela 4.25 - Plano Final - Relaxamento no "N-1". .............................91

Tabela 4.26 - Comparação entre os planos obtidos..............................92

Tabela A.1 - Tabela Decisão da Iteração 4 - Alternativa 1.....................106

Tabela A.2 - Tabela Decisão da Iteração 4 - Alternativa 2..................... 107

Tabela A.3 - Reforços consolidados até a Tabela Decisão da

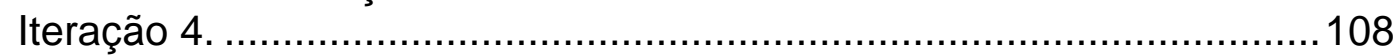

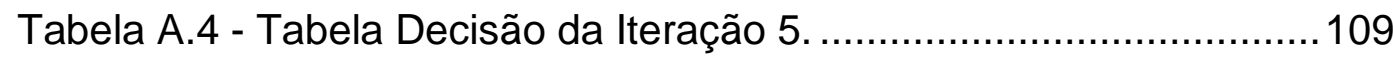

Tabela A.5 - Reforços consolidados até a Tabela Decisão da Iteração 5.

Tabela A. 6 - Tabela Decisão da Iteração 6 - Alternativa 1................... 111

Tabela A.7 - Tabela Decisão da Iteração 6 - Alternativa 2................... 112

Tabela A.8 - Tabela Decisão da Iteração 6 - Alternativa 3................... 113

Tabela A.9 - Tabela Decisão da Iteração 6 - Alternativa 4 ................... 114

Tabela A.10 - Tabela Decisão da Iteração 6 - Alternativa 5.................. 115

Tabela A.11 - Reforços consolidados até a Tabela Decisão da Iteração 6.

Tabela A.12 - Tabela Decisão da Iteração 7 - Alternativa 1.

Tabela A.13 - Tabela Decisão da Iteração 7 - Alternativa 2

Tabela A.14 - Tabela Decisão da Iteração 7 - Alternativa 3

Tabela A.15 - Tabela Decisão da Iteração 7 - Alternativa 4. 120

Tabela A.16 - Reforços consolidados até a Tabela Decisão da Iteração 7 .

Tabela A.17 Tabela Decisão da Iteração 8.

Tabela A.18 - Reforços consolidados até a Tabela Decisão da Iteração 8 .

Tabela A.19 - Tabela Decisão da Iteração 9 - Alternativa 1.

Tabela A.20 - Tabela Decisão da Iteração 9 - Alternativa 2. 125

Tabela A.21 - Reforços consolidados até a Tabela Decisão da Iteração 9.

Tabela A.22 - Tabela Decisão da Iteração 10.

Tabela A.23 - Reforços consolidados até a Tabela Decisão da Iteração 10. 


\section{Lista de Abreviaturas}

ACO - $\quad$ Otimização por Colônia de Formigas (Ant Colony Optimization)

ACS - $\quad$ Sistemas de Colônia de Formigas (Ant Colony Systems)

AHC - Algoritmo Heurístico Construtivo

AIS - $\quad$ Sistema Imunológico Artificial (Artificial Immune System)

AMC - Algoritmo Metaheurístico Construtivo

EENS - V Valor Esperado de Energia não Suprida (Expected Energy NotSupplied)

ES - $\quad$ Estratégia de Evolução (Evolutionary Strategy)

GA - $\quad$ Algoritmo Genético (Genetic Algorithm)

GRASP - Procedimento de Busca Adaptativa Aleatória Gulosa (Greedy Randomized Adaptive Search Procedure)

MA - $\quad$ Mecanismo de Adição

MC - Mecanismo de Cruzamento

MD - $\quad$ Mecanismo de Depuração

MM - Mecanismo de Mutação

MR - Mecanismo de Refinamento

MS - $\quad$ Mecanismo de Seleção

OO - $\quad$ Otimização Ordinal (Ordinal Optimization)

PET - $\quad$ Planejamento da Expansão da Transmissão

PSO - $\quad$ Otimização por Enxame de Partículas (Particle Swarm Optimization)

SA - $\quad$ Recozimento Simulado (Simulated Annealing)

SMCNS - Simulação Monte Carlo Não Sequencial

SMCS - Simulação Monte Carlo Sequencial

TS - Busca Tabu (Tabu Search) 


\title{
Lista de Símbolos
}

\author{
$\Omega_{\mathrm{IV}}-\quad$ Conjunto de Indivíduos Viáveis \\ $\Omega_{\mathrm{MA}}-\quad$ Conjunto Reduzido de Indivíduos obtidos pelo Mecanismo de Adição \\ $\Omega_{\mathrm{MCM}}-\quad$ Conjunto Reduzido de Indivíduos obtidos, de forma conjunta, pelos \\ Mecanismos de Cruzamento e de Mutação \\ $\Omega_{\mathrm{MD}}-\quad$ Conjunto de Indivíduos obtidos pelo Mecanismo de Depuração
}




\section{1 \\ Introdução}

Nas últimas duas décadas, tem-se observado uma maior preocupação ambiental pelo constante crescimento na produção de gases do efeito estufa por parte da indústria. Considerando esta preocupação no setor da produção de energia elétrica nos últimos anos, tem-se dado um acréscimo significativo no desenvolvimento de pesquisas e implementação de novas tecnologias, para gerar energia elétrica de maneira mais “amigável” com o meio ambiente, ou com menor repercussão negativa com este último.

Além de serem “amigáveis” com o ambiente, as fontes de energia renováveis podem representar uma boa opção de negócio pelo baixo custo para produzir energia elétrica. Ademais, tem-se que considerar o fato que em muitos casos, a implementação destas fontes tem sido fortemente apoiada pelos governos por meio de políticas de incentivo (e.g., financeiro, fiscal, etc.).

A elevada inserção das fontes renováveis de geração elétrica na matriz energética, traz consigo impactos significativos na operação e planejamento do sistema elétrico de potência, os quais devem ser devidamente abordados por técnicos, engenheiros e gerentes das empresas do setor elétrico. Faz-se então necessária a proposta de novas metodologias e ferramentas para atingir de forma apropriada a operação e o planejamento dos sistemas sob critérios de qualidade e segurança estabelecidos, sem perder o foco do investimento adequado. Assim, muitas das propostas atuais consideram o uso de fontes renováveis.

Em matéria de planejamento, seja de curto, médio ou longo prazo, o problema da inserção de fontes renováveis traz uma ampliação significativa na complexidade para solucioná-lo, principalmente pelo aumento das incertezas associadas à natureza das fontes renováveis, dificultando ainda mais a modelagem do problema em questão. Especificamente o planejamento da expansão da transmissão (PET) pode ser tratado utilizando metodologias e técnicas de otimização clássicas (programação matemática), as quais são mais atrativas em sistemas de pequeno e médio porte, onde a natureza do problema não apresenta uma elevada 
explosão combinatória, como acontece em sistemas de grande porte. Em sistemas de grande dimensão, faz-se necessário adotar outros tipos de metodologias e técnicas, como as metaheurísticas, que representam uma boa opção de modelagem, pois embora não garanta como resposta a melhor solução ótima possível, seu emprego proporcionará um conjunto de soluções viáveis de excelente qualidade para a escolha do planejador.

Este trabalho consiste em tratar o problema PET com significativa inserção de fontes de geração renovável, mais especificamente a geração eólica. A abordagem estará baseada no desacoplamento do problema de otimização em dois subproblemas, investimento e operação, sob o critério de segurança “N-1”. O problema de otimização será resolvido por técnicas metaheurísticas aplicadas adequadamente aos diversos cenários possíveis de geração eólica, considerando a importância individual de cada cenário baseado em dados históricos. O produto final da metodologia, que fundamenta esta dissertação, será a obtenção de um plano de expansão da rede de transmissão para um sistema com alta participação de fontes de geração eólica. Este plano terá a capacidade de operar em cada um dos cenários estabelecidos, garantindo assim, uma operação flexível e segura para o sistema avaliado, com baixo custo de investimento.

\section{1. \\ Considerações Gerais}

Um sistema elétrico de potência é o conjunto de subsistemas que incluem: geração, transmissão e distribuição de energia elétrica. A sinergia entre estes subsistemas pode ser resumida como: os elementos de geração de energia elétrica suprirão uma demanda ou carga, através de elementos de interligação, os quais transportarão a energia desde as usinas de geração até os pontos de distribuição.

Dado o permanente crescimento demográfico e econômico haverá também um aumento da demanda energética, surgindo assim a necessidade de se planejar tais sistemas de maneira ótima, considerando qualidade, segurança e os custos dos investimentos envolvidos. Desta forma, o planejamento dos sistemas de energia elétrica dependerá também do intervalo de tempo contemplado, tendo-se de maneira resumida os seguintes horizontes: 


\section{Planejamento de curto e curtíssimo prazo:}

- São períodos que abrangem desde horas até semanas;

- Neste horizonte, o planejamento está orientado principalmente à demanda de energia e à correta operação para suprir tal demanda;

- Inclui estudos de previsão do comportamento da carga e de manobras de operação e controle do sistema de potência elétrico (e.g., o controle automático de geração) com o montante de geração disponível.

\section{Planejamento de médio prazo:}

- São períodos que vão de meses até poucos anos;

- Neste horizonte, o planejamento está orientado aos três aspectos que formam um sistema elétrico de potência: geração, transmissão e carga;

- Conterá estudos de previsão de carga, previsão da geração disponível (e.g., previsão do nível das vazões em centrais hidroelétricas), e projetos em geração e transmissão que estarão próximos a concluir, e portanto, disponíveis.

\section{Planejamento de longo prazo:}

- São períodos de alguns anos até décadas;

- Semelhante ao horizonte anterior, também incluindo o planejamento da geração, transmissão e carga;

- Tem-se um número elevado de incertezas ao realizar previsões de carga (potência e energia) e usinas para expandir a capacidade de geração do sistema.

É importante destacar, que na medida em que o horizonte de planejamento aumenta, o número de incertezas a ser analisado também cresce, sendo permitidas certas simplificações para abordar o problema PET. Por exemplo, no planejamento de longo prazo da transmissão podem ser usados modelos lineares DC de rede para resolver as avaliações de fluxo de potência. À medida que o horizonte de planejamento é encurtado, o número de incertezas também se torna menor e modelos mais rigorosos para representar a rede elétrica são utilizados. Por exemplo, no médio, curto e curtíssimo prazo, ferramentas baseadas em modelos não lineares AC de rede devem ser utilizadas. 
O foco principal deste trabalho é o último horizonte descrito, i.e., planejamento de longo prazo para rede de transmissão de um sistema de potência de energia elétrica, considerando a inserção de fontes de geração eólica.

O objetivo principal do planejamento da expansão da rede de transmissão de um sistema elétrico de potência consiste em definir os reforços a serem implantados no sistema, respeitando aspectos regulatórios e critérios de qualidade e segurança, de modo a garantir o suprimento sem interrupção de energia elétrica, desde os elementos de geração do sistema até os pontos de demanda, observando sempre o investimento necessário para atingir este objetivo.

A pesquisa para encontrar novos e melhores caminhos para o problema PET torna-se mais difícil ao passar do tempo. Isto se dá pelo grande crescimento e diversidade das matrizes energéticas, o surgimento de novas incertezas e a adoção de novas políticas e regulações que devem ser consideradas. O problema pode ser classificado com de grande complexidade, estocástico e de natureza combinatória explosiva, podendo ser também classificado como um problema de programação não linear inteira mista [1].

Atualmente, o problema PET pode ser avaliado principalmente de duas maneiras:

- Uma abordagem determinística, que consiste em resolver o problema baseando-se em otimização matemática exata, considerando uma função objetivo (geralmente o custo de investimento) e um conjunto bem estabelecido de variáveis e restrições;

- Uma abordagem heurística e/ou metaheurística, que consiste em resolver o problema através de conjunto de técnicas que utilizam informações, regras e métodos que, embora possam não fornecer a solução ótima, fornecem um conjunto de boas soluções viáveis a serem consideradas pelo planejador.

A conveniência entre a aplicação de uma destas abordagens é critério de escolha do planejador para seu estudo, sendo ele/ela quem tem que considerar as vantagens e desvantagens [2] para a solução do problema a ser resolvido.

Outros aspectos importantes a considerar no problema PET são a segurança e a confiabilidade da rede ante uma possível contingência. Entretanto, devido ao esforço computacional requerido para realizar os cálculos desses aspectos, têm-se 
poucos trabalhos na literatura atual que consideram tais critérios embutidos na solução do problema PET. Há alguns trabalhos que realizam avaliações de segurança e/ou confiabilidade no final do processo de busca, somente para os planos factíveis de expansão da transmissão encontrados, obtendo assim custos de investimento geralmente mais elevados, quando comparados a um procedimento que avalie tais critérios durante o processo de busca [3].

A inserção de fontes renováveis no sistema sendo planejado, traz novos aspectos que devem ser incluídos na avaliação do problema PET, como a aparição de incertezas próprias à natureza da fonte (e.g., erros na previsão do vento em fontes eólicas), a modelagem das novas tecnologias (e.g., baterias), etc. Questionamentos surgem para serem resolvidos por meio de pesquisas e propostas e constituem novos desafios assumidos pela engenharia.

\section{2.}

\section{Desenvolvimento Histórico - Estado da Arte}

Nos últimos anos, a matriz de energia elétrica global tem sofrido importantes mudanças, tanto no incremento da demanda energética, como na inserção de novas alternativas de geração para suprir essa demanda. Isto se pode observar com o expressivo aumento de fontes renováveis ao redor do mundo [4]. Fato que vem sendo considerado entre os operadores e planejadores dos sistemas elétricos de potência, pois a natureza intermitente dessas fontes, eleva o grau de complexidade operacional do sistema ao aumentar significativamente o nível de incerteza. $\mathrm{Na}$ Figura 1.1, pode-se observar o crescimento na capacidade global instalada de fontes eólicas e adições por ano, e na Figura 1.2, a informação sobre os dez países com maior capacidade eólica instalada.

Tendo por objetivo, realizar o planejamento da rede de transmissão para uma demanda e geração previstas num horizonte de tempo, devem-se abranger os conceitos necessários para abordar o problema PET. Por exemplo, em [5], é utilizado o modelo AC para calcular fluxos de potência, e em [6] é apresentado de forma detalhada o conceito e desenvolvimento do fluxo de potência ótimo. 


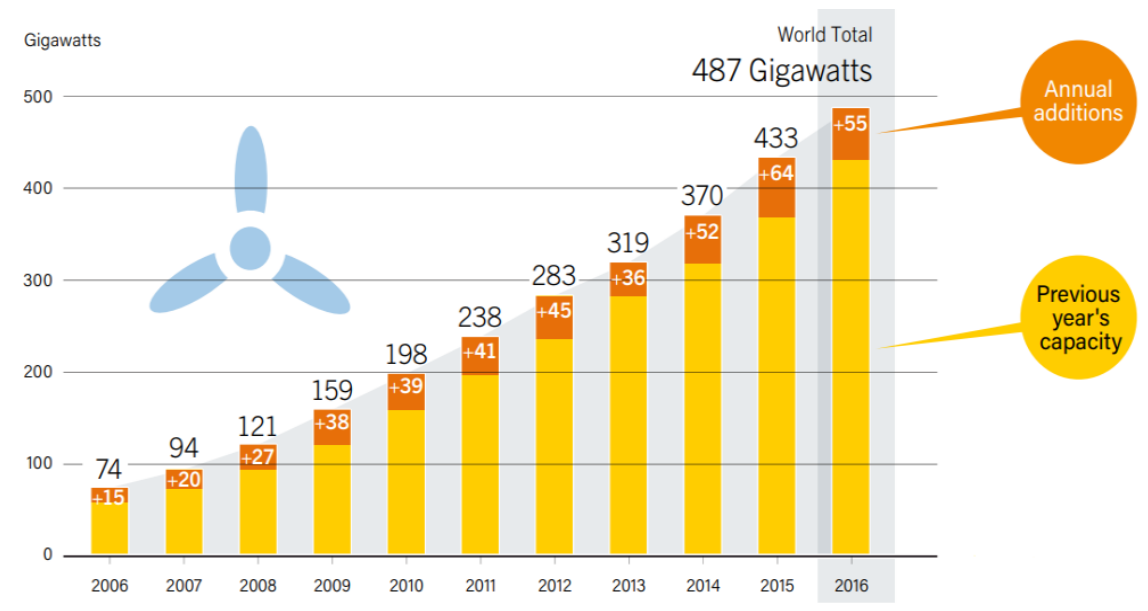

Figura 1.1 - Capacidade global instalada de fontes eólicas e adições por ano. [4]

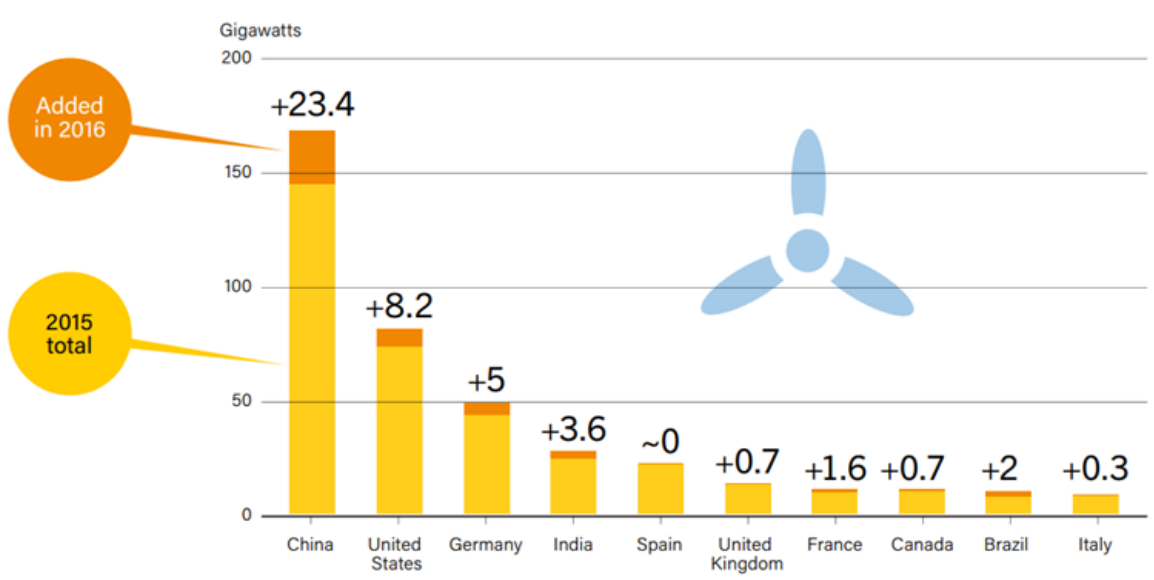

Figura 1.2 - Capacidade eólica instalada - Top 10 países [4].

Além dos conceitos, na literatura atual é possível encontrar diferentes abordagens para o problema PET. Uma destas é empregar técnicas matemáticas estritas para otimização, como em [7], [8], [9], [10] e [11]. Contudo uma abordagem matemática clássica garante a obtenção do ótimo global do problema de otimização, esta não é viável em sistemas de grande robustez devido à alta complexidade própria daqueles sistemas.

Outras maneiras disponíveis para abordar o problema PET são: uma abordagem heurística, que consiste em adotar técnicas advindas da experiência de especialistas na área do planejamento, como em [2]; ou uma abordagem metaheurística, que consiste em adotar técnicas baseadas na modelagem de comportamentos naturais como em [1], [12], [13], [14] e [15]. Estas duas abordagens, embora este- 
jam bem adaptadas para obter soluções de boa qualidade, não garantem a obtenção do ótimo local como a abordagem matemática clássica.

Por outro lado, na literatura disponível tem-se grande variedade de trabalhos concernentes à área do problema PET. Na referência [16], foi feito um levantamento bibliográfico compilando diversas pesquisas relacionadas ao problema PET, considerando a inserção de fontes de energia renovável.

Com o objetivo de adequar a rede de transmissão à alta penetração de fontes renováveis, existem alguns trabalhos na literatura com sugestões técnicas e recomendações, como é apresentado nas referências [17], [18] e [19]. Outro exemplo é publicado em [20], onde é proposta uma nova metodologia probabilística para avaliar os requesitos de reserva operativa em sistemas com alta inserção de fontes renováveis, a partir de simulação Monte Carlo cronológica.

Outros trabalhos têm sido apresentados na literatura, com procedimentos e metodologias bem definidas, como no caso da pesquisa desenvolvida em [21], que apresenta uma abordagem cronológica usando a simulação de Monte Carlo no PET. Nesta pesquisa é considerada a confiabilidade do sistema através do cálculo de índices probabilísticos, e, além disso, avaliado o desperdício da energia eólica.

Adicionalmente, na literatura atual respectiva ao problema PET, têm-se procedimentos probabilísticos para solução do mesmo. Um exemplo destes, pode ser o estudo realizado em [22], cujo objetivo é reduzir custos de investimento na geração eólica a partir do planejamento da expansão da rede de transmissão. Isto é feito com base num modelo estocástico binível para o planejamento da transmissão e da geração eólica, além do emprego de um método híbrido para representar as incertezas na carga e no potencial eólico.

Abordagens probabilísticas mais recentes são descritas em [23] e [24], onde de forma estocástica, tem-se por objetivo principal avaliar os impactos da penetração da geração eólica no sistema, considerando a resposta da demanda ante tal situação.

Em [25] e [26], é abordado o problema PET por meio de metodologias multiobjetivo. Em [25] procura-se a minimização do corte na energia eólica, e em [26], procura-se o menor custo de investimento para reforçar a rede considerando a confiabilidade. No recente trabalho realizado em [27], é proposta uma abordagem dinâmica considerando fontes renováveis, com uma formulação robusta 
adaptativa para considerar múltiplas variáveis ano por ano no processo dinâmico de planejamento.

Com relação no aspecto econômico, atualmente têm-se desenvolvidos trabalhos interessantes. Por exemplo, para artigos relacionados a aspectos econômicos e regulatórios para a inserção de fontes renováveis no sistema, pode-se citar a referência [28], onde se descreve um caso de conexão, sendo utilizadas redes coletoras com o objetivo de agrupar um conjunto de usinas renováveis para conectá-las a rede básica. Outro trabalho bem relacionado com aspectos econômicos é apresentado em [29], onde é proposto um modo de solução do problema PET associado ao planejamento análogo da potência reativa. O estudo procura a minimização do custo de investimento e a maximização do “bem-estar social”, respeitando restrições de confiabilidade, ao mesmo tempo em que são consideradas incertezas na geração eólica e na carga.

Também é considerada a parte técnica e operativa no problema PET. Por exemplo, em [30] é discutida a capacidade de transmissão requerida pelas linhas que interligam as áreas com elevada participação de fontes renováveis. Nesta discussão, procura-se responder qual deve ser a proporção, em relação à capacidade instalada de uma fazenda eólica, para que a linha de transmissão possa operar adequadamente.

Têm-se também trabalhos na literatura atual que incluem realizar o planejamento da expansão da geração em conjunto junto com o PET, para assim, conseguir coordenar de melhor modo a interação entre a integração eólica e o planejamento da rede de transmissão no horizonte contemplado, como é exposto em [31], [32] e [33].

Semelhante à geração hidráulica, a geração eólica pode-se localizar muito distante dos centros de carga distribuídos pelo sistema, sendo por isto que existem análises como em [34] e [35], que consideram os impactos nos estudos PET da alta penetração e localização da geração eólica.

Considerando o significativo avanço e participação das tecnologias para armazenamento de energia nas atuais pesquisas do setor elétrico, têm-se trabalhos que consideram o desenvolvimento de metodologias para o planejamento da rede de transmissão, junto à implementação de dispositivos para armazenamento de energia ao longo da mesma, como no trabalho realizado em [36]. 
Definir a capacidade de transmissão de linhas que interligam áreas de elevada participação renovável é uma questão bastante importante, e não considerar a intermitência dessas fontes pode trazer grandes implicações financeiras e operacionais. Por exemplo, considerar a capacidade de transmissão próxima da máxima potência instalada nas usinas, implica em custos mais elevados do que o necessário, possíveis prejuízos por parte dos investidores, além de ativos ociosos. Por outro lado, uma capacidade de transmissão considerada próxima da média de produção das fazendas eólicas pode ocasionar desperdícios de vento, maior risco de não chegar às metas de geração renovável e um consequente aumento dos custos de produção [37].

Diferentes trabalhos baseados em técnicas metaheurísticas têm comprovado ser excelentes ferramentas para resolver o problema PET para sistemas de médio e grande porte, pois encontram soluções de alta qualidade com um custo computacional relativamente baixo [38]. A maior vantagem destas ferramentas consiste em fazer uma pesquisa global na minimização de custos evitando pontos ótimos locais. Em outras palavras, as ferramentas metaheurísticas exploram de maneira eficiente o espaço de busca.

Nesta dissertação de mestrado o algoritmo metaheurístico aplicado no estudo é denominado Algoritmo Mataheurístico Construtivo (AMC) [1]. Trata-se de um processo de construção paralela, gradual, intercambiada e depurada e tem por objetivo identificar boas soluções (planos de expansão) para o problema PET estático. Este algoritmo é aplicado após a escolha dos cenários de geração eólica.

\section{3.}

\section{Estrutura da Dissertação}

A presente dissertação de mestrado inclui cinco capítulos. O presente capítulo busca introduzir o leitor às questões que motivaram o desenvolvimento deste trabalho, através da definição do problema PET e de um resumo do estado da arte mais específico à questão de geração eólica.

No Capítulo 2, trata-se, em linhas gerais, a modelagem do problema PET, bem como as principais abordagens adotadas para resolver o problema. São apresentados os conceitos acompanhados de uma extensão da revisão bibliográfica pertinente, para considerar as principais ferramentas desenvolvidas para o PET. Esta revisão aborda a modelagem matemática, os principais métodos de otimiza- 


\section{Capítulo 1}

ção utilizados, além da consideração da inserção significativa de fontes renováveis, especificamente fontes de geração eólica.

O Capítulo 3 apresenta, de forma detalhada, o Algoritmo Metaheurístico Construtivo (AMC) utilizado, seguido da metodologia proposta para solucionar o problema PET, a partir de cenários de geração eólica preestabelecidos. O Capítulo 4 apresenta os resultados obtidos com a aplicação da metodologia proposta no capítulo anterior, utilizando o sistema IEEE RTS modificado especificamente para esta dissertação.

Para finalizar, o Capítulo 5 apresenta as principais conclusões e observações vislumbradas no desenvolvimento deste trabalho e as propostas para trabalhos futuros. 


\section{2 PLANEJAMENTO DA EXPANSÃO DA TRANSMISSÃO}

O planejamento em sistemas elétricos de potência tem como objetivo garantir uma operação adequada do sistema, respeitando os critérios de qualidade e segurança necessários para suprir a demanda prevista de energia elétrica. Isto é feito procurando o modo mais econômico e seguro de conectar a demanda (distribuída em centros de carga) com as usinas de geração, por meio da rede de transmissão e subtransmissão.

A complexidade e forma de abordar um problema tipo PET vão depender diretamente do horizonte de tempo considerado, e da dimensão do sistema elétrico de potência. Para este trabalho em especifico, será realizado o planejamento da rede de transmissão com uma abordagem estática, considerando um horizonte de longo prazo, a partir de técnicas metaheurísticas.

\section{1. Modelagem do Problema}

O planejamento da expansão da rede de transmissão tem como objetivo principal definir os reforços ou novas linhas a serem implementadas no sistema, para garantir assim uma adequada conexão entre a geração e a demanda prevista no horizonte de tempo definido.

De modo geral, pode-se dizer que o problema PET é assumido como um problema de otimização composto por uma função objetivo (geralmente custo de investimento), a qual se deseja minimizar considerando um conjunto de restrições adjuntas. A modelagem matemática para este problema pode ser principalmente feita de duas maneiras: adotando modelos não lineares mais complexos ou adotando modelos lineares mais simples.

Adotar uma modelagem não linear para o planejamento da rede de transmissão, como o uso do modelo de rede AC [5], representa uma forma mais completa e mais próxima da realidade, pois ao se considerar a potência reativa que circula através da rede, calcula-se de forma mais precisa os fluxos nas linhas e transfor- 


\section{Capítulo 2}

madores e as perdas. Isto é de grande relevância em estudos posteriores de viabilidade e estabilidade, porém, o uso de um modelo de rede não linear implica num problema de programação matemática extremamente complexo. A adoção desta modelagem é comumente feita numa segunda fase do planejamento, já tendo obtido planos preliminares numa primeira fase abordada com modelos lineares mais simples, os quais serão submetidos ao modelo AC para obter maiores detalhes em estudos de viabilidade (dimensionamento de banco de capacitores, etc.) e estabilidade.

Existem duas alternativas ao modelo não linear AC de rede: Modelo de transportes e Modelo DC. O modelo de transportes é o mais simples entre os dois lineares, pois não considera a lei das tensões de Kirchhoff em sua formulação, e, portanto, só utiliza equações lineares nas restrições do problema de otimização. A adoção deste modelo de transportes pode resultar em soluções muito distantes da realidade. Por exemplo, podem-se obter planos de expansão que não se mantenham viáveis ao realizar uma avaliação que considere a segunda lei de Kirchhoff.

Em relação ao problema PET em questão, para horizontes de longo prazo, pode-se utilizar o modelo linear DC, pois assegura as duas leis de Kirchhoff; tensões e correntes. Como resultado, tem-se a obtenção de planos de expansão mais próximos da realidade, que podem até ser factíveis ao ser avaliados pelo modelo de rede AC. Se não forem factíveis ainda, requererão uma menor quantidade de reforços adicionais depois da avaliação com ferramentas baseadas nas equações do fluxo de potência AC. Assim, pode-se dizer que a adoção do modelo linear DC representa uma alternativa ideal para solucionar o problema PET de forma rápida, com obtenção de resultados com um bom grau de precisão, principalmente em ferramentas automáticas de busca. Com as simplificações decorrentes da utilização do fluxo de potência DC, o PET resulta em um problema de programação matemática mais simples e factível.

Outro conceito importante a considerar, é o despacho de fluxo de potência ótimo num sistema elétrico de potência [6]. Este despacho consiste na determinação do estado de uma rede elétrica, maximizando ou minimizando uma função objetivo enquanto se satisfaz um conjunto de restrições físicas e operacionais. Por um lado, têm-se restrições de igualdade que correspondem às equações de balanço de potência ativa e reativa em cada barra da rede. Ademais, têm-se desigualdades, que representam restrições funcionais como o monitoramento do fluxo em linhas e 
limites físicos e operacionais do sistema. Assim, o problema de Fluxo de Potência Ótimo (FPO) pode ser formulado matematicamente e, genericamente, por:

$\min$.

$$
f(x, u, p)
$$

s.a.

$$
\begin{gathered}
g_{i}(x, u, p)=0, i=1, \ldots, m \\
h_{i}(x, u, p) \leq 0, i=1, \ldots, r \\
x_{\min } \leq x \leq x_{\max }, \quad u_{\min } \leq u \leq u_{\max }
\end{gathered}
$$

onde:

$(x, u, p) \in R_{n}$ representa as variáveis de estado, controle e perturbação respectivamente;

$f(x, u, p)$ representa o índice de desempenho do sistema;

$g(x, u, p)$ representa as equações do fluxo de potência;

$h(x, u, p)$ representa as restrições funcionais, isto é, limites de potência ativa e reativa nas linhas de transmissão e transformadores, limites de injeção de potência reativa nas barras de controle de tensão e injeção de potência ativa na barra de referência;

$x_{\min }, x_{\max }, u_{\min }$, e $u_{\max }$, representam limites nas variáveis de estado e de controle, respectivamente.

\section{2 .}

\section{Abordagens Disponíveis para Resolver o Problema PET}

Sabendo que o problema PET é um problema de otimização, cujo objetivo é a minimização do custo de investimento requerido, existem diferentes caminhos que envolvem técnicas e métodos para resolvê-lo. A seguir, serão apresentadas as abordagens disponíveis para resolver o problema PET. 


\subsection{1.}

\section{Otimização clássica matemática}

Para esta abordagem, o problema PET é formulado como um problema de otimização com uma função objetivo estabelecida, geralmente a minimização dos custos, além de considerar um conjunto de restrições que podem ser de caráter operativo, econômico, ou até considerar a confiabilidade.

Na literatura atual, têm-se diversos trabalhos com esta abordagem clássica, como por exemplo, técnicas de programação linear [7] e [8], programação dinâmica [8], programação não linear [9], programação inteira mista [10] e baseadas em decomposição hierárquica ou de Benders [11].

A decomposição de Benders tem sido muito empregada devido à sua particularidade em solucionar o problema PET, a partir do estabelecimento de dois subproblemas: investimento e operação. Assumindo esta estrutura, a avaliação parte do subproblema de investimento num plano preliminar, para seguidamente considerar o subproblema de operação, onde são determinadas as restrições operacionais que foram violadas. Um novo estado operativo é gerado e utilizado no subproblema de investimento, de modo iterativo até convergir numa solução que satisfaça as restrições consideradas no problema.

A abordagem clássica matemática é uma boa alternativa em sistemas de pequeno e médio porte, pois possui limitações práticas na hora de considerar um número grande de variáveis e restrições próprias do problema. A principal vantagem da abordagem clássica matemática é, teoricamente, a garantia de encontrar o ótimo global para solucionar o problema.

\subsection{2.}

\section{Técnicas Heurísticas}

É um conjunto de regras recomendadas por especialistas em análises intuitivas advindas de suas experiências, constituindo assim, uma ferramenta aproximada de otimização de base empírica associada ao tipo de problema a resolver.

Esta alternativa não garante a obtenção do ótimo global do problema, contudo, pode fornecer como resultado soluções tecnicamente viáveis e economicamente atrativas com um baixo custo computacional, mesmo em problemas de grande porte [2]. 
Tendo em mente solucionar o problema PET, um procedimento usual na abordagem heurística, é a adição gradual de reforços a partir de análises de sensibilidade baseadas em características como a sobrecarga, corte de carga, distribuição de fluxos, entre outras, à medida que a configuração vai sendo modificada [1].

A abordagem heurística finaliza com o resultado de apenas um plano de expansão como solução final do problema PET. Entretanto, proporcionar ao planejador mais de uma opção de expansão para a rede em estudo pode representar grande relevância, tendo em vista as incertezas que não foram consideradas e a futura avaliação em fases futuras do planejamento com modelos mais próximos da realidade (e.g., o modelo de fluxos AC).

\subsection{3.}

\section{Técnicas Metaheurísticas}

São procedimento baseados na modelagem de comportamentos da natureza (e.g., processos evolucionários) aplicados a problemas de otimização. Semelhante ao caso das estratégias heurísticas, a abordagem do problema PET adotando estas técnicas não garante a obtenção do ótimo global, mas, com a utilização adequada da estratégia metaheurística adotada, pode-se conseguir soluções de excelente qualidade com um custo computacional relativamente baixo, mesmo para sistemas de grande porte.

A obtenção de um conjunto de soluções pode significar uma grande vantagem em fases futuras do planejamento da rede de transmissão, onde os planos já obtidos serão testados com modelos mais próximos à realidade. Por exemplo, cálculos mais precisos para os fluxos e as perdas nas linhas de transmissão de energia elétrica serão realizados e, consequentemente, avaliações da capacidade e localização de fontes de potência reativa serão obtidas para a melhora do perfil de tensão na rede.

As técnicas metaheurísticas podem ser classificadas de várias maneiras. Isto dependerá principalmente das referências adotadas para o agrupamento das mesmas. De acordo com [12], partindo da forma como as soluções do problema são manipuladas ao longo do processo de busca, classificam-se as ferramentas metaheurísticas das seguintes maneiras: 


\subsubsection{1.}

\section{Metaheurísticas de Busca Local}

Baseiam-se na realização de pequenas alterações numa única solução construída de modo iterativo. Partindo de uma solução inicialmente definida, são realizadas pequenas mudanças na solução, representando assim um movimento para uma nova solução vizinha no espaço de busca. A melhor solução pertencente a essa vizinhança de soluções representa um ótimo local do problema. Quando a solução corrente se aprisiona num ótimo local, são empregados métodos de fuga como a perturbação da solução corrente ou reinicialização da busca, a partir da geração de uma nova solução aleatória [12].

As técnicas metaheurísticas de busca local mais comumente utilizadas para solução do problema PET são as de Recozimento Simulado (Simulated Annealing - SA) e as de Busca Tabu (Tabu Search - TS).

\section{Recozimento Simulado (Simulated Annealing) - AS}

Define-se como uma metaheurística de busca local probabilística, e se fundamenta numa analogia da termodinâmica, sendo mais específico, no método de Recozimento Simulado. A busca é baseada na minimização da energia da estrutura cristalina de um material sólido, quando o mesmo é submetido ao processo de recozimento para remoção de defeitos em sua estrutura atômica. No AS, os estados possíveis de um material representam as soluções do espaço de busca, sendo as posições moleculares do sistema correspondentes às variáveis de decisão do problema de otimização. A energia de cada estado corresponde ao valor da função objetivo associada ao problema. A cada iteração, um novo estado vizinho ao corrente é gerado e passa a ser considerado como a nova solução corrente. Caso o novo estado apresente piora no valor da energia, é utilizada uma probabilidade de aceitação, o que permite ao SA escapar de uma solução de ótimo local. Uma das principais vantagens deste algoritmo é permitir testar soluções mais distantes da solução atual e dar mais independência do ponto inicial da pesquisa. Maiores detalhes sobre esta técnica podem ser encontrados em [13]. 


\section{Busca Tabu (Tabu Search) - TS}

A Busca Tabu é uma técnica de otimização cuja ideia fundamental consiste no uso de uma memória flexível dos estados previamente analisados. Esta memória guia o processo de modo que a busca não seja interrompida ou prejudicada quando não existem deslocamentos que melhorem a solução corrente. Com esta exploração do espaço, evita-se que haja um aprisionamento em soluções de ótimos locais. Esta metaheurística evita os ótimos locais que tenham sido recentemente visitados, resultando num efeito atrativo na trajetória de busca, garantindo deste modo uma busca mais inteligente, comparando-se com outros métodos tradicionais de busca de ótimos locais [38].

Como exemplos de sucesso desta técnica metaheurística, dentre os disponíveis na literatura para solução do problema PET, podem ser citados [14] e [39].

\subsubsection{2. Metaheurísticas Baseadas em População}

São estratégias que estão baseadas em evolução e seleção por aptidão das melhores soluções que vão sendo geradas ao longo do processo, até atingir um critério de convergência (repetição da melhor solução $n$ vezes) de modo a finalizar a busca. Nesta classificação, são mencionados os seguintes procedimentos: Otimização por Enxame de Partículas (Particle Swarm Optimization - PSO), Sistemas Imunológicos Artificiais (Artificial Immune System - AIS), Estratégias de Evolução (Evolution Strategies - ES) e Algoritmo Genético (Genetic Algorithm - GA).

\section{Enxame de Partículas (Particle Swarm Optimization) - PSO}

A metaheurística PSO é uma técnica estocástica baseada em população de soluções e inspirada nos comportamentos naturais de revoada de pássaros e movimento de cardume de peixes. Esta técnica consiste em compartilhar informação entre partículas (forma de representação de soluções) que têm movimento independente no espaço de busca, para determinar aquelas que possuem melhores valores de aptidão e orientar a busca nessa direção. É observado que, apesar de que cada organismo dentro do grupo possui um comportamento de movimento independente, existe algum tipo de informação que é compartilhada com os demais. Sendo assim, a cada geração, as soluções potenciais chamadas de partículas avan- 
çam através do espaço do problema seguindo as atuais melhores partículas, que possuem os melhores valores de aptidão no momento [1], [38].

\section{Sistemas Imunológicos Artificiais (Artificial Immune System) - AIS}

É uma estratégia computacional que se baseia na modelagem da atividade do sistema imunológico natural. Possui as seguintes características:

- Unicidade: cada animal tem seu próprio sistema imunológico, com capacidades e vulnerabilidades particulares.

- Reconhecimento de padrões internos e externos ao sistema: para eliminar células e moléculas que não pertencem ao organismo reconhecidas pelo SI.

- Detecção de anomalia: o SI pode detectar e reagir a agentes patogênicos (causadores de anomalias) a que o organismo nunca havia sido exposto anteriormente.

- Detecção imperfeita (traduzindo em tolerância a ruídos): um reconhecimento perfeito não é necessário para que o SI reaja contra um elemento causador de patologia (patógeno).

- Diversidade: existe uma quantidade limitada de células e moléculas no SI que são utilizadas para se obter o reconhecimento de um número praticamente infinito de elementos.

- Aprendizagem por reforço: a cada encontro com o mesmo patógeno, o sistema imunológico melhora a qualidade de sua resposta.

- Memória: os componentes do SI bem sucedidos no reconhecimento e combate às patologias são armazenados.

Portanto, esta metaheurística é considerada uma técnica robusta e adaptável, que possui capacidade de aprendizado e de memória [40]. Foi também aplicada ao problema PET multiestágios [38].

\section{Estratégias de Evolução (Evolution Strategies) - ES}

As estratégias evolutivas ou de evolução consistem em estabelecer uma população de indivíduos com o objetivo de evoluir melhorando tal população na medida em que o processo avança, como acontece na teoria da evolução natural das espécies. É uma técnica robusta e com poucos parâmetros a serem ajustados. 


\section{Capítulo 2}

Cada indivíduo representa uma possível solução para o problema de otimização abordado, onde a busca começa numa população inicial e, a cada geração (iteração), uma população de filhos é gerada por meio de perturbações (mutações) causadas em indivíduos copiados (clonados) da população atual. Por meio de estratégias de seleção os melhores indivíduos entre a população atual (progenitores) e os novos indivíduos gerados (clones modificados) são escolhidos para integrar a população da próxima geração. As novas populações tendem a apresentar melhores soluções para o problema em questão até que se repete o melhor indivíduo um número determinado de vezes em gerações consecutivas, resultando em convergência para finalizar o processo de busca. O principal mecanismo utilizado por esta técnica é o operador de mutação, responsável pela inserção de pequenas mudanças aleatórias nas informações (genes) dos indivíduos [38].

\section{Algoritmo Genético (Genetic Algorithm) - GA}

É outra metaheurística baseada em população, e de maneira semelhante à estratégia evolutiva descrita no item anterior é inspirada na teoria da seleção natural de espécies. Assim como na abordagem por ES, no GA, a cada geração, os indivíduos da população corrente são avaliados através de uma função objetivo, para aplicar um mecanismo de seleção que escolherá os indivíduos para serem os pais da próxima geração. Os pais escolhidos gerarão filhos por meio do cruzamento da informação contida em seus genes. Estes filhos gerados podem ainda sofrer perturbações que mudaram algumas de suas informações genéticas, a partir do emprego do mecanismo de mutação. O mecanismo de cruzamento utilizado por esta técnica pode apresentar diversas formas, mas, de modo geral, tem a função de combinar segmentos de informações entre os pais para gerar os novos filhos. O mecanismo de mutação é executado logo após o processo de cruzamento e tem por objetivo realizar modificações em determinadas propriedades genéticas de uma população. Este procedimento é repetido, geração após geração, até atingir uma convergência predefinida pelo usuário para finalizar a busca. [1] 


\subsubsection{3.}

\section{Metaheurísticas Construtivas}

As metaheurísticas classificadas como construtivas, estão baseadas na ideia de realizar uma construção gradual para obter uma solução. Isto se faz adicionando um elemento à solução parcial a cada passo iterativo. Dessa forma, partindo de uma opção inviável no começo, vai se construindo uma opção (solução não viável) parcial que vai sendo incrementada gradativamente até que um critério para finalização seja atingido (e.g., até que a solução se torne viável ou factível) [12]. Entre as metaheurísticas que se incluem nesta classificação, as mais comumente utilizadas para solução do problema de planejamento da expansão de sistemas de potência são o Procedimento de Busca Adaptativa Aleatória Gulosa (Greedy Randomized Adaptive Search Procedure - GRASP) [41] e a Otimização por Colônia de Formigas (Ant Colony Optimization - ACO) [38].

\section{Greedy Randomized Adaptive Search Procedure - GRASP}

A estratégia metaheurística GRASP, proposta inicialmente em [15], é uma técnica iterativa utilizada para solução de problemas de otimização combinatória. De uma forma geral, cada iteração desta técnica é composta por duas fases principais, uma fase de construção e uma fase de busca local. Na primeira fase, uma solução inicialmente vazia é iterativamente construída até se tornar viável por meio da adição gradual de novos elementos. A cada adição, um elemento é selecionado aleatoriamente dentre os elementos de uma lista de candidatos mais atrativos. A atratividade dos elementos é medida por meio de uma função heurística gulosa. Após cada adição dentro do processo construtivo, esta lista de candidatos é atualizada, refletindo a nova situação do problema. Na fase de busca local, a solução corrente, que inicialmente corresponde à solução construída na primeira fase, é substituída por uma nova solução vizinha de melhor qualidade, até não haver melhores. A melhor solução encontrada em todas as iterações da técnica GRASP é considerada como solução para o problema de otimização [1], [41].

\section{Colônia de Formigas (Ant Colony Optimization) - ACO}

Formigas são insetos que vivem em comunidade e que procuram estabelecer os menores caminhos entre sua colônia e fontes de alimentos. Tal resultado só é 
possível porque durante suas buscas as formigas deixam no solo rastros de uma substância conhecida por feromônio, marcando todo o seu caminho percorrido. Através desta realimentação positiva de informações, com o tempo, a probabilidade de uma formiga escolher um determinado caminho aumenta em proporção ao número de formigas que anteriormente fizeram a mesma escolha. Este processo ocasiona um crescimento mais acelerado da quantidade de feromônio sobre o menor caminho. Nesta estratégia metaheurística, as “formigas” usam regras de probabilidade para movimentar-se no espaço de busca. Estas regras são baseadas em algum conhecimento acerca do problema (alguma função heurística) [38].

\subsubsection{4. \\ Metaheurísticas Híbridas}

Algumas metaheurísticas apresentam abordagens que utilizam características de mais de uma técnica metaheurística, sendo assim, denominadas metaheurísticas híbridas [12]. Exemplos deste tipo de metaheurística são os algoritmos "meméticos” que utilizam operadores próprios de algoritmos evolucionários e de heurísticas e metaheurísticas de busca local.

Por último, existem métodos que envolvem mais de uma metaheurística e são baseados no conceito de multioperadores adaptativos evolucionários [42].

\section{3. Consideração de incertezas}

É um aspecto relacionado à qualidade e desempenho da solução obtida para o sistema diante critérios relacionados com o estado da rede, dados disponíveis no momento do planejamento ou possíveis ocorrências que pode afrontar o sistema. A consideração de incertezas pode-se realizar das seguintes maneiras:

\subsection{1.}

\section{Abordagem Determinística}

São considerados critérios tais como os "N-1" e "N-2" (contingências simples e/ou duplas). Para o critério “N-1” [43], durante a operação do sistema deve ser garantido o total atendimento da carga, sem que os equipamentos sejam sobrecarregados, mesmo para o caso de perda simples de qualquer componente da rede. 


\subsection{2.}

\section{Abordagem Não Determinística}

Numa abordagem não determinística, a metodologia deve levar em consideração algumas das várias incertezas associadas ao processo de planejamento. Estas, por sua vez, podem ser divididas nas seguintes duas categorias:

\subsubsection{1.}

\section{Incertezas Internas}

Que envolvem indefinições relacionadas às disponibilidades de equipamentos, a qualidade do sistema é avaliada a partir de índices de confiabilidade (e.g., Loss of Load Expectation - LOLE, Expected Energy not Supplied - EENS e Loss of Load Cost - LOLC) obtidos a partir de informações de disponibilidade de equipamentos do sistema. Geralmente, o comportamento de incertezas inerentes aos sistemas elétricos é representado por meio de modelos estocásticos. Um trabalho com grande ênfase no tratamento destas incertezas pode ser observado em [3], onde se comparam os custos obtidos entre avaliações a priori e a posteriori da confiabilidade, para estudos de expansão da transmissão.

\subsubsection{2. Incertezas Externas}

Que envolvem indefinições relacionadas aos seguintes aspectos:

- $\quad$ taxas de interesse e câmbio;

- projeções de mercado (demanda e energia);

- regras do novo ambiente competitivo;

- custos de combustíveis;

- restrições ambientais;

- novas tecnologias, etc.

De acordo com as três linhas de abordagens descritas acima, o PET pode ser resolvido considerando uma ou alguma(s) entre estas alternativas. Assim, uma metodologia mais completa busca resolver o problema de forma mais aproximada à realidade considerando incertezas internas e externas. Não obstante, uma abor- 
dagem mais completa que considere mais incertezas, aumenta a complexidade do problema tratado, implicando um alto custo computacional necessário para as avaliações requeridas ao longo do processo de planejamento, e pode aumentar dependendo da dimensão do sistema [37].

\section{4. \\ Conclusão}

Depois da revisão deste capítulo, pode-se dizer que a modelagem do problema PET é uma tarefa extremamente complexa, e que esta dependerá em grande medida da natureza e dimensão do sistema, além da abordagem adotada pelo planejador. Atualmente se conta com um amplo compêndio de ferramentas para resolver o problema PET, onde cada uma destas ferramentas possui um conjunto bem definido de características, no que se refere à metodologia e modelagem. Como foi mencionado, a escolha de um caminho para abordar o problema PET dependerá do planejador, pois é ele/ela quem terá em mente aspectos como a complexidade, o custo computacional, ou até certas preferências no método escolhido.

Neste trabalho de dissertação, é proposta uma nova metodologia de planejamento da expansão da transmissão a partir do estabelecimento inicial de cenários de geração eólica. Tem-se por objetivo, aproveitar plenamente a provável energia que pode ser fornecida pelo vento da área considerada. Isto se realizará levando em conta o contínuo atendimento a toda a demanda distribuída no sistema em estudo, com especial ênfase na consideração estrita do critério de segurança “N-1".

O problema PET será resolvido por meio do emprego de uma ferramenta metaheurística, a qual será descrita detalhadamente no próximo capítulo, denominada por Algoritmo Metaheurístico Construtivo (AMC-PET). Em seguida, por meio de duas etapas heurísticas, uma interativa e outra combinatória, as soluções obtidas para cada cenário são convergidas para uma única solução, capaz de atender a todos os cenários de geração eólica considerados. 


\section{3 \\ METODOLOGIA}

\section{1. Introdução}

Como foi mencionado no capítulo anterior, a obtenção da solução do problema PET pode ser feita de diversas maneiras, cada uma com suas próprias características e modos de proceder. Esta abordagem dependerá diretamente das considerações por parte do planejador, pois é ele quem decidirá de acordo com critérios como: o tempo de execução e a qualidade requerida no procedimento.

O presente capítulo consta de três partes, uma primeira parte destinada a expor a formulação do problema PET com critério de segurança. A seguir tem-se uma segunda parte, onde se faz uma descrição detalhada da ferramenta metaheurística, empregada nesta dissertação de mestrado para solução estática do problema PET. Termina-se com uma terceira parte, onde se faz a apresentação da metodologia proposta para a consideração de uma elevada participação de fontes renováveis intermitentes. É importante salientar que, embora apenas a geração eólica tenha sido considerada no presente estudo, a metodologia proposta, em geral, é capaz de representar a inserção de qualquer tipo de fonte renovável intermitente.

\section{2.}

\section{Formulação do Problema PET com Critério de Segurança}

O problema PET é definido como um problema de otimização de programação não linear mista inteira, de natureza combinatória explosiva, onde o porte do sistema e a inclusão de restrições de segurança são diretamente proporcionais à complexidade e dificuldade para encontrar o plano de expansão ótimo. Mesmo usando o modelo linear DC para representar a rede, a não linearidade permanece, devido às variáveis e incertezas próprias do problema. A ferramenta AMC-PET adotada em [1] para o desenvolvimento desta dissertação, descompõe o problema original em dois subproblemas: investimento e operação. 


\subsection{1.}

\section{Subproblema de Investimento}

Este subproblema tem por objetivo a identificação de planos de expansão com custos de investimento reduzidos, que sejam capazes de atender a demanda prevista atingindo os critérios de segurança considerados. O subproblema de investimento pode ser definido como:

Min.:

$$
f(n)=\sum_{(k m) \in \Omega_{r}} c_{k m} n_{k m}+\propto_{i n v}\left(c c(n)+\sum_{c=1}^{n c}\left[c c i(n)_{c}+s c(n)_{c}\right]\right)
$$

s.a.:

$$
0 \leq n_{k m} \leq n_{k m}^{\max }, \forall(k m) \in \Omega_{r}
$$

onde:

$f(n)$ é a função objetivo do problema;

$n$ é o vetor decisão (indivíduo);

$n_{k m}$ é o componente do vetor $n$ que armazena o número de reforços adicionados ao ramo candidato $k-m$;

$c_{k m}$ é o custo de adição de um reforço no ramo $k-m$; $\Omega r$ é o conjunto de todos os ramos candidatos;

$\alpha_{i n v}$ corresponde a uma penalização aplicada (para toda e qualquer decisão de investimento $n$ ) ao corte de carga da rede intacta ( $c c(n)$ ), ao corte de carga por ilhamento decorrente da contingência $c(\operatorname{cci}(n) c)$, e às sobrecargas decorrentes da contingência $c(s c(n) c)$;

$n c$ é o número de contingências observadas na aplicação do critério de segurança;

$n_{k m}^{m a x}$ é o número máximo de reforços que podem ser adicionados ao ramo candidato $k-m$.

Os cortes e sobrecargas são expressos em MW. Portanto, a penalidade $\alpha_{i n v}$ é dada em unidades monetárias por MW.

Neste estudo será adotado o critério de segurança “N-1". Portanto, para que um plano de expansão possa ser considerado viável o sistema de transmissão deve garantir o total atendimento da carga, sem sobrecarregar seus equipamentos, mesmo para o caso da contingência simples de qualquer um de seus circuitos (li- 


\section{Capítulo 3}

nha de transmissão ou transformador). A penalização $\alpha_{i n v}$, aplicada a eventuais cortes de carga e/ou sobrecargas nos equipamentos, visa permitir a consideração de soluções (i.e., planos) inviáveis em termos do critério de segurança adotado, principalmente em etapas iniciais do algoritmo de otimização proposto. Entretanto, o processo construtivo converge para soluções viáveis do problema PET [1].

\subsection{2.}

\section{Subproblema de Operação}

No subproblema de operação, a ferramenta AMC-PET faz avaliação tanto na condição de rede intacta quanto sob contingências simples, cada plano de expansão $n$ obtido ao longo do processo construtivo. Para a consideração da rede intacta, o despacho ótimo de geração, que minimiza o custo de produção e o corte de carga do sistema, é obtido pelo problema de otimização linear definido por:

Min.:

$$
\sum_{i \in \Omega_{b g}} c_{g i} g_{i}+\propto_{o p} \sum_{k \in \Omega_{b g}} r_{k}
$$

S.a.:

$$
\begin{gathered}
g+B \theta+r=d \\
\left|b_{k m} \theta_{k m}\right| \leq\left(n_{k m}^{0}+n_{k m}\right) f_{k m}^{\max } ; \forall(k m) \in \Omega_{r} \\
g^{\text {min }} \leq g \leq g^{\max } \\
0 \leq r \leq d \\
-\pi \leq \theta_{i} \leq \pi ; \quad \forall(i) \in \Omega_{b}, i \neq b s w \\
\theta_{b s w}=0
\end{gathered}
$$

onde:

$\Omega_{b g}$ é o conjunto das barras de geração;

$c_{g i}$ é o custo de produção dos geradores da barra $i$;

$g$ é o vetor de geração com componente $g_{i}$; 
$\alpha_{o p}$ é a penalização, de valor elevado em relação ao custo de produção (e.g., 10 vezes superior ao maior custo de produção), aplicada ao corte de carga;

$r$ é o vetor de geração fictícia para cada decisão de investimento $n$. O somatório das componentes $r_{k}$ do vetor $r$ fornece o valor de $c c(n)$ utilizado em (3.1);

$B$ é a matriz de susceptâncias do sistema;

$\theta$ é o vetor de ângulos das tensões nodais com componente $\theta_{i}$;

$d$ é o vetor de demanda;

$\theta_{k m}$ é a abertura angular apresentada pelas tensões das barras terminais $k$ e $m$;

$b_{k m}$ é a susceptância equivalente do ramo $k-m$;

$n_{k m}^{0}$ é o número de circuitos existentes no ramo $k-m$, na topologia base do sistema;

$f_{k m}^{\max }$ é o valor máximo de fluxo de potência ativa para cada circuito do ramo $k-m$; $g_{\min }$ e $g_{\max }$ são, respectivamente, vetores com os limites mínimos e máximos de potência das unidades geradoras;

bsw é o índice que representa a barra de referência angular para o sistema (barra swing).

Segundo [1], para a aplicação do critério “N-1”, em cada ramo ativo do sistema deve ser retirado um circuito. Nesta análise sob contingência, a ferramenta AMC-PET avalia a capacidade de atendimento da demanda sem a possibilidade de redespacho da geração, exceto para a barra de referência, para a qual são mantidos os seus limites mínimo e máximo de capacidade. Para esta parte na avaliação do problema, os limites de capacidade dos circuitos são ignorados, de modo a tornar possível o atendimento total da demanda, exceto em situações de ilhamento, quando, para uma dada contingência $c$, os possíveis cortes de carga (gerações fictícias) devem ser identificados e acumulados em $\operatorname{cci}(n) c$. As eventuais sobrecargas são contabilizadas por meio de $s c(n) c$.

Identificados os possíveis cortes de carga para a rede intacta $(c c(n))$ e sob cada contingência $(c c i(n) c)$, assim como as eventuais sobrecargas $(s c(n) c)$, o plano $n$ pode ser completamente avaliado pelo subproblema de investimento.

\section{3.}

\section{Algoritmo Metaheurístico Construtivo [1]}

A ferramenta metaheurística usada no desenvolvimento deste trabalho está baseada no algoritmo metaheurístico construtivo (AMC) proposto em [1] e [44], 
denominado AMC-PET, cujo objetivo é identificar boas soluções de planos de expansão numa abordagem estática do problema PET.

Este algoritmo consiste na construção iterativa e paralela de planos por meio da adição gradual de reforços sob critérios e índices de atratividade. O processo construtivo é fortemente influenciado pela troca de informação entre planos correntes e pela perturbação e depuração desses planos, obtendo-se assim um conjunto final que é submetido a um mecanismo de refinamento.

A dinâmica de construção é baseada em mecanismos de busca tanto local como global, que comumente são empregados por técnicas heurísticas e metaheurísticas de otimização.

Os índices de atratividade mencionados previamente terão a importante tarefa de servir de pauta para a identificação dos ramos que serão alterados em fases de adição ou depuração de reforços, aplicadas nos planos correntes ao longo do processo construtivo [1] e [44].

\subsection{1.}

\section{Conceitos Básicos}

\subsubsection{1.}

\section{Representação dos planos}

Cada plano será um indivíduo obtido por meio das mecânicas empregadas no algoritmo, e é representado como um vetor, composto por $n_{g}$ posições ou genes, que representarão o número de reforços de cada um dos ramos candidatos da rede de transmissão em estudo. Tem-se, assim, para cada gene uma variável de tipo inteira, que pode variar entre valores de zero e o número máximo de reforços que permita adicionar o problema.

\subsubsection{2.}

\section{Índices de Atratividade}

A ferramenta está programada para utilizar três índices para classificar os ramos candidatos nos planos correntes ao longo da sua execução.

- Índice de carregamento hipotético: Considerando o desempenho da rede intacta ("N-0"), este índice é usado para medir a atratividade dos ramos can- 
didatos ao recebimento de um reforço. É um índice expresso em pu (por unidade) da respectiva capacidade do circuito e é calculado para cada ramo, tanto ativo (i.e., já existente) quanto inativo, a partir da solução do fluxo de potência ótimo DC da seguinte forma:

$$
\operatorname{Ind}_{c h-i j}=\frac{\left|\theta_{i j}\right|}{x_{i j} f_{i j}^{\text {max }}}
$$

Onde:

$\left|\theta_{i j}\right|$ é o módulo da abertura angular, em radianos, das tensões terminais do ramo;

$x_{i j}$ é a reatância do ramo, em pu;

$f_{i j}^{\max }$ é a máxima capacidade do circuito a ser adicionado, em pu.

A partir deste índice, são identificados os circuitos com maior carregamento hipotético (sem considerar a consequente redução na abertura angular entre as barra terminais do ramo) após sua inserção. Em princípio, estes circuitos terão maior potencial para contribuir para uma melhor distribuição do fluxo de potência ativa, o que traz benefícios para alguns aspectos operativos do sistema como a redução das perdas ôhmicas e do nível de carregamento dos circuitos. Por consequência, tem-se uma melhora do desempenho do sistema, tanto para condição de rede intacta quando sob eventuais contingências.

O segundo e terceiro índices estão ligados ao critério de segurança "N-1" e são calculados para cada ramo a partir de análises de contingências nos ramos do plano corrente:

- Índice de sobrecarga própria: É o valor da somatória das sobrecargas "sc" observadas no próprio ramo ativo e candidato $i-j$, depois de considerar as possíveis contingências $n c$ no plano de expansão corrente " $n$ ”. Pode-se expressar como:

$$
\operatorname{Ind}_{s c-i j}^{\text {próprio }}=\sum_{k=1}^{n c} s c(n)_{i j-k}
$$


- Índice de sobrecarga em outros: Neste último índice, para um plano corrente " $n$ ", é considerada a contingência $c$, que corresponde à saída de um dos circuitos de um ramo ativo e candidato para observar e acumular as sobrecargas que acontecem sobre os outros ramos do sistema de transmissão $\left(s c(n)_{c-r s}\right)$. Caso a contingência $c$ resulte em corte de carga por ilhamento $\left(\operatorname{cci}(n)_{c}\right)$, este também é considerado. O cálculo deste índice pode ser expresso como:

$$
I n d_{s c-i j}^{\text {outros }}=\sum_{(r, s) \in \Omega_{r}^{a t i v o s}} s c(n)_{c-r s}+c c i(n)_{c}
$$

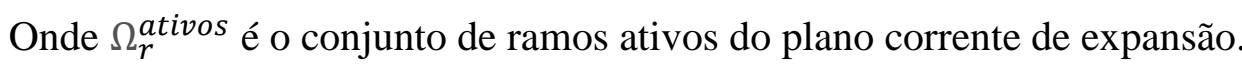

O(s) conjunto(s) dos números de reforços pré-selecionados para os índices já descritos será um parâmetro definido pelo planejador, neste trabalho o procedimento de escolha será apresentado no Capítulo 4.

\subsection{2.}

\section{Mecanismos Construtivos}

\subsubsection{1. Mecanismo de Adição - MA}

Consiste em incrementar de um reforço o plano corrente, para assim criar um novo plano de expansão. $\mathrm{O}$ reforço adicionado é selecionado a partir do conjunto estabelecido pelos índices de atratividade descritos na seção anterior e pelo desempenho da configuração obtida no problema de otimização. Os passos deste mecanismo são:

i) A partir do indivíduo (plano de expansão) corrente, calcular índices de atratividade para os ramos candidatos ao reforço do sistema e selecionar $n_{r}$ ramos mais atrativos (e.g., 5 ramos) a partir destes índices;

ii) Gerar $n_{r}$ novos indivíduos pela adição de um reforço em cada ramo selecionado no passo anterior;

iii) Avaliar cada um dos indivíduos criados; 
iv) Definir como resultado da aplicação do MA, o indivíduo (plano) que apresentar a melhor aptidão.

Para a aplicação do passo (i) é necessário definir a participação de cada índice de atratividade na composição dos $n_{r}$ ramos mais atrativos. Para $n_{r}=5$, podese utilizar, por exemplo, 1 ramo selecionado pelo $I n d_{c h-i j}$ e 2 ramos selecionados pelos $I n d_{s c-i j}^{\text {próprio }}$ e $I n d_{s c-i j}^{\text {outros }}$. O valor de $n_{r}$ e a participação de cada índice de atratividade devem ser cuidadosamente ajustados.

\subsubsection{2.}

\section{Mecanismo de Cruzamento - MC}

De maneira semelhante às metaheurísticas evolutivas (e.g. algoritmos genéticos), nesta ferramenta tem-se um mecanismo para combinar características entre dois planos correntes diferentes a fim de criar dois novos indivíduos. Para programar este mecanismo foi utilizado o cruzamento uniforme para pares de indivíduos. A escolha dos indivíduos é feita por meio de taxas de probabilidade ajustadas à aptidão dos planos correntes disponíveis na memória da ferramenta.

\subsubsection{3. Mecanismo de Mutação - MM}

Este mecanismo tem como finalidade aplicar modificações aleatórias nos genes de um plano considerado, isto por meio de dois sorteios para cada um dos genes do plano com taxas de probabilidade definidas:

O primeiro sorteio decidirá se o gene sofrerá mudança. Se for afirmativa a decisão tomada, passa-se para o segundo sorteio, onde se determinará se a informação armazenada no gene será incrementada ou decrementada de um reforço. Neste segundo sorteio são respeitados os limites superior e inferior do gene a modificar.

É importante mencionar que cada solução obtida do mecanismo de cruzamento (apresentado no item anterior) será submetida ao mecanismo de mutação.

Após a aplicação dos mecanismos de cruzamento e mutação, os planos obtidos serão avaliados de acordo com a função objetivo definida para o problema. 


\subsubsection{4.}

Mecanismo de Seleção - MS

É um mecanismo aplicado aos planos gerados a partir dos mecanismos de adição, cruzamento e mutação anteriormente expostos. Sua função é reduzir o conjunto de indivíduos inviáveis que serão considerados no seguinte nível, além de identificar possíveis soluções factíveis que serão armazenadas num conjunto de indivíduos viáveis.

Neste ponto é importante destacar, que a programação elaborada para esta ferramenta estabelece conjuntos para armazenar os planos escolhidos pelo MS. Salienta-se que a priorização dos indivíduos é feita a partir do valor de aptidão de cada um deles.

Conjunto de indivíduos viáveis $\left(\mathbf{\Omega}_{\mathrm{IV}}\right)$ : Conjunto com limite estabelecido para armazenar os planos viáveis para solução do problema de planejamento considerado.

Conjunto reduzido de indivíduos obtidos pelo mecanismo de adição $\left(\Omega_{\mathrm{MA}}\right)$ : Conjunto com limite estabelecido para armazenar planos inviáveis obtidos a partir do mecanismo de adição.

Conjunto reduzido de indivíduos obtidos pelos mecanismos de cruzamento e mutação $\left(\boldsymbol{\Omega}_{\mathrm{MCM}}\right)$ : Conjunto com limite estabelecido para armazenar planos inviáveis obtidos a partir dos mecanismos de cruzamento e mutação.

\subsubsection{5.}

\section{Mecanismo de depuração - MD}

Consiste em decrementar um dos genes de um indivíduo, com o objetivo de obter um novo plano com um reforço a menos. Para realizar este decremento é considerado um índice de efetividade, o qual é calculado para todos os ramos já reforçados do plano que está sendo depurado. E desta maneira, remover um reforço com o menor impacto negativo no desempenho do plano analisado.

Um quarto conjunto é estabelecido para armazenar planos inviáveis obtidos pelo mecanismo de depuração $\left(\boldsymbol{\Omega}_{\mathbf{M D}}\right)$. Eventuais planos viáveis obtidos pelo $\mathrm{MD}$ serão também armazenados no $\mathbf{\Omega}_{\mathrm{IV}}$. 


\subsubsection{6.}

\section{Mecanismo de Refinamento - MR}

É um mecanismo usado na parte final do procedimento estabelecido pela ferramenta AMC-PET. É aplicado aos indivíduos do conjunto $\mathbf{\Omega}_{\mathbf{I V}}$, consiste em remover um ou alguns reforços de cada plano obtido até este ponto, para subsequentemente avaliar se continuam sendo viáveis. Com isto, procura-se obter planos refinados com custo de investimento logicamente menor.

\subsection{3.}

\section{Algoritmo Descritivo}

Segundo [1] e [44], a base do algoritmo pode ser descrita nos seguintes passos executados em cada nível ou passo do processo iterativo de construção:

i) Adição - Aplicar o MA aos indivíduos dos conjuntos $\boldsymbol{\Omega}_{\mathrm{MA}}, \boldsymbol{\Omega}_{\mathrm{MCM}}$ e $\boldsymbol{\Omega}_{\mathrm{MD}}$ (deve-se notar que o $\boldsymbol{\Omega}_{\mathbf{M C M}}$ e $\boldsymbol{\Omega}_{\mathbf{M D}}$ ainda serão conjuntos vazios na primeira vez que este passo for executado);

ii) Cruzamento e Mutação - Unir todos os indivíduos obtidos no passo anterior e os indivíduos dos conjuntos $\boldsymbol{\Omega}_{\mathbf{M A}}, \boldsymbol{\Omega}_{\mathbf{M C M}}, \boldsymbol{\Omega}_{\mathbf{M D}}$ e $\boldsymbol{\Omega}_{\mathrm{IV}}$ (também vazio na primeira execução deste passo), formando o conjunto de indivíduos progenitores, aos quais os mecanismos MC e MM serão empregados. Estes mecanismos são aplicados de forma a gerar novos indivíduos (excluídas as repetições) com um número máximo de reforços igual ao número no nível construtivo mais um. A geração de novos indivíduos é interrompida quando o total de indivíduos obtidos é igual ao número de indivíduos progenitores;

iii) Seleção - Aplicar o MS aos indivíduos definidos no passo (i), para determinar o novo $\boldsymbol{\Omega}_{\mathrm{MA}}$, e aos indivíduos definidos no passo (ii), para determinar o novo $\boldsymbol{\Omega}_{\mathbf{M C M}}$. Eventuais indivíduos viáveis serão inseridos no $\boldsymbol{\Omega}_{\mathrm{IV}}$;

iv) Depuração - Aplicar o MD aos indivíduos dos conjuntos $\boldsymbol{\Omega}_{\mathrm{MA}}$ e $\boldsymbol{\Omega}_{\mathrm{MCM}}$ e, ainda, aos eventuais indivíduos viáveis identificados no nível construtivo corrente. Os indivíduos inviáveis decorrentes da aplicação do MD formam o novo $\boldsymbol{\Omega}_{\mathbf{M D}}$. Eventuais indivíduos viáveis são inseridos no $\boldsymbol{\Omega}_{\mathrm{IV}}$.

v) Atingido o critério de convergência, a parte iterativa do algoritmo é terminada. Finalmente, o mecanismo (MR) é aplicado ao $\mathbf{\Omega}_{\mathbf{I V}}$, visando refinar, se é possível, este conjunto de indivíduos, o qual contém as melhores soluções para o problema PET. 
Capítulo 3

A Figura 3.1 apresenta o fluxograma representativo do AMC-PET. Em seguida, a Figura 3.2 é utilizada para elucidar a interação entre os conjuntos e os mecanismos implementados, para cada nível construtivo. Esta figura apresenta a dinâmica de evolução do processo iterativo do AMC-PET para um determinado nível construtivo k (com k > 1). Pode-se observar a interação entre os mecanismos e conjuntos nos passos (i), (ii), (iii) e (iv) do algoritmo próprio da ferramenta. As linhas contínuas representam o fluxo de indivíduos inviáveis pelo processo construtivo, já as linhas tracejadas representam o fluxo dos indivíduos viáveis. 


\section{Capítulo 3}

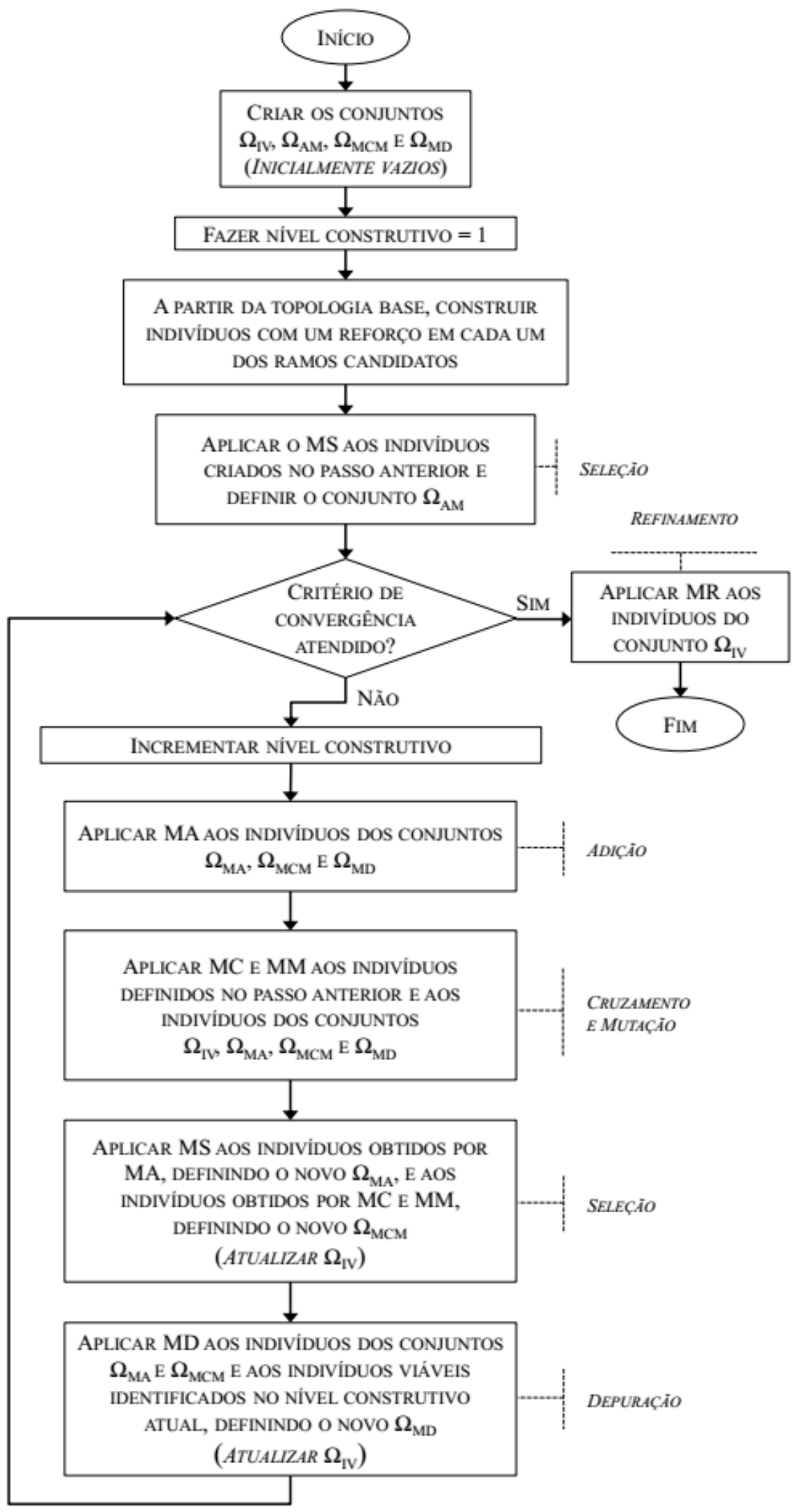

Figura 3.1 - Fluxograma representativo do AMC-PET [44]. 


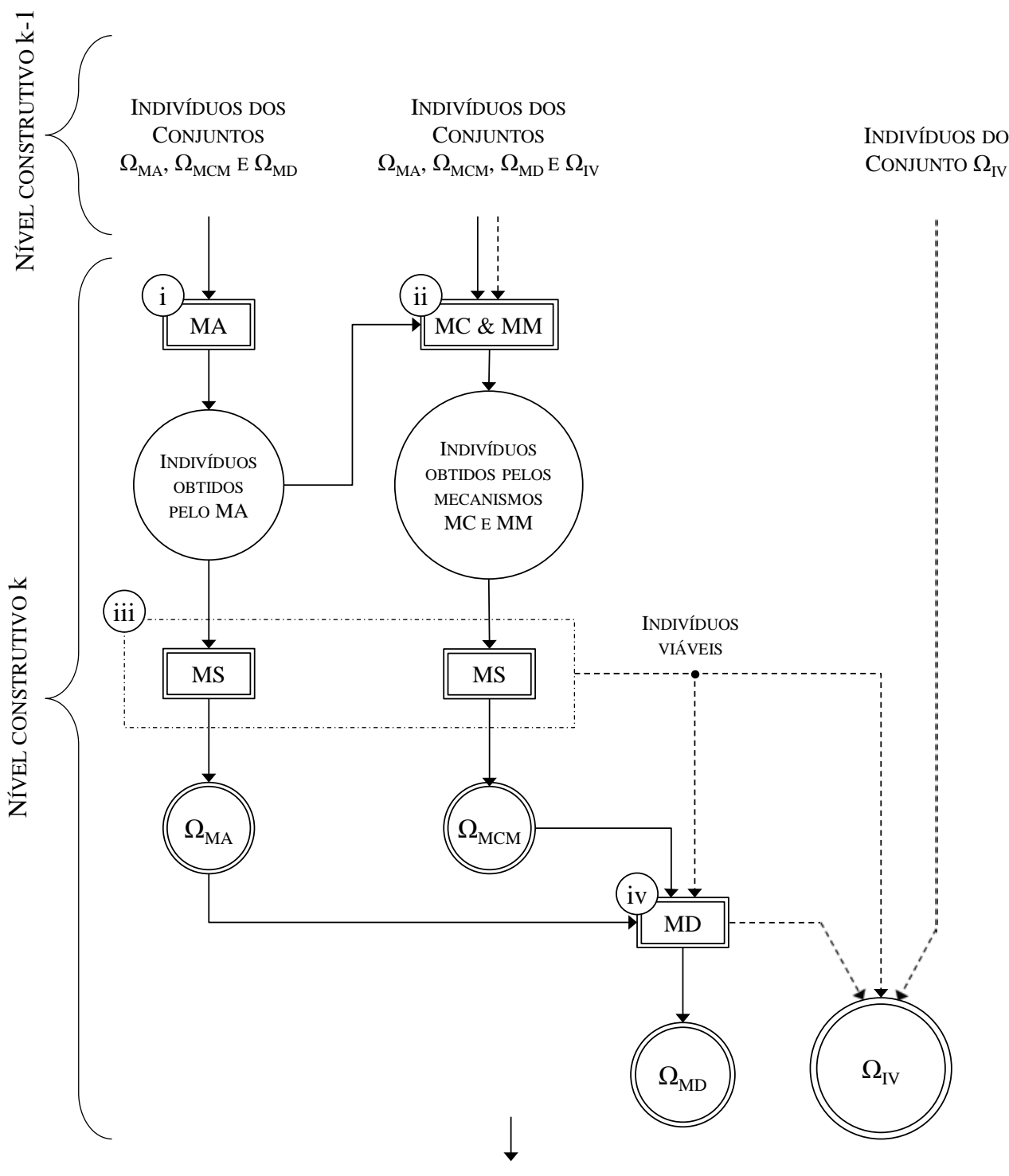

NíveL CONSTRUTIVo $k+1$

Figura 3.2 Dinâmica entre conjuntos e mecanismos na evolução iterativa do AMC-PET [1].

\section{4.}

Algoritmo Proposto para o PET Considerando a Intermitência da Geração Eólica

Depois de explicar com detalhe o algoritmo da ferramenta metaheurística construtiva utilizada para o desenvolvimento deste trabalho de dissertação de mestrado, nesta seção, será apresentada de maneira detalhada a metodologia proposta para planejamento da expansão da rede de transmissão com inserção de fontes renováveis, em particular a geração eólica. 


\subsection{1.}

\section{Estabelecimento dos Cenários de Geração Eólica}

Para começar o planejamento da expansão da rede de transmissão de um sistema elétrico de potência dado, deve-se estabelecer o conjunto de cenários de geração eólica a considerar para o pleno aproveitamento da possível energia que pode ser fornecida pelo vento.

Nesta dissertação, a tarefa do estabelecimento dos cenários de geração eólica é feita a partir de séries de capacidade eólica utilizadas em [21], as quais serão particionadas ou “clusterizadas” com o método conhecido como K-means [45]. Este método parte de um conjunto de dados:

$$
X=\left\{x_{i}\right\}, i=1, \ldots, n
$$

O qual é particionado em $K$ clusters:

$$
C=\left\{c_{k}, k=1, \ldots, K\right\}
$$

Para a obtenção destes clusters foi utilizada a distância Euclidiana. Deste modo, é encontrada uma partição onde o erro quadrático entre a média empírica (centroide) de cada cluster e os pontos que fazem parte do mesmo seja minimizado.

Sendo $u_{k}$ o centroide do cluster $c_{k}$, o valor do erro quadrático entre $u_{k}$ e os pontos do cluster $c_{k}$ é definido como:

$$
J\left(c_{k}\right)=\sum_{x_{i} \in c_{k}}\left\|x_{i}-u_{k}\right\|^{2}
$$

O objetivo do método é a minimização da soma do erro quadrático em todos os clusters:

$$
J(C)=\sum_{k=1}^{K} \sum_{x_{i} \in c_{k}}\left\|x_{i}-u_{k}\right\|^{2}
$$


Com a aplicação do K-means são obtidos os centroides (valores mais representativos) para cada cenário de geração eólica. É importante salientar, que aplicar este método apresenta a vantagem de capturar a correlação existente entre os potenciais eólicos de regiões diferentes. O número de centroides, ou cenários de geração eólica ( $\left.\mathrm{N}_{\mathrm{CEN}}\right)$, a serem utilizados deve ser estabelecido a critério do planejador.

\subsection{2.}

\section{Ajuste do Conjunto de Parâmetros da Ferramenta AMC-PET}

Os parâmetros de entrada que têm impacto na eficiência da ferramenta AMC-PET são: os tamanhos dos conjuntos $\boldsymbol{\Omega}_{\mathbf{M A}}$ e $\boldsymbol{\Omega}_{\mathbf{M C M}}$, o número de ramos candidatos a serem avaliados pelo mecanismo de adição $\left(n_{r}\right)$, a participação de cada índice de atratividade na composição destes $n_{r}$ ramos candidatos (ver Subseção 3.2.2.1), o critério de parada ou convergência e o número de execuções por teste realizado.

Como ocorre para qualquer metaheurística, o conjunto de parâmetros de entrada do AMC-PET deve ser escolhido após inúmeros testes tomando como guia a proposta de tese concernente à ferramenta metaheurística construtiva [1], priorizando o desempenho na obtenção da melhor solução conhecida e o tempo requerido para a execução.

\subsection{3.}

\section{Tabela Decisão}

Depois do estabelecimento dos cenários a serem considerados no PET proposto, e conhecendo-se o número de reforços máximos possíveis que se podem inserir nos ramos candidatos, pode-se estabelecer a forma da Tabela Decisão, a qual faz parte da base da metodologia proposta da presente dissertação de mestrado. A Tabela Decisão conterá essencialmente duas partes, as quais são detalhadas a seguir. 


\subsubsection{1.}

\section{Matriz dos planos soluções para cada cenário}

É uma matriz composta pelos planos obtidos com o emprego da ferramenta AMC-PET que representam a melhor solução de expansão para cada um dos cenários estabelecidos. Esta matriz tem a estrutura ramos candidatos versus cenários de geração eólica, onde cada coluna apresenta o melhor plano encontrado para cada cenário. Cada célula de uma dada coluna (cenário) contém o número de reforços inseridos em um dado ramo candidato pela melhor solução encontrada para o respectivo cenário.

\subsubsection{2.}

\section{Grau de Incidência - GI}

O Grau de Incidência deve ser calculado para todos os ramos candidatos. Conforme seu nome indica, ele fornece uma medida para a incidência de reforços em um dado ramo, considerados todos os cenários de geração eólica.

Dada a quantidade máxima de reforços que poderão ser adicionados em um dado ramo $i\left(N R_{i}^{\max }\right)$, haverá $N R_{i}^{\max }$ níveis de GI para este ramo. A título de exemplo, se em um determinado ramo é possível adicionar até 3 reforços, haverá 3 GIs associados ao mesmo (GI1, GI2 e GI3). O GI1 de um ramo candidato é fornecido pela expressão:

$$
\mathrm{GI} 1=\sum_{i=1}^{N_{C E N}} B R_{i}
$$

onde $N_{C E N}$ é o número de cenários de geração e $B R_{i}$ é uma variável binária que assume o valor 1 se há 1 ou mais reforços no ramo candidato em questão e 0 em caso contrário. Para GIs de maior nível, a variável $B R_{\mathrm{i}}$ deve atuar de acordo com o número do nível (e.g., para GI3 a variável binária BRi será igual a 1 somente se houver 3 ou mais reforços no ramo).

Partindo da informação da quantidade de reforços nos planos de cada cenário, para cada ramo candidato $i$ (linha da matriz dos planos solução para cada cenário), realiza-se o cálculo de GI para cada nível $\left(1,2, \ldots N R_{i}^{\max }\right)$. Após o cálculo 
de todos os GIs é obtida a forma final da Tabela Decisão, a qual é ilustrada pela Tabela 3.1.

Tabela 3.1 - Exemplo para a estrutura da Tabela Decisão.

\begin{tabular}{|c|c|c|c|c|c||c|c|}
\hline \multirow{2}{*}{ Ramo } & \multicolumn{5}{|c||}{ Melhor Plano Para Cada Cenário } & \multicolumn{2}{|c|}{ Graus de Incidência } \\
\cline { 2 - 8 } & $\mathbf{1}$ & $\mathbf{2}$ & $\mathbf{3}$ & $\mathbf{4}$ & $\mathbf{5}$ & GI1 & GI2 \\
\hline A & 1 & 0 & 1 & 2 & 1 & 4 & 1 \\
\hline B & 1 & 1 & 2 & 0 & 0 & 3 & 1 \\
\hline C & 1 & 2 & 2 & 2 & 1 & 5 & 3 \\
\hline D & 1 & 1 & 0 & 0 & 1 & 3 & 0 \\
\hline
\end{tabular}

Neste exemplo, o problema constaria de: 4 ramos candidatos, 5 cenários estabelecidos e um número máximo de 2 reforços possíveis para inserir em cada ramo candidato. Percebe-se, neste exemplo, que já na construção da Tabela Decisão, ou seja, sem nenhum esforço para uniformizar os planos de expansão, existe uma “decisão consolidada”, a qual consiste em adicionar 1 reforço no ramo candidato C. Esta decisão consolidada é prontamente identificada a partir do GI1 do ramo C (igual a $\mathrm{N}_{\mathrm{CEN}}$ ). Logicamente, o nível do GI, neste caso igual a 1, define a quantidade de reforços adicionados ao ramo.

\subsection{4.}

\section{Etapa Iterativa para a Convergência dos Planos de Expansão}

Nesta etapa da metodologia, o processo de convergência ou uniformização dos melhores planos de expansão, obtidos para cada cenário de geração eólica, se dá de forma iterativa, sendo baseado nos GIs de cada ramo candidato. A seguir, são apresentados os principais passos realizados na etapa iterativa, os quais serão repetidos enquanto houver ao menos um GI maior que 1. Portanto, ao final desta etapa, todos os GIs serão iguais a $\mathrm{N}_{\mathrm{CEN}}, 0$ ou 1 .

i) identificar o ramo candidato cuja decisão de investimento está mais próxima de ser uniformizada (com maior valor de GI) para atender a todos os $\mathrm{N}_{\mathrm{CEN}}$ cenários;

ii) acrescentar, arbitrariamente, um reforço ao ramo identificado na decisão de cada cenário com o menor número de reforços neste ramo;

iii) avaliar, via ferramenta AMC-PET, os cenários cuja decisão foi alterada; 
iv) atualizar a Tabela Decisão.

Percebe-se que o maior valor de GI (descartados os GIs iguais a $\mathrm{N}_{\mathrm{CEN}}$ ) define o ramo candidato que passará pela uniformização de decisão. Logicamente, poderá ocorrer empate entre os maiores valores de GI. No entanto, prevalecerá sempre o GI de menor nível (e.g., GI1 em relação a GI2). Porém, quando houver empate entre GIs de mesmo nível, deve-se avaliar a uniformização, uma a uma, de todos os ramos candidatos relacionados. Para se escolher qual destas uniformizações deve ser adotada, é utilizado um parâmetro que mede o grau de proximidade entre os planos presentes na Tabela Decisão resultante. Este parâmetro é descrito a seguir.

\subsubsection{1.}

\section{Grau de Uniformidade GU}

É um parâmetro adotado pela presente metodologia para medir o grau de semelhança entre as soluções obtidas para os $\mathrm{N}_{\mathrm{CEN}}$ cenários de geração eólica. Este parâmetro é calculado conforme expressão (3.11).

$$
G U=\sum F_{G U}(G I)
$$

Onde o somatório é feito para todos os GIs (i.e., de qualquer nível e para todos os ramos candidatos) e $\mathrm{F}_{\mathrm{GU}}$ é a função dada pela expressão (3.12). Por questão de simplificação da apresentação da função $\mathrm{F}_{\mathrm{GU}}$, adotou-se $\mathrm{N}_{\mathrm{CEN}}$ igual a 10. Salienta-se que a aplicação desta função para qualquer outro número de cenários é trivial e intuitiva.

$$
F_{G U}=\left\{\begin{aligned}
1,0 & \text { se } G I=10 \text { ou } 0 \\
-0,1 & \text { se } G I=9 \\
-0,2 & \text { se } G I=8 \\
-0,3 & \text { se } G I=7 \\
-0,4 & \text { se } G I=6 \\
-0,5 & \text { se } G I=5 \\
-0,6 & \text { se } G I=4 \\
0,0 & \text { se } G I=3,2 \text { ou } 1
\end{aligned}\right.
$$


O princípio básico que norteia a composição da função $F_{\mathrm{GU}}$ é bastante simples: a solução final, a qual atenderá a todos os $\mathrm{N}_{\mathrm{CEN}}$ cenários, terá apenas os valores 0 e 10 para todos os GIs. Portanto, os GIs com estes valores recebem pontuação positiva $(1,0)$. Adicionalmente, quanto maior o valor do GI, mais próximo o respectivo ramo estará de uma decisão uniformizada, pois a tendência natural é caminhar para o valor 10. Adotou-se, então, atribuir valores negativos, começando por -0,1 para um GI igual a 9 e terminando em -0,6 para um GI igual a 4. Optouse, ainda, por atribuir valores nulos para GIs iguais a 3, 2 ou 1. Conforme já destacado, ao final da etapa iterativa, todos os GIs serão iguais a 10, 0 ou 1. Logicamente, é desejável que a quantidade de GIs iguais a 1 seja mínima. Porém, a existência destes GIs é inevitável. Com relação aos valores 3 e 2, percebeu-se, conforme esperado, que para alguns ramos candidatos houve, ao longo da etapa iterativa, a convergência para o valor unitário ou até mesmo nulo.

\subsection{5.}

\section{Etapa Combinatória para a Convergência dos Planos de Expansão}

Nesta etapa, a uniformização dos melhores planos de expansão é concluída. Para isto, são exploradas todas as combinações envolvendo os ramos candidatos que contenham os chamados "reforços exclusivos remanescentes”. Conforme explicado na subseção anterior, neste ponto da metodologia, a Tabela Decisão conterá GIs iguais a $\mathrm{N}_{\mathrm{CEN}}, 0$ ou 1 . Todo GI igual a 1 estará associado a um reforço exclusivo, ou seja, a um reforço que só foi encontrado em um dos cenários de geração considerados.

Portanto, o objetivo desta etapa é obter o melhor subconjunto (de menor investimento) dos ramos candidatos com reforço exclusivo remanescente (i.e., com $\mathrm{GI}=1)$.

Por motivo de eficiência, a exploração combinatória tem início pelo menor subconjunto possível (i.e., viável, para todos os cenários). Em princípio, este subconjunto seria formado por apenas 1 ramo candidato com reforço exclusivo, aquele com o menor custo de investimento. Porém, alguns dos reforços remanescentes podem acorrer para um mesmo cenário de geração. Dependendo da forma como isto vier a ocorrer, em comparação com os outros cenários, até mesmo o tamanho do menor subconjunto pode ser maior que 1. Esta situação será verificada no estudo de aplicação da metodologia. A etapa combinatória é interrompida assim que 
ao menos uma solução viável para todos os cenários é obtida e que as demais soluções (subconjuntos) apresentem custo de investimento maior que a melhor solução obtida.

\subsection{6.}

\section{Algoritmo Descritivo}

A metodologia proposta nesta dissertação pode ser resumida nos seguintes passos:

i) Estabelecimento de cenários - Aplicando o método K-means aos dados das séries de potência eólica disponíveis obtêm-se os $N_{C E N}$ cenários a serem considerados ao longo da metodologia;

ii) Configuração da ferramenta AMC-PET - Através de inúmeros testes, tomando como guia a proposta de tese concernente à ferramenta metaheurística construtiva [1], determinam-se os parâmetros para execução da ferramenta considerando principalmente o desempenho e o custo computacional;

iii) Obtenção do melhor plano de expansão para cada cenário de geração eólica - Primeiramente, com o emprego da ferramenta AMC-PET, previamente configurada, é obtido o melhor plano de expansão para cada um dos cenários;

iv) Construção da Tabela Decisão - A partir dos planos obtidos no passo (iii) são obtidos os GIs para cada ramo candidato e construída a Tabela Decisão;

v) Etapa Iterativa para a Convergência dos Planos de Expansão - Esta etapa é composta pelos seguintes subpassos:

v.a) selecionar o ramo candidato a ser considerado, ou seja, aquele com o maior valor de GI, MAX $_{\mathrm{GI}}$ (descartados os GIs iguais a $\mathrm{N}_{\mathrm{CEN}}$ e os GIs de maior nível para ramos em que houver empate no valor do GI);

v.b) se $\mathrm{MAX}_{\mathrm{GI}}=1$ (fim da etapa iterativa) ir para o passo (vi); caso contrário, prosseguir para o subpasso (v.c);

v.c) caso haja empate entre dois ou mais ramos selecionados (com GI igual a $\left.\mathrm{MAX}_{\mathrm{GI}}\right)$, ir para o subpasso (v.f); caso contrário, prosseguir para o subpasso (v.d); 
v.d) para o ramo candidato selecionado, uniformizar a decisão de investimento (i.e., adicionar, arbitrariamente, 1 reforço nos cenários de geração eólica com quantidade menor de reforços ao nível de GI considerado no ramo);

v.e) avaliar, via AMC-PET, cada cenário de geração afetado pelo subpasso (v.d) e ir para o subpasso (v.h);

v.f) para cada ramo candidato selecionado: uniformizar a decisão de investimento; avaliar cada cenário afetado pela uniformização; obter uma Tabela Decisão “provisória ou momentânea”; calcular o GU, dado pela Equação (3.18);

v.g) selecionar o ramo candidato que proporciona o maior valor de GU;

v.h) atualizar a Tabela Decisão e retornar ao subpasso (v.a);

vi) Etapa Combinatória para a Convergência dos Planos de Expansão - Esta etapa conclui todo o procedimento adotado pela metodologia proposta, fornecendo uma solução de excelente qualidade, a qual é capaz de atender a todos os cenários de geração eólica obtidos no primeiro passo, via método Kmeans.

Na Figura 3.3, se apresenta o fluxograma representativo do algoritmo da metodologia proposta nesta dissertação de mestrado. 


\section{Capítulo 3}

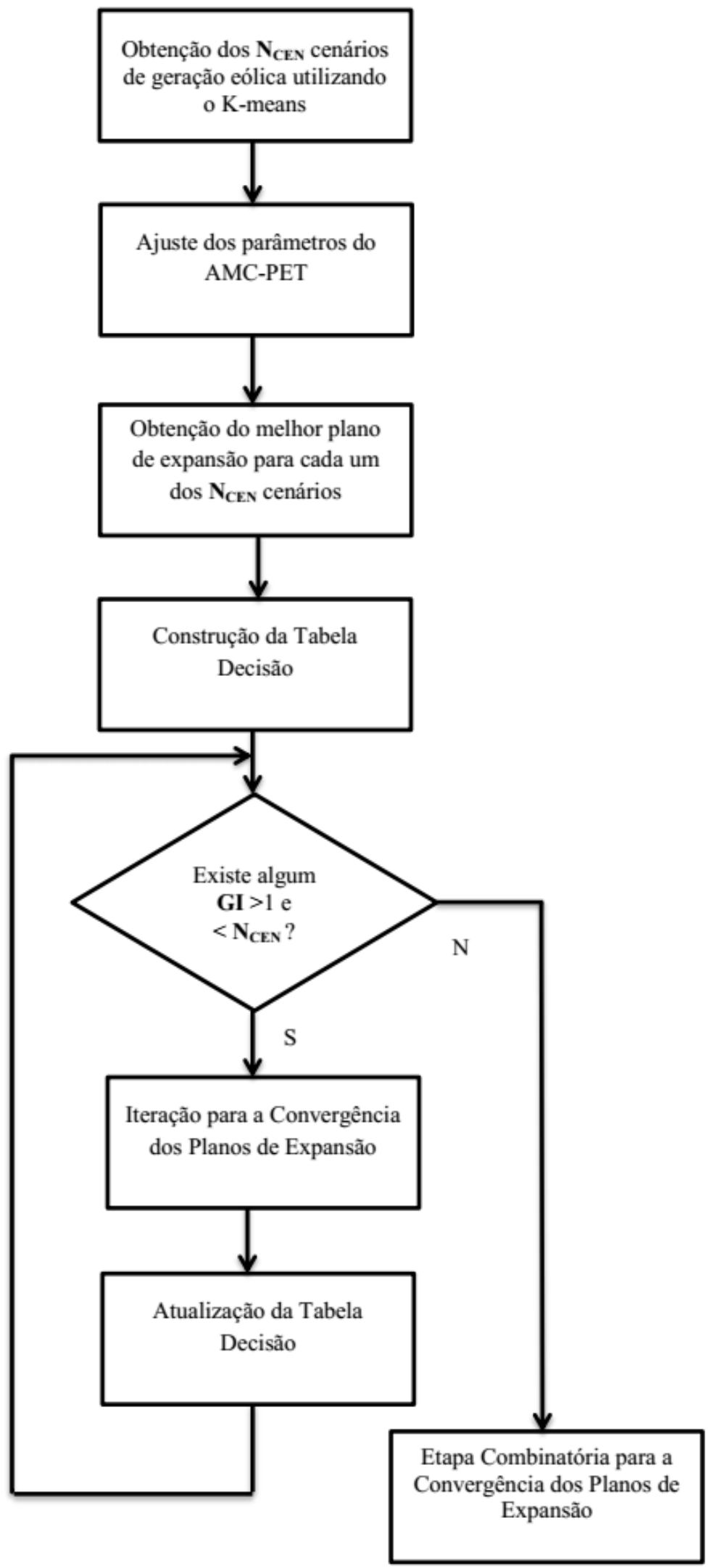

Figura 3.3 - Fluxograma da metodologia proposta para o PET considerando a intermitência da geração eólica. 


\section{5.}

\section{Conclusão}

Neste capítulo se iniciou com a formulação do problema PET estático com critério de segurança “N-1”. Tal formulação está baseada na decomposição do problema original em dois subproblemas: investimento e operação, e foi acompanhada no documento com a exibição das equações que argumentam esta abordagem de decomposição adotada.

Seguidamente à formulação do problema, foi detalhado o algoritmo da ferramenta AMC-PET, adotada para este trabalho. Foram expostos os parâmetros e os mecanismos implementados que compõem a ferramenta empregada, além da forma de proceder da mesma em sua execução.

Depois disso, foi explicada a metodologia proposta nesta dissertação de mestrado, a qual consiste numa abordagem do problema PET considerando a volatilidade ou intermitência da geração eólica a partir de um estabelecimento inicial de cenários. Isto é proposto com a finalidade de aproveitar plenamente a possível energia que pode ser fornecida pelas centrais eólicas instaladas no sistema. Em outras palavras, a ideia é obter um plano de expansão final de boa qualidade, com a faculdade de operar de forma flexível sob os cenários de geração eólica estabelecidos, respeitando-se o critério de segurança “N-1". 


\section{4 \\ APLICAÇÃO}

\section{1. \\ Introdução}

Para este capítulo, a metodologia proposta nesta dissertação é aplicada ao sistema teste denominado IEEE RTS_Wind. Será apresentado de maneira clara, cada elemento pertencente à metodologia junto ao desenvolvimento da mesma. Por fim, serão expostos os resultados obtidos que abrem a análise e discussão própria deste capítulo.

\section{2.}

\section{Sistema Teste}

A rede elétrica utilizada para testes é obtida após modificações aplicadas ao sistema IEEE RTS - Reliability Test System [46]. Primeiramente, para ampliar a participação da geração a partir de fontes renováveis, foram substituídas algumas unidades de geração térmicas por unidades eólicas, tendo-se assim um sistema com elevada participação de fontes renováveis. Posteriormente, para configurar um problema PET de longo prazo, a geração e a carga do sistema foram duplicadas. Tem-se, então, o sistema denominado “IEEE RTS_Wind”, cuja configuração constitui o Caso Base, o qual deve receber reforços em sua rede de transmissão. Na Figura 4.1 é apresentada a representação gráfica do sistema IEEE RTS_Wind. 


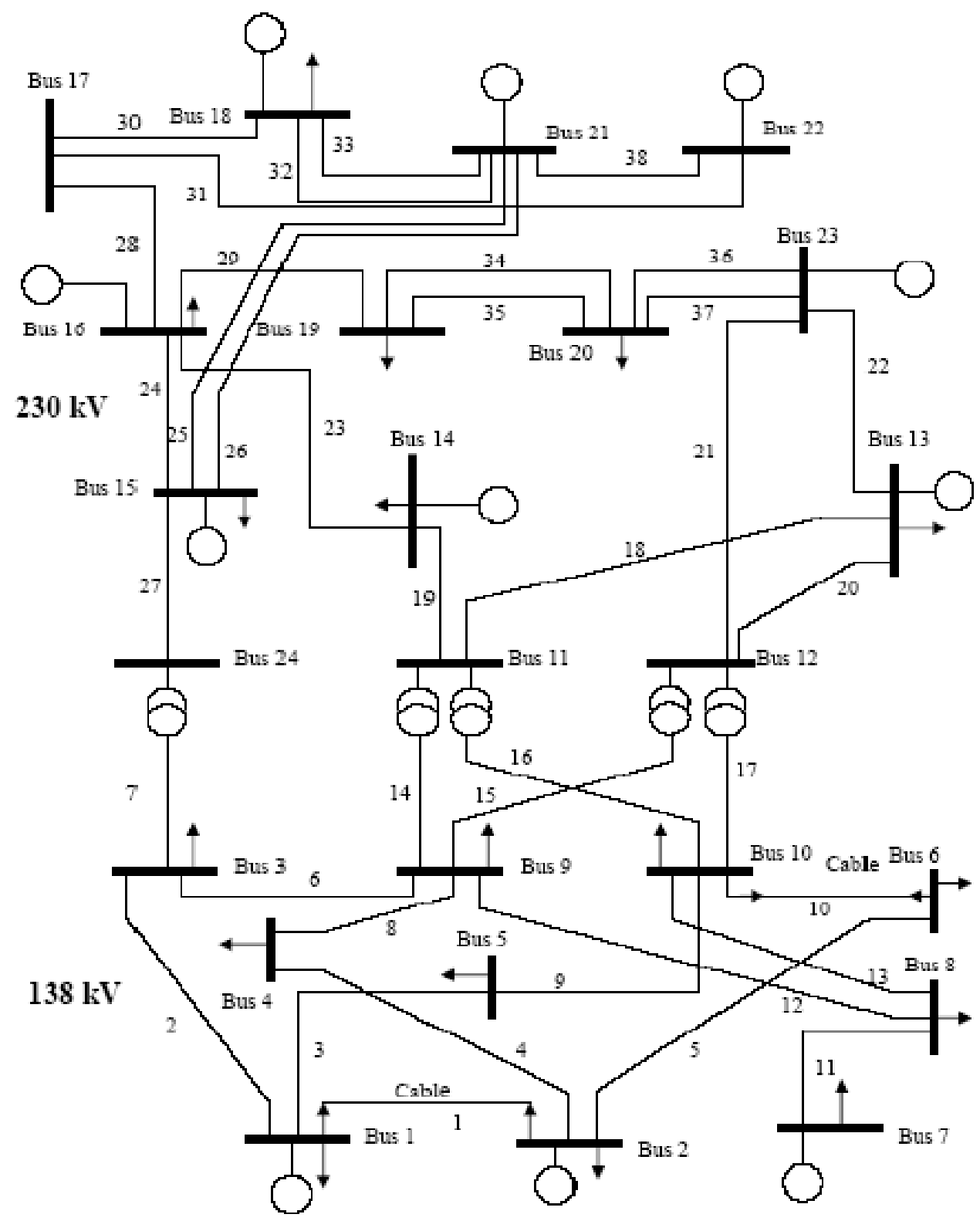

Figura 4.1 - Esquema representativo do sistema IEEE-RTS

\subsection{1.}

\section{Informação das Barras}

O sistema IEEE RTS_Wind consta de 24 barras com valores de geração e carga predefinidos para abordar o planejamento estático baseado no estabelecimento de cenários de geração eólica. Salienta-se que a geração eólica foi inserida nas barras 1 e 15, em substituição a uma parcela da geração térmica presente em cada barra. Na barra 1, 152 MW térmicos (2×76 MW) foram substituídos por 1048 MW eólicos (262×4 MW), já considerando a duplicação da geração. Quanto 


\section{Capítulo 4}

à barra 15, uma unidade de 155 MW foi substituída por 792 MW de geração eólica (198×4 MW), também já considerando a duplicação da geração.

Os montantes de geração eólica alocados nas barras 1 e 15 foram definidos a partir dos valores médios de capacidade das respectivas regiões, em pu. Estes valores médios são extraídos das séries históricas de capacidade eólica disponíveis para cada região, as quais são detalhadas na Seção 4.3. A Tabela 4.1 apresenta as alterações aplicadas às barras 1 e 15 , relativas às substituições de térmicas por eólicas (incluindo a duplicação da geração).

Tabela 4.1 - Geração Eólica para o Sistema IEEE RTS_Wind

\begin{tabular}{|c|c|c|c|c|}
\hline \multirow{2}{*}{ Barra } & RTS & \multicolumn{3}{|c|}{ IEEE RTS_Wind } \\
\cline { 2 - 5 } & $\begin{array}{c}\text { Capacidade Térmica } \\
\text { Substituída } \\
\text { (MW) }\end{array}$ & \multicolumn{2}{|c|}{ Capacidade Eólica Média } & $\begin{array}{c}\text { Capacidade } \\
\text { Eólica Instalada } \\
\text { (MW) }\end{array}$ \\
\cline { 3 - 5 } & 152 & $\mathbf{( M W )}$ & $\mathbf{( p u )}$ & 1048 \\
\hline 1 & 155 & 304 & 0,2901 & 792 \\
\hline 15 & & 310 & 0,3916 & \multirow{2}{*}{} \\
\hline
\end{tabular}

A Tabela 4.2 condensa os valores de geração máxima (PG $\mathrm{MAX}_{\mathrm{M}}$ ), demanda $\left(\mathrm{P}_{\mathrm{D}}\right)$, tipo de barra e a prioridade de despacho de cada geração para a solução do fluxo de potência ótimo “N-0”.

Ao trocar as fontes térmicas pelas renováveis no sistema, tem-se uma participação significativa de fontes renováveis intermitentes (1840 MW) na matriz energética do mesmo, 22,9\% da capacidade instalada do sistema (8036 MW). 
Tabela 4.2 - Informação das barras do sistema IEEE RTS_Wind.

\begin{tabular}{|c|c|c|c|c|}
\hline Barra & $\begin{array}{c}\text { PG }_{\text {MAX }} \\
\text { (MW) }\end{array}$ & $\begin{array}{c}\mathbf{P}_{\mathrm{D}} \\
(\mathbf{M W})\end{array}$ & Tipo & Prioridade \\
\hline \multirow{2}{*}{01} & 80 & \multirow{2}{*}{216} & \multirow{2}{*}{ PV } & 5 \\
\hline & 1048 & & & 1 \\
\hline \multirow{2}{*}{02} & 80 & \multirow{2}{*}{194} & \multirow{2}{*}{ PV } & 3 \\
\hline & 304 & & & 3 \\
\hline 03 & 0 & 360 & PQ & - \\
\hline 04 & 0 & 148 & $P Q$ & - \\
\hline 05 & 0 & 142 & PQ & - \\
\hline 06 & 0 & 272 & PQ & - \\
\hline 07 & 600 & 250 & PV & 4 \\
\hline 08 & 0 & 342 & $\mathrm{PQ}$ & - \\
\hline 09 & 0 & 350 & PQ & - \\
\hline 10 & 0 & 390 & PQ & - \\
\hline 11 & 0 & 0 & PQ & - \\
\hline 12 & 0 & 0 & PQ & - \\
\hline 13 & 1182 & 530 & SW & 6 \\
\hline 14 & 0 & 388 & $\mathrm{PQ}$ & - \\
\hline \multirow{2}{*}{15} & 120 & \multirow{2}{*}{634} & \multirow{2}{*}{ PV } & 7 \\
\hline & 792 & & & 2 \\
\hline 16 & 310 & 200 & PV & 9 \\
\hline 17 & 0 & 0 & PQ & - \\
\hline 18 & 800 & 666 & $\mathrm{PV}$ & 11 \\
\hline 19 & 0 & 362 & $\mathrm{PQ}$ & - \\
\hline 20 & 0 & 256 & PQ & - \\
\hline 21 & 800 & 0 & $\mathrm{PV}$ & 10 \\
\hline 22 & 600 & 0 & PV & 12 \\
\hline \multirow{2}{*}{23} & 620 & \multirow{2}{*}{0} & \multirow{2}{*}{ PV } & 8 \\
\hline & 700 & & & 8 \\
\hline 24 & 0 & 0 & $\mathrm{PQ}$ & - \\
\hline
\end{tabular}

\subsection{2.}

\section{Rede de Transmissão Inicial}

O sistema tem uma rede de transmissão inicial que consta de 38 linhas cujas características são detalhadas na Tabela 4.3. 
Tabela 4.3 - Dados de circuitos existentes do sistema IEEE RTS_Wind.

\begin{tabular}{|c|c|c|c|c|c|}
\hline Circuito & De & Para & $\begin{array}{c}\mathbf{R} \\
\text { (pu) }\end{array}$ & $\begin{array}{c}\mathrm{X} \\
(\mathrm{pu})\end{array}$ & $\begin{array}{c}\text { Capacidade } \\
\text { (MW) }\end{array}$ \\
\hline 1 & 01 & 02 & 0,0026 & 0,0139 & 175 \\
\hline 2 & 01 & 03 & 0,0546 & 0,2112 & 175 \\
\hline 3 & 01 & 05 & 0,0218 & 0,0845 & 175 \\
\hline 4 & 02 & 04 & 0,0328 & 0,1267 & 175 \\
\hline 5 & 02 & 06 & 0,0497 & 0,1920 & 175 \\
\hline 6 & 03 & 09 & 0,0308 & 0,1190 & 175 \\
\hline 7 & 03 & 24 & 0,0023 & 0,0839 & 400 \\
\hline 8 & 04 & 09 & 0,0268 & 0,1037 & 175 \\
\hline 9 & 05 & 10 & 0,0228 & 0,0883 & 175 \\
\hline 10 & 06 & 10 & 0,0139 & 0,0605 & 175 \\
\hline 11 & 07 & 08 & 0,0159 & 0,0614 & 175 \\
\hline 12 & 08 & 09 & 0,0427 & 0,1651 & 175 \\
\hline 13 & 08 & 10 & 0,0427 & 0,1651 & 175 \\
\hline 14 & 09 & 11 & 0,0023 & 0,0839 & 400 \\
\hline 15 & 09 & 12 & 0,0023 & 0,0839 & 400 \\
\hline 16 & 10 & 11 & 0,0023 & 0,0839 & 400 \\
\hline 17 & 10 & 12 & 0,0023 & 0,0839 & 400 \\
\hline 18 & 11 & 13 & 0,0061 & 0,0476 & 500 \\
\hline 19 & 11 & 14 & 0,0054 & 0,0418 & 500 \\
\hline 20 & 12 & 13 & 0,0061 & 0,0476 & 500 \\
\hline 21 & 12 & 23 & 0,0124 & 0,0966 & 500 \\
\hline 22 & 13 & 23 & 0,0111 & 0,0865 & 500 \\
\hline 23 & 14 & 16 & 0,0050 & 0,0389 & 500 \\
\hline 24 & 15 & 16 & 0,0022 & 0,0173 & 500 \\
\hline 25 & 15 & 21 & 0,0063 & 0,0490 & 500 \\
\hline 26 & 15 & 21 & 0,0063 & 0,0490 & 500 \\
\hline 27 & 15 & 24 & 0,0067 & 0,0519 & 500 \\
\hline 28 & 16 & 17 & 0,0033 & 0,0259 & 500 \\
\hline 29 & 16 & 19 & 0,0030 & 0,0231 & 500 \\
\hline 30 & 17 & 18 & 0,0018 & 0,0144 & 500 \\
\hline 31 & 17 & 22 & 0,0135 & 0,1053 & 500 \\
\hline 32 & 18 & 21 & 0,0033 & 0,0259 & 500 \\
\hline 33 & 18 & 21 & 0,0033 & 0,0259 & 500 \\
\hline 34 & 19 & 20 & 0,0051 & 0,0396 & 500 \\
\hline 35 & 19 & 20 & 0,0051 & 0,0396 & 500 \\
\hline 36 & 20 & 23 & 0,0028 & 0,0216 & 500 \\
\hline 37 & 20 & 23 & 0,0028 & 0,0216 & 500 \\
\hline 38 & 21 & 22 & 0,0087 & 0,0678 & 500 \\
\hline
\end{tabular}

\subsection{3.}

\section{Dados dos Ramos Candidatos}

Os ramos candidatos correspondem aos 34 ramos existentes e mais 7 ramos novos [1], [42], [48], conformando-se, assim, 41 ramos candidatos. O processo de planejamento realiza-se atendendo um limite máximo para cada ramo candidato de 3 elementos de transmissão a inserir. 
Capítulo 4

Os valores que caracterizam cada um dos ramos candidatos são expostos na informação contida na Tabela 4.4. Vale destacar que os ramos 35 a 41 são novos.

Tabela 4.4 - Dados dos Ramos Candidatos do sistema IEEE RTS_Wind.

\begin{tabular}{|c|c|c|c|c|c|c|}
\hline Ramo & De & Para & $\begin{array}{c}\mathbf{R} \\
\mathbf{( p u )}\end{array}$ & $\begin{array}{c}\mathbf{X} \\
\mathbf{( p u )}\end{array}$ & $\begin{array}{c}\text { Capacidade } \\
\mathbf{( M W )}\end{array}$ & $\left.\begin{array}{c}\text { Custo } \\
(\mathbf{1 0}\end{array} \mathbf{\text { }}\right)$ \\
\hline 01 & 01 & 02 & 0,0026 & 0,0139 & 175 & 3 \\
\hline 02 & 01 & 03 & 0,0546 & 0,2112 & 175 & 55 \\
\hline 03 & 01 & 05 & 0,0218 & 0,0845 & 175 & 22 \\
\hline 04 & 02 & 04 & 0,0328 & 0,1267 & 175 & 33 \\
\hline 05 & 02 & 06 & 0,0497 & 0,1920 & 175 & 50 \\
\hline 06 & 03 & 09 & 0,0308 & 0,1190 & 175 & 31 \\
\hline 07 & 03 & 24 & 0,0023 & 0,0839 & 400 & 50 \\
\hline 08 & 04 & 09 & 0,0268 & 0,1037 & 175 & 27 \\
\hline 09 & 05 & 10 & 0,0228 & 0,0883 & 175 & 23 \\
\hline 10 & 06 & 10 & 0,0139 & 0,0605 & 175 & 16 \\
\hline 11 & 07 & 08 & 0,0159 & 0,0614 & 175 & 16 \\
\hline 12 & 08 & 09 & 0,0427 & 0,1651 & 175 & 43 \\
\hline 13 & 08 & 10 & 0,0427 & 0,1651 & 175 & 43 \\
\hline 14 & 09 & 11 & 0,0023 & 0,0839 & 400 & 50 \\
\hline 15 & 09 & 12 & 0,0023 & 0,0839 & 400 & 50 \\
\hline 16 & 10 & 11 & 0,0023 & 0,0839 & 400 & 50 \\
\hline 17 & 10 & 12 & 0,0023 & 0,0839 & 400 & 50 \\
\hline 18 & 11 & 13 & 0,0061 & 0,0476 & 500 & 66 \\
\hline 19 & 11 & 14 & 0,0054 & 0,0418 & 500 & 58 \\
\hline 20 & 12 & 13 & 0,0061 & 0,0476 & 500 & 66 \\
\hline 21 & 12 & 23 & 0,0124 & 0,0966 & 500 & 134 \\
\hline 22 & 13 & 23 & 0,0111 & 0,0865 & 500 & 120 \\
\hline 23 & 14 & 16 & 0,0050 & 0,0389 & 500 & 54 \\
\hline 24 & 15 & 16 & 0,0022 & 0,0173 & 500 & 24 \\
\hline 25 & 15 & 21 & 0,0063 & 0,0490 & 500 & 68 \\
\hline 26 & 15 & 24 & 0,0067 & 0,0519 & 500 & 72 \\
\hline 27 & 16 & 17 & 0,0033 & 0,0259 & 500 & 36 \\
\hline 28 & 16 & 19 & 0,0030 & 0,0231 & 500 & 32 \\
\hline 29 & 17 & 18 & 0,0018 & 0,0144 & 500 & 20 \\
\hline 30 & 17 & 22 & 0,0135 & 0,1053 & 500 & 146 \\
\hline 31 & 18 & 21 & 0,0033 & 0,0259 & 500 & 36 \\
\hline 32 & 19 & 20 & 0,0051 & 0,0396 & 500 & 55 \\
\hline 33 & 20 & 23 & 0,0028 & 0,0216 & 500 & 30 \\
\hline 34 & 21 & 22 & 0,0087 & 0,0678 & 500 & 94 \\
\hline 35 & 01 & 08 & 0,0174 & 0,1344 & 500 & 35 \\
\hline 36 & 02 & 08 & 0,0164 & 0,1267 & 500 & 33 \\
\hline 37 & 06 & 07 & 0,0249 & 0,1920 & 500 & 50 \\
\hline 38 & 13 & 14 & 0,0058 & 0,0447 & 500 & 62 \\
\hline 39 & 14 & 23 & 0,0080 & 0,0620 & 500 & 86 \\
\hline 40 & 16 & 23 & 0,0106 & 0,0822 & 500 & 114 \\
\hline 41 & 19 & 23 & 0,0078 & 0,0606 & 500 & 84 \\
\hline & & & & & & \\
\hline
\end{tabular}




\section{3.}

\section{Obtenção dos Cenários de Geração Eólica - Passo I}

Devido à alta flutuação intrínseca em fontes de geração eólica, neste trabalho é proposta uma metodologia, para planejar a rede de transmissão de um SEP a partir de cenários pré-estabelecidos. Deste modo, pretende-se obter uma rede planejada capaz de viabilizar um melhor aproveitamento da energia eólica, ao menor custo possível.

Para determinar os cenários a considerar ao longo do planejamento da rede de transmissão do sistema IEEE RTS_Wind, parte-se de séries históricas de potência eólica. Neste caso, consideram-se séries horárias que representam a variabilidade da energia eólica de 5 anos em duas regiões da Holanda [47], obtidas pelo instituto de meteorologia e pesquisa do mesmo país. O motivo desta escolha radica principalmente na disponibilidade e dimensão dos dados amostrados, que conformam as séries de vento que foram utilizadas. Para ilustrar a volatilidade da energia que pode ser suprida pelas eólicas, a Figura 4.2 apresenta a média móvel mensal de disponibilidade de energia para as duas regiões escolhidas.

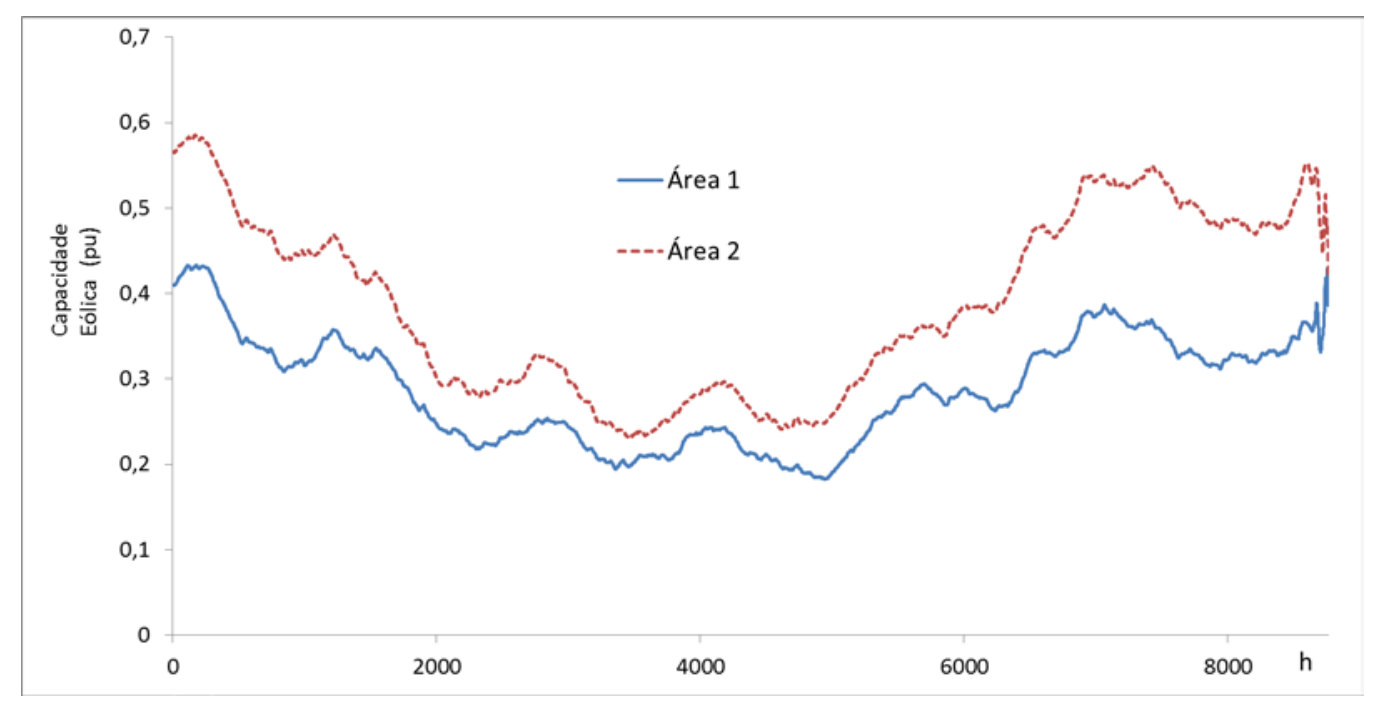

Figura 4.2 - Média móvel mensal das séries de capacidade eólica por área.

Para a avaliação particular da metodologia no sistema IEEE RTS_Wind, as séries das Áreas 1 e 2 foram escolhidas para considerar a inserção de geração eólica nas barras 1 e 15, respectivamente. Os dados destas séries foram submetidos a “clusterização” pelo método K-means [45], conforme mencionado na Seção 3.4. 
Executando o Passo i da metodologia proposta, definem-se 10 clusters representativos para os 43800 dados de cada região (mostra horária de 5 anos). Conformando-se assim os cenários estabelecidos para considerar desde o começo até o final do presente estudo.

A seguir, apresenta-se a Tabela 4.5 que contém a informação dos cenários de geração eólica estabelecidos.

Tabela 4.5 - Resumo dos cenários estabelecidos.

\begin{tabular}{|c|c|c|c|}
\hline \multirow{2}{*}{ Cenário } & \multicolumn{2}{|c|}{ Capacidade Eólica (pu) } & \multirow{2}{*}{ Probabilidade } \\
\cline { 2 - 3 } & Barra 1 & Barra 15 & \\
\hline 1 & 0,0726 & 0,0759 & 0,2452 \\
\hline 2 & 0,2896 & 0,1669 & 0,0905 \\
\hline 3 & 0,0993 & 0,2272 & 0,1253 \\
\hline 4 & 0,4351 & 0,3781 & 0,0807 \\
\hline 5 & 0,1630 & 0,3882 & 0,1100 \\
\hline 6 & 0,2120 & 0,5840 & 0,0763 \\
\hline 7 & 0,7046 & 0,6132 & 0,0418 \\
\hline 8 & 0,4579 & 0,6320 & 0,0723 \\
\hline 9 & 0,3158 & 0,8310 & 0,0388 \\
\hline 10 & 0,7523 & 0,9074 & 0,1192 \\
\hline
\end{tabular}

É importante destacar que a aplicação do método K-means para obter os cenários de geração eólica, proporciona a vantagem de considerar correlação existente entre a variabilidade eólica das duas regiões de vento escolhidas neste trabalho.

\section{4.}

\section{Ajuste dos Parâmetros do AMC-PET - Passo II}

Para este trabalho foram realizados vários testes para estabelecer os parâmetros de entrada, configurando assim a forma de execução da ferramenta AMCPET em cada cenário estabelecido. Nos testes considerou-se principalmente a taxa de sucesso para obtenção da melhor solução conhecida (dada pelo valor do custo de investimento) e o tempo médio gasto para consegui-la. Os parâmetros de entrada variados para realizar os testes foram os tamanhos dos conjuntos $\Omega_{\mathrm{MA}}$ e $\Omega_{\mathrm{MCM}}$, o número de ramos candidatos a serem avaliados pelo mecanismo de adição, a participação de cada índice de atratividade na composição destes ramos candidatos e o critério de convergência ou parada. 
Primeiramente, foram realizados diversos testes utilizando-se a configuração base do sistema IEEE RTS_Wind e um cenário intermediário, o Cenário 4. A Tabela 4.6 apresenta os três melhores ajustes de parâmetros encontrados, os quais foram selecionados para a presente aplicação.

Tabela 4.6 - Conjuntos de Ajustes para configurar a ferramenta AMC-PET

\begin{tabular}{|c|c|c|c|c|c|c|}
\hline \multirow{2}{*}{ Ajuste } & \multirow{2}{*}{$\begin{array}{c}\text { Tamanho } \\
\text { do } \Omega_{\mathrm{MA}}\end{array}$} & \multirow{2}{*}{$\begin{array}{c}\text { Tamanho } \\
\Omega_{\mathrm{MCM}}\end{array}$} & \multicolumn{3}{|c|}{ Ramos Candidatos Avaliados pelo MA } & \multirow{2}{*}{$\begin{array}{c}\text { Critério } \\
\text { de } \\
\text { Parada }\end{array}$} \\
\hline & & & $\operatorname{Ind}_{c h-i j}$ & $\operatorname{Ind}_{s c-i j}^{\text {próprio }}$ & $\operatorname{Ind}_{s c-i j}^{\text {outros }}$ & \\
\hline 1 & 20 & 20 & 1 & 1 & 2 & 6 \\
\hline 2 & 20 & 20 & 2 & 2 & 1 & 6 \\
\hline 3 & 20 & 20 & 1 & 2 & 2 & 6 \\
\hline
\end{tabular}

Em seguida, para cada um dos ajustes selecionados, foram realizadas 20 execuções do AMC-PET para cada um dos 10 cenários de geração eólica definidos via método K-means, no passo (i) da metodologia. A Tabela 4.7 apresenta os resultados obtidos (melhor solução e taxa de sucesso), assim como a quantidade de execuções definidas para cada ajuste, para cada um dos cenários. Esta quantidade de execuções é obtida de tal modo que a expectativa de acerto seja superior a 1. A expectativa de acerto (i.e., de encontrar a melhor solução conhecida) para cada cenário é calculada multiplicando-se a taxa de sucesso pelo número de execuções por ajuste e, ainda, pelo número de ajustes. Por exemplo, para o Cenário 1 tem-se a expectativa de 1,6 acerto $(=0,067 \times 8 \times 3)$.

Tabela 4.7 - Número de execuções definidas para a ferramenta AMC-PET segundo cada cenário.

\begin{tabular}{|c|c|c|c|c|}
\hline Cenário & $\begin{array}{c}\text { Melhor solução } \\
\mathbf{( 1 0}^{\mathbf{6}} \mathbf{\text { ) }}\end{array}$ & $\begin{array}{c}\text { Sucesso } \\
\mathbf{( p u )}\end{array}$ & $\begin{array}{c}\text { Execuções } \\
\text { por Ajuste }\end{array}$ & $\begin{array}{c}\text { Expectativa } \\
\text { de Acerto }\end{array}$ \\
\hline 1 & 322 & 0,067 & 8 & 1,6 \\
\hline 2 & 241 & 0,90 & 2 & 5,4 \\
\hline 3 & 295 & 0,42 & 2 & 2,5 \\
\hline 4 & 215 & 0,43 & 2 & 2,6 \\
\hline 5 & 295 & 0,28 & 4 & 3,4 \\
\hline 6 & 263 & 0,22 & 4 & 2,6 \\
\hline 7 & 291 & 0,083 & 8 & 2,0 \\
\hline 8 & 215 & 0,40 & 2 & 2,4 \\
\hline 9 & 237 & 0,57 & 2 & 3,4 \\
\hline 10 & 296 & 0,15 & 4 & 1,8 \\
\hline
\end{tabular}


Nas próximas seções serão apresentados os resultados obtidos com a aplicação dos demais passos da metodologia (iii, iv, $v$ e vi). O plano de expansão obtido mediante a abordagem adotada é comparado com soluções intermediárias, resultantes da superposição das soluções dos 10 cenários, em dois momentos: após o passo iii (Obtenção do melhor plano de expansão para cada cenário de geração eólica) e ao término do passo $v$ (Etapa Iterativa para a Convergência dos Planos de Expansão). Adicionalmente, a metodologia proposta é repetida utilizando-se duas estratégias, as quais propiciam soluções com menor custo de investimento.

\section{5. Obtenção do melhor plano de expansão para cada cenário e cons- trução da Tabela Decisão - Passos III e IV}

Nesta parte da metodologia proposta, inicia-se com a obtenção do melhor plano solução para cada cenário estabelecido por meio da ferramenta AMC-PET. Em seguida, é construída a “Tabela Decisão”, a qual representa um elemento base para a metodologia proposta. Obtém-se, então, a Tabela 4.8, a qual será constantemente atualizada para o desenvolvimento dos passo $v$ e vi. Em relação à Tabela 3.1, a Tabela 4.8 acrescenta duas linhas, as quais fornecem o total de reforços e custo de investimento para a melhor solução de cada cenário de geração eólica. No canto inferior direito é fornecido o custo de investimento médio para os 10 cenários. 
Tabela 4.8 - Tabela Decisão Inicial.

\begin{tabular}{|c|c|c|c|c|c|c|c|c|c|c|c|c|c|}
\hline \multirow{2}{*}{ Ramo } & \multicolumn{10}{|c|}{ Melhor Plano Para Cada Cenário } & \multicolumn{3}{|c|}{ Graus de Incidência } \\
\hline & 1 & 2 & 3 & 4 & 5 & 6 & 7 & 8 & 9 & 10 & GI1 & GI2 & GI3 \\
\hline 01-02 & 1 & 0 & 0 & 0 & 0 & 0 & 0 & 0 & 0 & 0 & 1 & 0 & 0 \\
\hline 01-03 & 0 & 0 & 0 & 0 & 0 & 0 & 0 & 0 & 0 & 0 & 0 & 0 & 0 \\
\hline 01-05 & 0 & 0 & 0 & 2 & 0 & 1 & 2 & 2 & 0 & 2 & 5 & 4 & 0 \\
\hline $02-04$ & 0 & 0 & 0 & 0 & 0 & 0 & 0 & 0 & 0 & 0 & 0 & 0 & 0 \\
\hline $02-06$ & 0 & 0 & 0 & 0 & 0 & 0 & 0 & 0 & 0 & 0 & 0 & 0 & 0 \\
\hline 03-09 & 1 & 1 & 1 & 1 & 1 & 1 & 1 & 1 & 1 & 1 & 10 & 0 & 0 \\
\hline $03-24$ & 0 & 0 & 0 & 0 & 0 & 0 & 0 & 0 & 0 & 0 & 0 & 0 & 0 \\
\hline $\begin{array}{l}04-09 \\
\end{array}$ & 0 & 0 & 0 & 0 & 0 & 0 & 0 & 0 & 0 & 0 & 0 & 0 & 0 \\
\hline $05-10$ & 0 & 0 & 0 & 0 & 0 & 0 & 1 & 0 & 0 & 1 & 2 & 0 & 0 \\
\hline 06-10 & 2 & 2 & 2 & 1 & 2 & 2 & 1 & 1 & 2 & 1 & 10 & 6 & 0 \\
\hline $\begin{array}{l}07-08 \\
\end{array}$ & 2 & 2 & 2 & 2 & 2 & 2 & 0 & 2 & 2 & 0 & 8 & 8 & 0 \\
\hline 08-09 & 0 & 0 & 0 & 0 & 0 & 0 & 0 & 0 & 0 & 0 & 0 & 0 & 0 \\
\hline 08-10 & 0 & 0 & 0 & 0 & 0 & 0 & 0 & 0 & 0 & 0 & 0 & 0 & 0 \\
\hline 09-11 & 0 & 0 & 0 & 0 & 0 & 0 & 0 & 0 & 0 & 0 & 0 & 0 & 0 \\
\hline 09-12 & 0 & 0 & 0 & 0 & 0 & 0 & 1 & 0 & 0 & 0 & 1 & 0 & 0 \\
\hline $10-11$ & 0 & 0 & 1 & 0 & 1 & 0 & 0 & 0 & 0 & 0 & 2 & 0 & 0 \\
\hline $10-12$ & 1 & 1 & 0 & 0 & 0 & 1 & 0 & 0 & 1 & 0 & 4 & 0 & 0 \\
\hline $11-13$ & 0 & 1 & 1 & 0 & 1 & 1 & 0 & 0 & 0 & 0 & 4 & 0 & 0 \\
\hline $11-14$ & 0 & 0 & 0 & 0 & 0 & 0 & 0 & 0 & 0 & 0 & 0 & 0 & 0 \\
\hline $12-13$ & 1 & 0 & 0 & 0 & 0 & 0 & 0 & 0 & 0 & 0 & 1 & 0 & 0 \\
\hline $12-23$ & 0 & 0 & 0 & 0 & 0 & 0 & 0 & 0 & 0 & 0 & 0 & 0 & 0 \\
\hline $13-23$ & 0 & 0 & 0 & 0 & 0 & 0 & 0 & 0 & 0 & 0 & 0 & 0 & 0 \\
\hline $14-16$ & 1 & 0 & 1 & 0 & 1 & 0 & 0 & 0 & 0 & 0 & 3 & 0 & 0 \\
\hline $15-16$ & 1 & 0 & 0 & 0 & 0 & 0 & 0 & 0 & 0 & 0 & 1 & 0 & 0 \\
\hline $15-21$ & 0 & 0 & 0 & 0 & 0 & 0 & 0 & 0 & 0 & 0 & 0 & 0 & 0 \\
\hline $15-24$ & 0 & 0 & 0 & 0 & 0 & 0 & 0 & 0 & 0 & 0 & 0 & 0 & 0 \\
\hline 16-17 & 0 & 0 & 0 & 0 & 0 & 0 & 0 & 0 & 0 & 0 & 0 & 0 & 0 \\
\hline $16-19$ & 0 & 0 & 0 & 0 & 0 & 0 & 0 & 0 & 0 & 0 & 0 & 0 & 0 \\
\hline $17-18$ & 0 & 0 & 0 & 0 & 0 & 0 & 0 & 0 & 0 & 0 & 0 & 0 & 0 \\
\hline $17-22$ & 0 & 0 & 0 & 0 & 0 & 0 & 0 & 0 & 0 & 0 & 0 & 0 & 0 \\
\hline $18-21$ & 0 & 0 & 0 & 0 & 0 & 0 & 0 & 0 & 0 & 0 & 0 & 0 & 0 \\
\hline $19-20$ & 0 & 0 & 0 & 0 & 0 & 0 & 0 & 0 & 0 & 1 & 1 & 0 & 0 \\
\hline $20-23$ & 1 & 1 & 1 & 1 & 1 & 1 & 1 & 1 & 1 & 1 & 10 & 0 & 0 \\
\hline $21-22$ & 0 & 0 & 0 & 0 & 0 & 0 & 0 & 0 & 0 & 0 & 0 & 0 & 0 \\
\hline 01-08 & 0 & 0 & 0 & 0 & 0 & 0 & 1 & 0 & 0 & 1 & 2 & 0 & 0 \\
\hline $02-08$ & 0 & 0 & 0 & 0 & 0 & 0 & 0 & 0 & 0 & 0 & 0 & 0 & 0 \\
\hline $\begin{array}{l}06-07 \\
\end{array}$ & 0 & 0 & 0 & 0 & 0 & 0 & 0 & 0 & 0 & 0 & 0 & 0 & 0 \\
\hline 13-14 & 0 & 0 & 0 & 1 & 0 & 0 & 1 & 1 & 1 & 1 & 5 & 0 & 0 \\
\hline $14-23$ & 0 & 0 & 0 & 0 & 0 & 0 & 0 & 0 & 0 & 0 & 0 & 0 & 0 \\
\hline $16-23$ & 0 & 0 & 0 & 0 & 0 & 0 & 0 & 0 & 0 & 0 & 0 & 0 & 0 \\
\hline $19-23$ & 0 & 0 & 0 & 0 & 0 & 0 & 0 & 0 & 0 & 0 & 0 & 0 & 0 \\
\hline Reforços & 11 & 8 & 9 & 8 & 9 & 99 & 99 & 8 & 8 & 9 & Custo & Médio & $\left.10^{6} \$\right)$ \\
\hline $\begin{array}{c}\text { Custo } \\
\left(1^{6} \$\right)\end{array}$ & 322 & 241 & 295 & 215 & 295 & 263 & 291 & 215 & 237 & 296 & & 267 & \\
\hline
\end{tabular}

Para a Tabela 4.8 (o mesmo valerá para as atualizações da Tabela Decisão), adotou-se a cor azul claro para destacar os ramos candidatos que receberam 1 reforço, assim como todo GI1 igual a 10. Um tom mais forte de azul é utilizado para destacar os ramos com 2 reforços. Um tom ainda mais forte seria utilizado caso 
houvesse ao menos um ramo com 3 reforços. Estes tons médio e forte seriam utilizados para o caso de GI2 igual a 10 e GI3 igual 10, respectivamente. Com a cor abóbora claro está destacada a célula do GI1 correspondente ao ramo 07-08.

$\mathrm{Na}$ Tabela 4.8, fica claro que existem 3 decisões consolidadas (3 GI1s com valor 10), as quais são apresentadas na Tabela 4.9.

Tabela 4.9 - Reforços consolidados na Tabela Decisão Inicial.

\begin{tabular}{|c|c|}
\hline Ramo & Quantidade de Reforços \\
\hline $03-09$ & 1 \\
\hline $06-10$ & 1 \\
\hline $20-23$ & 1 \\
\hline
\end{tabular}

\section{6.}

\section{Etapa Iterativa para Convergência dos Planos de Expansão - Passo V}

Conforme o passo (v), a etapa iterativa tem como objetivo a uniformização dos planos dos cenários, com base nos GIs dos ramos candidatos. Esta etapa é interrompida assim que todas as decisões não consolidadas sejam formadas pelos chamados reforços exclusivos remanescentes.

\subsection{1. Iteração 1}

Na primeira iteração do passo $v$ deve-se identificar, por meio da Tabela Decisão Inicial (Tabela 4.8), qual ramo candidato passará por uma uniformização da quantidade de reforços adicionados. No presente estudo, este ramo é o 07-08, o qual tem seu GI1 (de valor 8) destacado. Cabe salientar que o GI2 deste mesmo ramo também tem valor 8. Porém, conforme determina o subpasso v.a, devem ser desconsiderados "os GIs de maior nível para ramos em que houver empate no valor do GI”.

Deste modo, seguindo o que determina os subpassos v.d e v.e , os Cenários 7 e 10 devem ser reavaliados, após a adição arbitrária de 1 reforço no ramo 07-08. Em seguida, é atualizada a Tabela Decisão, a qual é exibida na Tabela 4.10. Percebe-se que, para os dois cenários reavaliados, o AMC-PET encontrou soluções que determinam a adição de 2 reforços no ramo 07-08, uniformizando ainda mais a decisão para este ramo. 
Capítulo 4

Tabela 4.10 - Tabela Decisão da Iteração 1.

\begin{tabular}{|c|c|c|c|c|c|c|c|c|c|c|c|c|c|}
\hline \multirow{2}{*}{ Ramo } & \multicolumn{10}{|c|}{ Melhor Plano Para Cada Cenário } & \multicolumn{3}{|c|}{ Graus de Incidência } \\
\hline & 1 & 2 & 3 & 4 & 5 & 6 & 7 & 8 & 9 & 10 & GI1 & GI2 & GI3 \\
\hline 01-02 & 1 & 0 & 0 & 0 & 0 & 0 & 1 & 0 & 0 & 1 & 3 & 0 & 0 \\
\hline $01-03$ & 0 & 0 & 0 & 0 & 0 & 0 & 0 & 0 & 0 & 0 & 0 & 0 & 0 \\
\hline $01-05$ & 0 & 0 & 0 & 2 & 0 & 1 & 2 & 2 & 0 & 2 & 5 & 4 & 0 \\
\hline $02-04$ & 0 & 0 & 0 & 0 & 0 & 0 & 1 & 0 & 0 & 1 & 2 & 0 & 0 \\
\hline $02-06$ & 0 & 0 & 0 & 0 & 0 & 0 & 0 & 0 & 0 & 0 & 0 & 0 & 0 \\
\hline $03-09$ & 1 & 1 & 1 & 1 & 1 & 1 & 1 & 1 & 1 & 1 & 10 & 0 & 0 \\
\hline $03-24$ & 0 & 0 & 0 & 0 & 0 & 0 & 0 & 0 & 0 & 0 & 0 & 0 & 0 \\
\hline 04-09 & 0 & 0 & 0 & 0 & 0 & 0 & 0 & 0 & 0 & 0 & 0 & 0 & 0 \\
\hline $05-10$ & 0 & 0 & 0 & 0 & 0 & 0 & 1 & 0 & 0 & 1 & 2 & 0 & 0 \\
\hline 06-10 & 2 & 2 & 2 & 1 & 2 & 2 & 1 & 1 & 2 & 1 & 10 & 6 & 0 \\
\hline 07-08 & 2 & 2 & 2 & 2 & 2 & 2 & 2 & 2 & 2 & 2 & 10 & 10 & 0 \\
\hline 08-09 & 0 & 0 & 0 & 0 & 0 & 0 & 0 & 0 & 0 & 0 & 0 & 0 & 0 \\
\hline $08-10$ & 0 & 0 & 0 & 0 & 0 & 0 & 0 & 0 & 0 & 0 & 0 & 0 & 0 \\
\hline 09-11 & 0 & 0 & 0 & 0 & 0 & 0 & 0 & 0 & 0 & 0 & 0 & 0 & 0 \\
\hline 09-12 & 0 & 0 & 0 & 0 & 0 & 0 & 0 & 0 & 0 & 0 & 0 & 0 & 0 \\
\hline $10-11$ & 0 & 0 & 1 & 0 & 1 & 0 & 0 & 0 & 0 & 0 & 2 & 0 & 0 \\
\hline $10-12$ & 1 & 1 & 0 & 0 & 0 & 1 & 0 & 0 & 1 & 0 & 4 & 0 & 0 \\
\hline $11-13$ & 0 & 1 & 1 & 0 & 1 & 1 & 0 & 0 & 0 & 0 & 4 & 0 & 0 \\
\hline $11-14$ & 0 & 0 & 0 & 0 & 0 & 0 & 0 & 0 & 0 & 0 & 0 & 0 & 0 \\
\hline $12-13$ & 1 & 0 & 0 & 0 & 0 & 0 & 0 & 0 & 0 & 0 & 1 & 0 & 0 \\
\hline $12-23$ & 0 & 0 & 0 & 0 & 0 & 0 & 0 & 0 & 0 & 0 & 0 & 0 & 0 \\
\hline $13-23$ & 0 & 0 & 0 & 0 & 0 & 0 & 0 & 0 & 0 & 0 & 0 & 0 & 0 \\
\hline $14-16$ & 1 & 0 & 1 & 0 & 1 & 0 & 0 & 0 & 0 & 0 & 3 & 0 & 0 \\
\hline 15-16 & 1 & 0 & 0 & 0 & 0 & 0 & 0 & 0 & 0 & 0 & 1 & 0 & 0 \\
\hline $15-21$ & 0 & 0 & 0 & 0 & 0 & 0 & 0 & 0 & 0 & 0 & 0 & 0 & 0 \\
\hline $15-24$ & 0 & 0 & 0 & 0 & 0 & 0 & 0 & 0 & 0 & 0 & 0 & 0 & 0 \\
\hline $\begin{array}{l}16-17 \\
\end{array}$ & 0 & 0 & 0 & 0 & 0 & 0 & 0 & 0 & 0 & 0 & 0 & 0 & 0 \\
\hline $16-19$ & 0 & 0 & 0 & 0 & 0 & 0 & 0 & 0 & 0 & 0 & 0 & 0 & 0 \\
\hline $17-18$ & 0 & 0 & 0 & 0 & 0 & 0 & 0 & 0 & 0 & 0 & 0 & 0 & 0 \\
\hline $17-22$ & 0 & 0 & 0 & 0 & 0 & 0 & 0 & 0 & 0 & 0 & 0 & 0 & 0 \\
\hline $18-21$ & 0 & 0 & 0 & 0 & 0 & 0 & 0 & 0 & 0 & 0 & 0 & 0 & 0 \\
\hline $19-20$ & 0 & 0 & 0 & 0 & 0 & 0 & 1 & 0 & 0 & 1 & 2 & 0 & 0 \\
\hline $20-23$ & 1 & 1 & 1 & 1 & 1 & 1 & 1 & 1 & 1 & 1 & 10 & 0 & 0 \\
\hline $21-22$ & 0 & 0 & 0 & 0 & 0 & 0 & 0 & 0 & 0 & 0 & 0 & 0 & 0 \\
\hline 01-08 & 0 & 0 & 0 & 0 & 0 & 0 & 0 & 0 & 0 & 0 & 0 & 0 & 0 \\
\hline $02-08$ & 0 & 0 & 0 & 0 & 0 & 0 & 0 & 0 & 0 & 0 & 0 & 0 & 0 \\
\hline $06-07$ & 0 & 0 & 0 & 0 & 0 & 0 & 0 & 0 & 0 & 0 & 0 & 0 & 0 \\
\hline $13-14$ & 0 & 0 & 0 & 1 & 0 & 0 & 1 & 1 & 1 & 1 & 5 & 0 & 0 \\
\hline $14-23$ & 0 & 0 & 0 & 0 & 0 & 0 & 0 & 0 & 0 & 0 & 0 & 0 & 0 \\
\hline $16-23$ & 0 & 0 & 0 & 0 & 0 & 0 & 0 & 0 & 0 & 0 & 0 & 0 & 0 \\
\hline $19-23$ & 0 & 0 & 0 & 0 & 0 & 0 & 0 & 0 & 0 & 0 & 0 & 0 & 0 \\
\hline Reforços & 11 & 8 & 9 & 8 & 9 & 9 & 12 & 8 & 8 & 12 & \multicolumn{3}{|c|}{ Custo Médio (10 $\$$ \$) } \\
\hline $\begin{array}{l}\text { Custo } \\
\left(10^{6} \$\right)\end{array}$ & 322 & 241 & 295 & 215 & 295 & 263 & 329 & 215 & 237 & 329 & \multicolumn{3}{|c|}{274,1} \\
\hline InRef & 0 & 0 & 0 & 0 & 0 & 0 & 3 & 0 & 0 & 3 & \multicolumn{3}{|c|}{$\overline{\text { GU }}$} \\
\hline InCus & 0 & 0 & 0 & 0 & 0 & 0 & 38 & 0 & 0 & 33 & \multicolumn{3}{|c|}{105,8} \\
\hline
\end{tabular}

Pode-se observar que a Tabela 4.10 inclui algumas informações que não estão presentes na Tabela 4.8, as quais fornecem: 
- $\quad$ o incremento no número de reforços para cada cenário reavaliado na presente iteração (InRef);

- o incremento no custo de investimento (InCus), também para cada cenário reavaliado na iteração;

- $\quad$ o Grau de Uniformidade (GU) entre os planos, calculado conforme a expressão (3.11).

Cabe destacar que o GU não foi utilizado nesta iteração. No entanto, ele será sempre calculado e exibido para descrever como estará evoluindo a uniformização das decisões de investimento.

Concluída a Iteração 1, tem-se uma ampliação na consolidação das decisões de investimento por cenário. A nova consolidação é apresentada pela Tabela 4.11.

Tabela 4.11 - Reforços consolidados até a Tabela Decisão da Iteração 1.

\begin{tabular}{|c|c|c|}
\hline Ramo Candidato & Quantidade de Reforços & Tabela Decisão \\
\hline $03-09$ & 1 & \multirow{2}{*}{ Inicial } \\
\hline $06-10$ & 1 & \\
\hline $20-23$ & 1 & Iteração 1 \\
\hline $07-08$ & 2 & \\
\hline
\end{tabular}

\subsection{2.}

\section{Iteração 2}

Partindo do resultado da iteração 1, apresentado na Tabela 4.10, ao procurar a célula do GI com o valor mais próximo a 10, encontra-se que está na linha pertencente ao ramo 06-10, com um valor de 6 para GI2.

Conforme determina o passo ( $v$ ), deve-se adicionar, arbitrariamente, mais um reforço no ramo 06-10, para os cenários: 4, 7, 8 e 10. Ao se reavaliar estes cenários, obtém-se a Tabela 4.12. 
Capítulo 4

Tabela 4.12 - Tabela Decisão da Iteração 2.

\begin{tabular}{|c|c|c|c|c|c|c|c|c|c|c|c|c|c|}
\hline \multirow{2}{*}{ Ramo } & \multicolumn{10}{|c|}{ Plano Para Cada Cenário } & \multicolumn{3}{|c|}{ Graus de Incidência } \\
\hline & 1 & 2 & 3 & 4 & 5 & 6 & 7 & 8 & 9 & 10 & GI1 & GI2 & GI3 \\
\hline 01-02 & 1 & 0 & 0 & 0 & 0 & 0 & 1 & 0 & 0 & 1 & 3 & 0 & 0 \\
\hline 01-03 & 0 & 0 & 0 & 0 & 0 & 0 & 0 & 0 & 0 & 0 & 0 & 0 & 0 \\
\hline 01-05 & 0 & 0 & 0 & 2 & 0 & 1 & 2 & 2 & 0 & 2 & 5 & 4 & 0 \\
\hline $02-04$ & 0 & 0 & 0 & 0 & 0 & 0 & 1 & 0 & 0 & 1 & 2 & 0 & 0 \\
\hline $02-06$ & 0 & 0 & 0 & 0 & 0 & 0 & 0 & 0 & 0 & 0 & 0 & 0 & 0 \\
\hline 03-09 & 1 & 1 & 1 & 1 & 1 & 1 & 1 & 1 & 1 & 1 & 10 & 0 & 0 \\
\hline 03-24 & 0 & 0 & 0 & 0 & 0 & 0 & 0 & 0 & 0 & 0 & 0 & 0 & 0 \\
\hline 04-09 & 0 & 0 & 0 & 0 & 0 & 0 & 0 & 0 & 0 & 0 & 0 & 0 & 0 \\
\hline $\begin{array}{l}05-10 \\
\end{array}$ & 0 & 0 & 0 & 0 & 0 & 0 & 1 & 0 & 0 & 1 & 2 & 0 & 0 \\
\hline 06-10 & 2 & 2 & 2 & 2 & 2 & 2 & 2 & 2 & 2 & 2 & 10 & 10 & 0 \\
\hline 07-08 & 2 & 2 & 2 & 2 & 2 & 2 & 2 & 2 & 2 & 2 & 10 & 10 & 0 \\
\hline 08-09 & 0 & 0 & 0 & 0 & 0 & 0 & 0 & 0 & 0 & 0 & 0 & 0 & 0 \\
\hline $08-10$ & 0 & 0 & 0 & 0 & 0 & 0 & 0 & 0 & 0 & 0 & 0 & 0 & 0 \\
\hline $09-11$ & 0 & 0 & 0 & 0 & 0 & 0 & 0 & 0 & 0 & 0 & 0 & 0 & 0 \\
\hline 09-12 & 0 & 0 & 0 & 0 & 0 & 0 & 0 & 0 & 0 & 0 & 0 & 0 & 0 \\
\hline $10-11$ & 0 & 0 & 1 & 0 & 1 & 0 & 0 & 0 & 0 & 0 & 2 & 0 & 0 \\
\hline $10-12$ & 1 & 1 & 0 & 0 & 0 & 1 & 0 & 0 & 1 & 0 & 4 & 0 & 0 \\
\hline 11-13 & 0 & 1 & 1 & 0 & 1 & 1 & 0 & 0 & 0 & 0 & 4 & 0 & 0 \\
\hline 11-14 & 0 & 0 & 0 & 0 & 0 & 0 & 0 & 0 & 0 & 0 & 0 & 0 & 0 \\
\hline $12-13$ & 1 & 0 & 0 & 0 & 0 & 0 & 0 & 0 & 0 & 0 & 1 & 0 & 0 \\
\hline $12-23$ & 0 & 0 & 0 & 0 & 0 & 0 & 0 & 0 & 0 & 0 & 0 & 0 & 0 \\
\hline $13-23$ & 0 & 0 & 0 & 0 & 0 & 0 & 0 & 0 & 0 & 0 & 0 & 0 & 0 \\
\hline 14-16 & 1 & 0 & 1 & 0 & 1 & 0 & 0 & 0 & 0 & 0 & 3 & 0 & 0 \\
\hline $15-16$ & 1 & 0 & 0 & 0 & 0 & 0 & 0 & 0 & 0 & 0 & 1 & 0 & 0 \\
\hline 15-21 & 0 & 0 & 0 & 0 & 0 & 0 & 0 & 0 & 0 & 0 & 0 & 0 & 0 \\
\hline $15-24$ & 0 & 0 & 0 & 0 & 0 & 0 & 0 & 0 & 0 & 0 & 0 & 0 & 0 \\
\hline $16-17$ & 0 & 0 & 0 & 0 & 0 & 0 & 0 & 0 & 0 & 0 & 0 & 0 & 0 \\
\hline 16-19 & 0 & 0 & 0 & 0 & 0 & 0 & 0 & 0 & 0 & 0 & 0 & 0 & 0 \\
\hline $17-18$ & 0 & 0 & 0 & 0 & 0 & 0 & 0 & 0 & 0 & 0 & 0 & 0 & 0 \\
\hline $17-22$ & 0 & 0 & 0 & 0 & 0 & 0 & 0 & 0 & 0 & 0 & 0 & 0 & 0 \\
\hline $18-21$ & 0 & 0 & 0 & 0 & 0 & 0 & 0 & 0 & 0 & 0 & 0 & 0 & 0 \\
\hline $19-20$ & 0 & 0 & 0 & 0 & 0 & 0 & 1 & 0 & 0 & 1 & 2 & 0 & 0 \\
\hline $20-23$ & 1 & 1 & 1 & 1 & 1 & 1 & 1 & 1 & 1 & 1 & 10 & 0 & 0 \\
\hline $21-22$ & 0 & 0 & 0 & 0 & 0 & 0 & 0 & 0 & 0 & 0 & 0 & 0 & 0 \\
\hline 01-08 & 0 & 0 & 0 & 0 & 0 & 0 & 0 & 0 & 0 & 0 & 0 & 0 & 0 \\
\hline $02-08$ & 0 & 0 & 0 & 0 & 0 & 0 & 0 & 0 & 0 & 0 & 0 & 0 & 0 \\
\hline 06-07 & 0 & 0 & 0 & 0 & 0 & 0 & 0 & 0 & 0 & 0 & 0 & 0 & 0 \\
\hline $13-14$ & 0 & 0 & 0 & 1 & 0 & 0 & 1 & 1 & 1 & 1 & 5 & 0 & 0 \\
\hline $14-23$ & 0 & 0 & 0 & 0 & 0 & 0 & 0 & 0 & 0 & 0 & 0 & 0 & 0 \\
\hline 16-23 & 0 & 0 & 0 & 0 & 0 & 0 & 0 & 0 & 0 & 0 & 0 & 0 & 0 \\
\hline $19-23$ & 0 & 0 & 0 & 0 & 0 & 0 & 0 & 0 & 0 & 0 & 0 & 0 & 0 \\
\hline Reforços & 11 & 8 & 9 & 9 & 9 & 9 & 13 & 9 & 8 & 13 & \multicolumn{3}{|c|}{ Custo Médio $\left(10^{6} \$\right)$} \\
\hline $\begin{array}{c}\text { Custo } \\
\left(1^{6} \$\right)\end{array}$ & 322 & 241 & 295 & 231 & 295 & 263 & 345 & 231 & 237 & 345 & \multicolumn{3}{|c|}{280,5} \\
\hline InRef & 0 & 0 & 0 & 1 & 0 & 0 & 1 & 1 & 0 & 1 & \multicolumn{3}{|c|}{$\overline{\text { GU }}$} \\
\hline InCus & 0 & 0 & 0 & 16 & 0 & 0 & 16 & 16 & 0 & 16 & \multicolumn{3}{|c|}{107,2} \\
\hline InRefA & 0 & 0 & 0 & 1 & 0 & 0 & 4 & 1 & 0 & 4 & \\
\hline InCusA & 0 & 0 & 0 & 16 & 0 & 0 & 54 & 16 & 0 & 49 & & & \\
\hline
\end{tabular}


A Tabela 4.12, além de conter a informação exposta na Tabela Decisão 4.11, também inclui os valores:

- do incremento acumulado no número de reforços para cada cenário reavaliado (InRefA) até o presente passo da etapa iterativa;

- do incremento acumulado no custo de investimento (InCusA), também para cada cenário reavaliado até o presente passo da etapa iterativa.

Nesta iteração, da mesma forma que na iteração anterior, não é considerado o valor do grau de uniformidade, mas destaca-se que este valor apresentou um aumento, significando uma maior uniformização dos planos dos cenários. Como resultado desta iteração, tem-se um acréscimo na consolidação das decisões de investimento, após a reavaliação dos cenários, própria da iteração. As decisões consolidadas até o momento são apresentadas na Tabela 4.13.

Tabela 4.13 - Reforços consolidados até a Tabela Decisão da Iteração 2.

\begin{tabular}{|c|c|c|}
\hline Ramo Candidato & Quantidade de Reforços & Tabela Decisão \\
\hline $03-09$ & 1 & \multirow{2}{*}{ Inicial } \\
\hline $06-10$ & 1 & \\
\hline $20-23$ & 1 & Iteração 1 \\
\hline $07-08$ & 2 & Iteração 2 \\
\hline $06-10$ & 2 &
\end{tabular}

\subsection{3.}

\section{Iteração 3}

De maneira semelhante ao que foi feito nas iterações anteriores, com a informação resultante da iteração anterior, contida na Tabela 4.12, procura-se o(s) GI(s) com o valor mais próximo a 10. Observa-se que é 5 neste caso, e conforme os subpassos (v.c) e (v.f), como houve empate entre os dois ramos selecionados, considerou-se duas alternativas de decisão como próprias da atual iteração.

\section{Alternativa 1}

Adicionar um reforço no ramo 01-05 nos cenários 1, 2, 3, 5 e 9. O resultado da avaliação desta primeira alternativa da terceira iteração é exposto na Tabela 4.14. 
Tabela 4.14 - Tabela Decisão da Iteração 3 - Alternativa 1.

\begin{tabular}{|c|c|c|c|c|c|c|c|c|c|c|c|c|c|}
\hline \multirow{2}{*}{ Ramo } & \multicolumn{10}{|c|}{ Plano Para Cada Cenário } & \multicolumn{3}{|c|}{ Graus de Incidência } \\
\hline & 1 & 2 & 3 & 4 & 5 & 6 & 7 & 8 & 9 & 10 & GI1 & GI2 & GI3 \\
\hline $01-02$ & 1 & 0 & 0 & 0 & 0 & 0 & 1 & 0 & 0 & 1 & 3 & 0 & 0 \\
\hline $01-03$ & 0 & 0 & 0 & 0 & 0 & 0 & 0 & 0 & 0 & 0 & 0 & 0 & 0 \\
\hline $01-05$ & 1 & 1 & 1 & 2 & 1 & 1 & 2 & 2 & 1 & 2 & 10 & 4 & 0 \\
\hline $02-04$ & 0 & 0 & 0 & 0 & 0 & 0 & 1 & 0 & 0 & 1 & 2 & 0 & 0 \\
\hline $02-06$ & 0 & 0 & 0 & 0 & 0 & 0 & 0 & 0 & 0 & 0 & 0 & 0 & 0 \\
\hline 03-09 & 1 & 1 & 1 & 1 & 1 & 1 & 1 & 1 & 1 & 1 & 10 & 0 & 0 \\
\hline $03-24$ & 0 & 0 & 0 & 0 & 0 & 0 & 0 & 0 & 0 & 0 & 0 & 0 & 0 \\
\hline 04-09 & 0 & 0 & 0 & 0 & 0 & 0 & 0 & 0 & 0 & 0 & 0 & 0 & 0 \\
\hline $05-10$ & 0 & 0 & 0 & 0 & 0 & 0 & 1 & 0 & 0 & 1 & 2 & 0 & 0 \\
\hline 06-10 & 2 & 2 & 2 & 2 & 2 & 2 & 2 & 2 & 2 & 2 & 10 & 10 & 0 \\
\hline 07-08 & 2 & 2 & 2 & 2 & 2 & 2 & 2 & 2 & 2 & 2 & 10 & 10 & 0 \\
\hline 08-09 & 0 & 0 & 0 & 0 & 0 & 0 & 0 & 0 & 0 & 0 & 0 & 0 & 0 \\
\hline 08-10 & 0 & 0 & 0 & 0 & 0 & 0 & 0 & 0 & 0 & 0 & 0 & 0 & 0 \\
\hline 09-11 & 0 & 0 & 0 & 0 & 0 & 0 & 0 & 0 & 0 & 0 & 0 & 0 & 0 \\
\hline 09-12 & 0 & 0 & 0 & 0 & 0 & 0 & 0 & 0 & 0 & 0 & 0 & 0 & 0 \\
\hline $10-11$ & 1 & 0 & 1 & 0 & 1 & 0 & 0 & 0 & 0 & 0 & 3 & 0 & 0 \\
\hline $10-12$ & 0 & 1 & 0 & 0 & 0 & 1 & 0 & 0 & 1 & 0 & 3 & 0 & 0 \\
\hline $11-13$ & 1 & 1 & 1 & 0 & 1 & 1 & 0 & 0 & 0 & 0 & 5 & 0 & 0 \\
\hline $11-14$ & 0 & 0 & 0 & 0 & 0 & 0 & 0 & 0 & 0 & 0 & 0 & 0 & 0 \\
\hline $12-13$ & 0 & 0 & 0 & 0 & 0 & 0 & 0 & 0 & 0 & 0 & 0 & 0 & 0 \\
\hline $12-23$ & 0 & 0 & 0 & 0 & 0 & 0 & 0 & 0 & 0 & 0 & 0 & 0 & 0 \\
\hline $13-23$ & 0 & 0 & 0 & 0 & 0 & 0 & 0 & 0 & 0 & 0 & 0 & 0 & 0 \\
\hline $14-16$ & 1 & 0 & 1 & 0 & 1 & 0 & 0 & 0 & 0 & 0 & 3 & 0 & 0 \\
\hline $15-16$ & 1 & 0 & 0 & 0 & 0 & 0 & 0 & 0 & 0 & 0 & 1 & 0 & 0 \\
\hline $15-21$ & 0 & 0 & 0 & 0 & 0 & 0 & 0 & 0 & 0 & 0 & 0 & 0 & 0 \\
\hline $15-24$ & 0 & 0 & 0 & 0 & 0 & 0 & 0 & 0 & 0 & 0 & 0 & 0 & 0 \\
\hline $16-17$ & 0 & 0 & 0 & 0 & 0 & 0 & 0 & 0 & 0 & 0 & 0 & 0 & 0 \\
\hline $16-19$ & 0 & 0 & 0 & 0 & 0 & 0 & 0 & 0 & 0 & 0 & 0 & 0 & 0 \\
\hline $17-18$ & 0 & 0 & 0 & 0 & 0 & 0 & 0 & 0 & 0 & 0 & 0 & 0 & 0 \\
\hline $17-22$ & 0 & 0 & 0 & 0 & 0 & 0 & 0 & 0 & 0 & 0 & 0 & 0 & 0 \\
\hline $18-21$ & 0 & 0 & 0 & 0 & 0 & 0 & 0 & 0 & 0 & 0 & 0 & 0 & 0 \\
\hline $19-20$ & 0 & 0 & 0 & 0 & 0 & 0 & 1 & 0 & 0 & 1 & 2 & 0 & 0 \\
\hline $20-23$ & 1 & 1 & 1 & 1 & 1 & 1 & 1 & 1 & 1 & 1 & 10 & 0 & 0 \\
\hline $21-22$ & 0 & 0 & 0 & 0 & 0 & 0 & 0 & 0 & 0 & 0 & 0 & 0 & 0 \\
\hline 01-08 & 0 & 0 & 0 & 0 & 0 & 0 & 0 & 0 & 0 & 0 & 0 & 0 & 0 \\
\hline $02-08$ & 0 & 0 & 0 & 0 & 0 & 0 & 0 & 0 & 0 & 0 & 0 & 0 & 0 \\
\hline $06-07$ & 0 & 0 & 0 & 0 & 0 & 0 & 0 & 0 & 0 & 0 & 0 & 0 & 0 \\
\hline $13-14$ & 0 & 0 & 0 & 1 & 0 & 0 & 1 & 1 & 1 & 1 & 5 & 0 & 0 \\
\hline $14-23$ & 0 & 0 & 0 & 0 & 0 & 0 & 0 & 0 & 0 & 0 & 0 & 0 & 0 \\
\hline $16-23$ & 0 & 0 & 0 & 0 & 0 & 0 & 0 & 0 & 0 & 0 & 0 & 0 & 0 \\
\hline $19-23$ & 0 & 0 & 0 & 0 & 0 & 0 & 0 & 0 & 0 & 0 & 0 & 0 & 0 \\
\hline Reforços & 12 & 9 & 10 & 9 & 10 & 9 & 13 & 9 & 9 & 13 & \multicolumn{3}{|c|}{ Custo Médio $\left(10^{6} \$\right)$} \\
\hline $\begin{array}{c}\text { Custo } \\
\left(10^{6} \$\right)\end{array}$ & 344 & 263 & 317 & 231 & 317 & 263 & 345 & 231 & 259 & 345 & \multicolumn{3}{|c|}{291,5} \\
\hline InRef & 1 & 1 & 1 & 0 & 1 & 0 & 0 & 0 & 1 & 0 & \multicolumn{3}{|c|}{ (GU } \\
\hline InCus & 22 & 22 & 22 & 0 & 22 & 0 & 0 & 0 & 22 & 0 & \multicolumn{3}{|c|}{110,4} \\
\hline InRefA & 1 & 1 & 1 & 1 & 1 & 0 & 4 & 1 & 1 & 4 & \\
\hline InCusA & 22 & 22 & 22 & 16 & 22 & 0 & 54 & 16 & 22 & 49 & & & \\
\hline
\end{tabular}


Capítulo 4

\section{Alternativa 2}

Tabela 4.15 - Tabela Decisão da Iteração 3 - Alternativa 2.

\begin{tabular}{|c|c|c|c|c|c|c|c|c|c|c|c|c|c|}
\hline \multirow{2}{*}{ Ramo } & \multicolumn{10}{|c|}{ Plano Para Cada Cenário } & \multicolumn{3}{|c|}{ Graus de Incidência } \\
\hline & 1 & 2 & 3 & 4 & 5 & 6 & 7 & 8 & 9 & 10 & GI1 & GI2 & GI3 \\
\hline 01-02 & 1 & 0 & 0 & 0 & 0 & 0 & 1 & 0 & 0 & 1 & 3 & 0 & 0 \\
\hline 01-03 & 0 & 0 & 0 & 0 & 0 & 0 & 0 & 0 & 0 & 0 & 0 & 0 & 0 \\
\hline 01-05 & 0 & 0 & 0 & 2 & 0 & 0 & 2 & 2 & 0 & 2 & 4 & 4 & 0 \\
\hline $02-04$ & 0 & 0 & 0 & 0 & 0 & 0 & 1 & 0 & 0 & 1 & 2 & 0 & 0 \\
\hline $02-06$ & 0 & 0 & 0 & 0 & 0 & 0 & 0 & 0 & 0 & 0 & 0 & 0 & 0 \\
\hline 03-09 & 1 & 1 & 1 & 1 & 1 & 1 & 1 & 1 & 1 & 1 & 10 & 0 & 0 \\
\hline 03-24 & 0 & 1 & 0 & 0 & 0 & 0 & 0 & 0 & 0 & 0 & 1 & 0 & 0 \\
\hline 04-09 & 0 & 0 & 0 & 0 & 0 & 0 & 0 & 0 & 0 & 0 & 0 & 0 & 0 \\
\hline $05-10$ & 0 & 0 & 0 & 0 & 0 & 0 & 1 & 0 & 0 & 1 & 2 & 0 & 0 \\
\hline 06-10 & 2 & 2 & 2 & 2 & 2 & 2 & 2 & 2 & 2 & 2 & 10 & 10 & 0 \\
\hline 07-08 & 2 & 2 & 2 & 2 & 2 & 2 & 2 & 2 & 2 & 2 & 10 & 10 & 0 \\
\hline 08-09 & 0 & 0 & 0 & 0 & 0 & 0 & 0 & 0 & 0 & 0 & 0 & 0 & 0 \\
\hline $08-10$ & 0 & 0 & 0 & 0 & 0 & 0 & 0 & 0 & 0 & 0 & 0 & 0 & 0 \\
\hline 09-11 & 0 & 0 & 0 & 0 & 0 & 0 & 0 & 0 & 0 & 0 & 0 & 0 & 0 \\
\hline $09-12$ & 0 & 0 & 0 & 0 & 0 & 0 & 0 & 0 & 0 & 0 & 0 & 0 & 0 \\
\hline $10-11$ & 0 & 0 & 1 & 0 & 0 & 1 & 0 & 0 & 0 & 0 & 2 & 0 & 0 \\
\hline $10-12$ & 1 & 1 & 0 & 0 & 1 & 1 & 0 & 0 & 1 & 0 & 5 & 0 & 0 \\
\hline $11-13$ & 0 & 0 & 0 & 0 & 1 & 0 & 0 & 0 & 0 & 0 & 1 & 0 & 0 \\
\hline 11-14 & 0 & 0 & 1 & 0 & 0 & 0 & 0 & 0 & 0 & 0 & 1 & 0 & 0 \\
\hline $12-13$ & 1 & 0 & 0 & 0 & 0 & 0 & 0 & 0 & 0 & 0 & 1 & 0 & 0 \\
\hline $12-23$ & 0 & 0 & 0 & 0 & 0 & 0 & 0 & 0 & 0 & 0 & 0 & 0 & 0 \\
\hline $13-23$ & 0 & 0 & 0 & 0 & 0 & 0 & 0 & 0 & 0 & 0 & 0 & 0 & 0 \\
\hline 14-16 & 1 & 0 & 1 & 0 & 0 & 0 & 0 & 0 & 0 & 0 & 2 & 0 & 0 \\
\hline $15-16$ & 0 & 0 & 0 & 0 & 0 & 0 & 0 & 0 & 0 & 0 & 0 & 0 & 0 \\
\hline $15-21$ & 0 & 0 & 0 & 0 & 0 & 0 & 0 & 0 & 0 & 0 & 0 & 0 & 0 \\
\hline $15-24$ & 0 & 0 & 0 & 0 & 0 & 0 & 0 & 0 & 0 & 0 & 0 & 0 & 0 \\
\hline $16-17$ & 0 & 0 & 0 & 0 & 0 & 0 & 0 & 0 & 0 & 0 & 0 & 0 & 0 \\
\hline 16-19 & 0 & 0 & 0 & 0 & 0 & 0 & 0 & 0 & 0 & 0 & 0 & 0 & 0 \\
\hline $17-18$ & 1 & 0 & 0 & 0 & 0 & 0 & 0 & 0 & 0 & 0 & 1 & 0 & 0 \\
\hline $17-22$ & 0 & 0 & 0 & 0 & 0 & 0 & 0 & 0 & 0 & 0 & 0 & 0 & 0 \\
\hline $18-21$ & 0 & 0 & 0 & 0 & 0 & 0 & 0 & 0 & 0 & 0 & 0 & 0 & 0 \\
\hline $19-20$ & 0 & 0 & 0 & 0 & 0 & 0 & 1 & 0 & 0 & 1 & 2 & 0 & 0 \\
\hline $20-23$ & 1 & 1 & 1 & 1 & 1 & 1 & 1 & 1 & 1 & 1 & 10 & 0 & 0 \\
\hline $21-22$ & 0 & 0 & 0 & 0 & 0 & 0 & 0 & 0 & 0 & 0 & 0 & 0 & 0 \\
\hline 01-08 & 0 & 0 & 0 & 0 & 0 & 0 & 0 & 0 & 0 & 0 & 0 & 0 & 0 \\
\hline 02-08 & 0 & 0 & 0 & 0 & 0 & 0 & 0 & 0 & 0 & 0 & 0 & 0 & 0 \\
\hline $06-07$ & 0 & 0 & 0 & 0 & 0 & 0 & 0 & 0 & 0 & 0 & 0 & 0 & 0 \\
\hline $13-14$ & 1 & 1 & 1 & 1 & 1 & 1 & 1 & 1 & 1 & 1 & 10 & 0 & 0 \\
\hline $14-23$ & 0 & 0 & 0 & 0 & 0 & 0 & 0 & 0 & 0 & 0 & 0 & 0 & 0 \\
\hline 16-23 & 0 & 0 & 0 & 0 & 0 & 0 & 0 & 0 & 0 & 0 & 0 & 0 & 0 \\
\hline 19-23 & 0 & 0 & 0 & 0 & 0 & 0 & 0 & 0 & 0 & 0 & 0 & 0 & 0 \\
\hline Reforços & 12 & 9 & 10 & 9 & 9 & 9 & 13 & 9 & 8 & 13 & \multicolumn{3}{|c|}{ Custo Médio $\left(10^{6} \$\right)$} \\
\hline $\begin{array}{c}\text { Custo } \\
\left(10^{6} \$\right)\end{array}$ & 380 & 287 & 349 & 231 & 303 & 287 & 345 & 231 & 237 & 345 & \multicolumn{3}{|c|}{299,5} \\
\hline InRef & 1 & 1 & 1 & 0 & 0 & 0 & 0 & 0 & 0 & 0 & \multicolumn{3}{|c|}{$\overline{\text { GU }}$} \\
\hline InCus & 58 & 46 & 54 & 0 & 8 & 24 & 0 & 0 & 0 & 0 & \multicolumn{3}{|c|}{107,3} \\
\hline InRefA & 1 & 1 & 1 & 1 & 0 & 0 & 4 & 1 & 0 & 4 & \\
\hline InCusA & 58 & 46 & 54 & 16 & 8 & 24 & 54 & 16 & 0 & 49 & & & \\
\hline
\end{tabular}


Esta segunda alternativa consistiu em adicionar um reforço no ramo 13-14 para os cenários 1, 2, 3, 5 e 6 . Após as reavaliações destes cenários, obteve-se a Tabela 4.15.

Considerando os valores calculados para o grau de uniformidade GU de cada uma das alternativas, como foi estabelecido no subpasso (v.g), a Alternativa 1 tem um valor mais atrativo, porque é maior. Deste modo, fica esta alternativa, como a escolhida para a terceira iteração. Por esta razão, apenas a Tabela 4.14 apresenta GIs destacados (com fundo abóbora claro), apontando os ramos que serão avaliados na Iteração 4. Por fim da corrente iteração, a consolidação de reforços é exposta na Tabela 4.16 .

Tabela 4.16 - Reforços consolidados até a Tabela Decisão da Iteração 3.

\begin{tabular}{|c|c|c|}
\hline Ramo Candidato & Quantidade de Reforços & Tabela Decisão \\
\hline $03-09$ & 1 & \multirow{2}{*}{ Inicial } \\
\hline $06-10$ & 1 & \\
\hline $20-23$ & 1 & Iteração 1 \\
\hline $07-08$ & 2 & Iteração 2 \\
\hline $06-10$ & 2 & Iteração 3 \\
\hline $01-05$ & 1 & \\
\hline
\end{tabular}

\subsection{4.}

\section{Iterações 4 a 10}

Para completar a etapa iterativa do processo de convergência para uma solução que atenda a todos os cenários considerados, foram necessárias mais 7 iterações. A Tabela 4.17 resume as principais informações acerca destas iterações, com destaque para o GI que define o(s) ramo(s) selecionado(s), para o Custo Médio e para o GU, de cada iteração. As tabelas utilizadas ao longo das Iterações 4 a 10 são fornecidas no apêndice - A do presente documento. 
Tabela 4.17 - Resumo das Iterações 4 a 10.

\begin{tabular}{|c|c|c|c|c|c|}
\hline Iteração & $\begin{array}{c}\text { GI } \\
\text { Utilizado }\end{array}$ & $\begin{array}{c}\text { Número de } \\
\text { Alternativas }\end{array}$ & $\begin{array}{c}\text { Ramos } \\
\text { Selecionados }\end{array}$ & $\begin{array}{c}\text { Custo Médio } \\
\text { Vencedor } \\
\mathbf{( 1 0} \mathbf{5})\end{array}$ & $\begin{array}{c}\text { GU } \\
\text { Vencedor }\end{array}$ \\
\hline 4 & GI1=5 & 2 & $11-13 ; 13-14$ & 309,6 & 111,4 \\
\hline 5 & GI2=4 & 1 & $01-05$ & 322,8 & 113 \\
\hline 6 & GI1=3 & 5 & $\begin{array}{c}01-02 ; 10-11 ; \\
10-12 ; 14-16 ; \\
19-20\end{array}$ & 324,9 & 114 \\
\hline 7 & GI1=3 & 4 & $\begin{array}{c}10-11 ; 10-12 ; \\
14-16 ; 19-20\end{array}$ & 365,6 & 115,4 \\
\hline 8 & GI1=4 & 1 & $14-16$ & 397,1 & 116 \\
\hline 9 & GI1=3 & 2 & $10-11 ; 10-12$ & 415,4 & 118 \\
\hline 10 & GI1=2 & 1 & $17-18$ & 431,4 & 119 \\
\hline
\end{tabular}

Por ser necessária para a próxima etapa da metodologia proposta, a Tabela 4.18, a qual contém as informações da Iteração 10, é apresentada a seguir. É também apresentada a Tabela 4.19, contendo as decisões consolidadas ao longo da etapa iterativa. 
Tabela 4.18 - Tabela Decisão da Iteração 10.

\begin{tabular}{|c|c|c|c|c|c|c|c|c|c|c|c|c|c|}
\hline \multirow{2}{*}{ Ramo } & \multicolumn{10}{|c|}{ Plano Para Cada Cenário } & \multicolumn{3}{|c|}{ Graus de Incidência } \\
\hline & 1 & 2 & 3 & 4 & 5 & 6 & 7 & 8 & 9 & 10 & GI1 & GI2 & GI3 \\
\hline 01-02 & 1 & 1 & 1 & 1 & 1 & 1 & 1 & 1 & 1 & 1 & 10 & 0 & 0 \\
\hline 01-03 & 0 & 0 & 0 & 0 & 0 & 0 & 0 & 0 & 0 & 1 & 1 & 0 & 0 \\
\hline 01-05 & 2 & 2 & 2 & 2 & 2 & 2 & 2 & 2 & 2 & 2 & 10 & 10 & 0 \\
\hline $02-04$ & 0 & 0 & 0 & 0 & 0 & 0 & 1 & 0 & 0 & 0 & 1 & 0 & 0 \\
\hline $02-06$ & 0 & 0 & 0 & 0 & 0 & 0 & 0 & 0 & 0 & 0 & 0 & 0 & 0 \\
\hline 03-09 & 1 & 1 & 1 & 1 & 1 & 1 & 1 & 1 & 1 & 1 & 10 & 0 & 0 \\
\hline $03-24$ & 0 & 0 & 0 & 0 & 0 & 0 & 0 & 0 & 0 & 0 & 0 & 0 & 0 \\
\hline 04-09 & 0 & 0 & 0 & 0 & 0 & 0 & 0 & 0 & 0 & 0 & 0 & 0 & 0 \\
\hline 05-10 & 0 & 0 & 0 & 0 & 0 & 0 & 1 & 0 & 0 & 0 & 1 & 0 & 0 \\
\hline 06-10 & 2 & 2 & 2 & 2 & 2 & 2 & 2 & 2 & 2 & 2 & 10 & 10 & 0 \\
\hline 07-08 & 2 & 2 & 2 & 2 & 2 & 2 & 2 & 2 & 2 & 2 & 10 & 10 & 0 \\
\hline 08-09 & 0 & 0 & 0 & 0 & 0 & 0 & 0 & 0 & 0 & 0 & 0 & 0 & 0 \\
\hline 08-10 & 0 & 0 & 0 & 0 & 0 & 0 & 0 & 0 & 0 & 0 & 0 & 0 & 0 \\
\hline $09-11$ & 0 & 0 & 0 & 0 & 0 & 0 & 0 & 0 & 0 & 0 & 0 & 0 & 0 \\
\hline $09-12$ & 0 & 0 & 0 & 0 & 0 & 0 & 0 & 0 & 0 & 0 & 0 & 0 & 0 \\
\hline $10-11$ & 1 & 1 & 1 & 1 & 1 & 1 & 1 & 1 & 1 & 1 & 10 & 0 & 0 \\
\hline $10-12$ & 0 & 0 & 0 & 0 & 0 & 0 & 0 & 0 & 0 & 0 & 0 & 0 & 0 \\
\hline $11-13$ & 1 & 1 & 1 & 1 & 1 & 1 & 1 & 1 & 1 & 1 & 10 & 0 & 0 \\
\hline $11-14$ & 0 & 0 & 0 & 0 & 0 & 0 & 0 & 0 & 0 & 0 & 0 & 0 & 0 \\
\hline $12-13$ & 0 & 0 & 0 & 0 & 0 & 0 & 0 & 0 & 0 & 0 & 0 & 0 & 0 \\
\hline $12-23$ & 0 & 0 & 0 & 0 & 0 & 0 & 0 & 0 & 0 & 0 & 0 & 0 & 0 \\
\hline $13-23$ & 0 & 0 & 0 & 0 & 0 & 0 & 0 & 0 & 0 & 0 & 0 & 0 & 0 \\
\hline $14-16$ & 1 & 1 & 1 & 1 & 1 & 1 & 1 & 1 & 1 & 1 & 10 & 0 & 0 \\
\hline 15-16 & 0 & 0 & 0 & 0 & 0 & 0 & 0 & 0 & 0 & 0 & 0 & 0 & 0 \\
\hline $15-21$ & 0 & 0 & 0 & 0 & 0 & 0 & 0 & 0 & 0 & 0 & 0 & 0 & 0 \\
\hline $15-24$ & 0 & 0 & 0 & 0 & 0 & 0 & 0 & 0 & 0 & 0 & 0 & 0 & 0 \\
\hline 16-17 & 0 & 0 & 0 & 0 & 0 & 0 & 0 & 0 & 0 & 0 & 0 & 0 & 0 \\
\hline $16-19$ & 0 & 0 & 0 & 0 & 0 & 0 & 0 & 0 & 0 & 0 & 0 & 0 & 0 \\
\hline $17-18$ & 1 & 1 & 1 & 1 & 1 & 1 & 1 & 1 & 1 & 1 & 10 & 0 & 0 \\
\hline $17-22$ & 0 & 0 & 0 & 0 & 0 & 0 & 0 & 0 & 0 & 0 & 0 & 0 & 0 \\
\hline $18-21$ & 0 & 0 & 0 & 0 & 0 & 0 & 0 & 0 & 0 & 0 & 0 & 0 & 0 \\
\hline $19-20$ & 1 & 1 & 1 & 1 & 1 & 1 & 1 & 1 & 1 & 1 & 10 & 0 & 0 \\
\hline $20-23$ & 1 & 1 & 1 & 1 & 1 & 1 & 1 & 1 & 1 & 1 & 10 & 0 & 0 \\
\hline $21-22$ & 0 & 0 & 0 & 0 & 0 & 0 & 0 & 0 & 0 & 0 & 0 & 0 & 0 \\
\hline 01-08 & 0 & 0 & 0 & 0 & 0 & 0 & 0 & 0 & 0 & 0 & 0 & 0 & 0 \\
\hline $02-08$ & 0 & 0 & 0 & 0 & 0 & 0 & 0 & 0 & 0 & 1 & 1 & 0 & 0 \\
\hline $\begin{array}{l}06-07 \\
\end{array}$ & 0 & 0 & 0 & 0 & 0 & 0 & 0 & 0 & 0 & 0 & 0 & 0 & 0 \\
\hline $13-14$ & 0 & 0 & 0 & 0 & 0 & 0 & 0 & 0 & 0 & 0 & 0 & 0 & 0 \\
\hline $14-23$ & 0 & 0 & 0 & 0 & 0 & 0 & 0 & 0 & 0 & 0 & 0 & 0 & 0 \\
\hline $16-23$ & 0 & 0 & 0 & 0 & 0 & 0 & 0 & 0 & 0 & 0 & 0 & 0 & 0 \\
\hline $19-23$ & 0 & 0 & 0 & 0 & 0 & 0 & 0 & 0 & 0 & 0 & 0 & 0 & 0 \\
\hline Reforços & 14 & 14 & 14 & 14 & 14 & 14 & 16 & 14 & 14 & 16 & \multicolumn{3}{|c|}{ Custo Médio $\left(10^{6} \$\right)$} \\
\hline $\begin{array}{c}\text { Custo } \\
\left(10^{6} \$\right) \\
\end{array}$ & 417 & 417 & 417 & 417 & 417 & 417 & 473 & 417 & 417 & 505 & \multicolumn{3}{|c|}{431,4} \\
\hline InRef & 0 & 1 & 1 & 1 & 1 & 1 & 1 & 1 & 0 & 1 & \multicolumn{3}{|c|}{ GU } \\
\hline InCus & 0 & 20 & 20 & 20 & 20 & 20 & 20 & 20 & 0 & 20 & \multicolumn{3}{|c|}{119} \\
\hline InRefA & 3 & 6 & 5 & 6 & 5 & 5 & 7 & 6 & 6 & 7 & \\
\hline InCusA & 95 & 176 & 122 & 202 & 122 & 154 & 182 & 202 & 180 & 209 & & & \\
\hline
\end{tabular}


Tabela 4.19 - Reforços consolidados até a Tabela Decisão da Iteração 10.

\begin{tabular}{|c|c|c|}
\hline Ramo Candidato & Quantidade de Reforços & \multirow{2}{*}{ Tabela Decisão } \\
\cline { 1 - 2 } $03-09$ & 1 & \multirow{2}{*}{ Inicial } \\
\cline { 1 - 2 } $06-10$ & 1 & \multirow{2}{*}{ Iteração 1 } \\
\cline { 1 - 2 } $20-23$ & 1 & Iteração 2 \\
\hline $07-08$ & 2 & Iteração 3 \\
\hline $06-10$ & 2 & Iteração 4 \\
\hline $01-05$ & 1 & Iteração 5 \\
\hline $11-13$ & 1 & Iteração 6 \\
\hline $01-05$ & 2 & Iteração 7 \\
\hline $01-02$ & 1 & Iteração 8 \\
\hline $19-20$ & 1 & Iteração 9 \\
\hline $14-16$ & 1 & Iteração 10 \\
\hline $10-11$ & 1 & \\
\hline $17-18$ & 1 & \\
\hline
\end{tabular}

\section{7.}

\section{Etapa Combinatória Para a Convergência dos Planos de Expansão - Passo VI}

Para continuar com o procedimento, parte-se da Tabela Decisão da Iteração 10 (Tabela 4.18). Nesta subsequente etapa, o proceder está baseado em tentar encontrar uma solução, analisando as combinações com os 4 reforços exclusivos remanescentes, os quais estão destacados com fundo vermelho claro. Como estes 4 reforços estão presentes em apenas 2 cenários (7 e 9), o processo combinatório fica bastante simples.

Conforme definido na Subseção 3.4.5, a exploração combinatória deve começar pelo menor subconjunto possível. Então, foram investigadas, primeiramente, todas as combinações com 2 reforços, para os 2 cenários em questão. Estas combinações são apresentadas na Tabela 4.20. É fácil constatar (ver Tabela 4.18) que as Combinações 3 e 4 já foram simuladas para os Cenários 10 e 7, respectivamente. 
Capítulo 4

Tabela 4.20 - Combinações possíveis com 2 dos 4 reforços exclusivos remanescentes.

\begin{tabular}{|c|c|c|c|c|c|c|}
\hline \multirow{2}{*}{ Ramo } & \multicolumn{7}{|c|}{ Combinações } \\
\cline { 2 - 7 } & $\mathbf{1}$ & $\mathbf{2}$ & $\mathbf{3}$ & $\mathbf{4}$ & $\mathbf{5}$ & $\mathbf{6}$ \\
\hline $01-03$ & 1 & 1 & 1 & 0 & 0 & 0 \\
\hline $02-04$ & 1 & 0 & 0 & 1 & 1 & 0 \\
\hline $05-10$ & 0 & 1 & 0 & 1 & 0 & 1 \\
\hline $02-08$ & 0 & 0 & 1 & 0 & 1 & 1 \\
\hline
\end{tabular}

Após as devidas análises envolvendo os Cenários 7 e 10, percebe-se que a Combinação 3, presente no Cenário 10 da Tabela 4.18, é também suficiente para o atendimento do Cenário 7. Como não há nenhuma combinação com 3 dos reforços remanescentes, a qual apresente custo inferior ao da Combinação 3, o processo pode ser interrompido. Vale destacar que a solução final, contida na Tabela 4.21 foi avaliada também para os demais cenários, mostrando-se sempre viável. 
Capítulo 4

Tabela 4.21 - Plano Final - Resultado da aplicação da metodologia proposta.

\begin{tabular}{|c|c|c|c|c|c|c|c|c|c|c|c|c|c|}
\hline \multirow{2}{*}{ Ramo } & \multicolumn{10}{|c|}{ Melhor Plano Para Cada Cenário } & \multicolumn{3}{|c|}{ Graus de Incidência } \\
\hline & 1 & 2 & 3 & 4 & 5 & 6 & 7 & 8 & 9 & 10 & GI1 & GI2 & GI3 \\
\hline 01-02 & 1 & 1 & 1 & 1 & 1 & 1 & 1 & 1 & 1 & 1 & 10 & 0 & 0 \\
\hline 01-03 & 1 & 1 & 1 & 1 & 1 & 1 & 1 & 1 & 1 & 1 & 10 & 0 & 0 \\
\hline 01-05 & 2 & 2 & 2 & 2 & 2 & 2 & 2 & 2 & 2 & 2 & 10 & 10 & 0 \\
\hline $02-04$ & 0 & 0 & 0 & 0 & 0 & 0 & 0 & 0 & 0 & 0 & 0 & 0 & 0 \\
\hline $02-06$ & 0 & 0 & 0 & 0 & 0 & 0 & 0 & 0 & 0 & 0 & 0 & 0 & 0 \\
\hline $\begin{array}{l}03-09 \\
\end{array}$ & 1 & 1 & 1 & 1 & 1 & 1 & 1 & 1 & 1 & 1 & 10 & 0 & 0 \\
\hline $03-24$ & 0 & 0 & 0 & 0 & 0 & 0 & 0 & 0 & 0 & 0 & 0 & 0 & 0 \\
\hline 04-09 & 0 & 0 & 0 & 0 & 0 & 0 & 0 & 0 & 0 & 0 & 0 & 0 & 0 \\
\hline 05-10 & 0 & 0 & 0 & 0 & 0 & 0 & 0 & 0 & 0 & 0 & 0 & 0 & 0 \\
\hline 06-10 & 2 & 2 & 2 & 2 & 2 & 2 & 2 & 2 & 2 & 2 & 10 & 10 & 0 \\
\hline 07-08 & 2 & 2 & 2 & 2 & 2 & 2 & 2 & 2 & 2 & 2 & 10 & 10 & 0 \\
\hline 08-09 & 0 & 0 & 0 & 0 & 0 & 0 & 0 & 0 & 0 & 0 & 0 & 0 & 0 \\
\hline 08-10 & 0 & 0 & 0 & 0 & 0 & 0 & 0 & 0 & 0 & 0 & 0 & 0 & 0 \\
\hline 09-11 & 0 & 0 & 0 & 0 & 0 & 0 & 0 & 0 & 0 & 0 & 0 & 0 & 0 \\
\hline 09-12 & 0 & 0 & 0 & 0 & 0 & 0 & 0 & 0 & 0 & 0 & 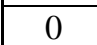 & 0 & 0 \\
\hline 10-11 & 1 & 1 & 1 & 1 & 1 & 1 & 1 & 1 & 1 & 1 & 10 & 0 & 0 \\
\hline $10-12$ & 0 & 0 & 0 & 0 & 0 & 0 & 0 & 0 & 0 & 0 & 0 & 0 & 0 \\
\hline $11-13$ & 1 & 1 & 1 & 1 & 1 & 1 & 1 & 1 & 1 & 1 & 10 & 0 & 0 \\
\hline 11-14 & 0 & 0 & 0 & 0 & 0 & 0 & 0 & 0 & 0 & 0 & 0 & 0 & 0 \\
\hline $12-13$ & 0 & 0 & 0 & 0 & 0 & 0 & 0 & 0 & 0 & 0 & 0 & 0 & 0 \\
\hline $12-23$ & 0 & 0 & 0 & 0 & 0 & 0 & 0 & 0 & 0 & 0 & 0 & 0 & 0 \\
\hline $13-23$ & 0 & 0 & 0 & 0 & 0 & 0 & 0 & 0 & 0 & 0 & 0 & 0 & 0 \\
\hline $14-16$ & 1 & 1 & 1 & 1 & 1 & 1 & 1 & 1 & 1 & 1 & 10 & 0 & 0 \\
\hline $15-16$ & 0 & 0 & 0 & 0 & 0 & 0 & 0 & 0 & 0 & 0 & 0 & 0 & 0 \\
\hline $15-21$ & 0 & 0 & 0 & 0 & 0 & 0 & 0 & 0 & 0 & 0 & 0 & 0 & 0 \\
\hline $15-24$ & 0 & 0 & 0 & 0 & 0 & 0 & 0 & 0 & 0 & 0 & 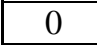 & 0 & 0 \\
\hline 16-17 & 0 & 0 & 0 & 0 & 0 & 0 & 0 & 0 & 0 & 0 & 0 & 0 & 0 \\
\hline 16-19 & 0 & 0 & 0 & 0 & 0 & 0 & 0 & 0 & 0 & 0 & 0 & 0 & 0 \\
\hline 17-18 & 1 & 1 & 1 & 1 & 1 & 1 & 1 & 1 & 1 & 1 & 10 & 0 & 0 \\
\hline $17-22$ & 0 & 0 & 0 & 0 & 0 & 0 & 0 & 0 & 0 & 0 & 0 & 0 & 0 \\
\hline 18-21 & 0 & 0 & 0 & 0 & 0 & 0 & 0 & 0 & 0 & 0 & 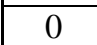 & 0 & 0 \\
\hline $19-20$ & 1 & 1 & 1 & 1 & 1 & 1 & 1 & 1 & 1 & 1 & 10 & 0 & 0 \\
\hline $20-23$ & 1 & 1 & 1 & 1 & 1 & 1 & 1 & 1 & 1 & 1 & 10 & 0 & 0 \\
\hline $21-22$ & 0 & 0 & 0 & 0 & 0 & 0 & 0 & 0 & 0 & 0 & 0 & 0 & 0 \\
\hline 01-08 & 0 & 0 & 0 & 0 & 0 & 0 & 0 & 0 & 0 & 0 & 0 & 0 & 0 \\
\hline $02-08$ & 1 & 1 & 1 & 1 & 1 & 1 & 1 & 1 & 1 & 1 & 10 & 0 & 0 \\
\hline $06-07$ & 0 & 0 & 0 & 0 & 0 & 0 & 0 & 0 & 0 & 0 & 0 & 0 & 0 \\
\hline $13-14$ & 0 & 0 & 0 & 0 & 0 & 0 & 0 & 0 & 0 & 0 & 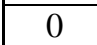 & 0 & 0 \\
\hline $14-23$ & 0 & 0 & 0 & 0 & 0 & 0 & 0 & 0 & 0 & 0 & 0 & 0 & 0 \\
\hline $16-23$ & 0 & 0 & 0 & 0 & 0 & 0 & 0 & 0 & 0 & 0 & 0 & 0 & 0 \\
\hline $19-23$ & 0 & 0 & 0 & 0 & 0 & 0 & 0 & 0 & 0 & 0 & 0 & 0 & 0 \\
\hline Reforços & 16 & 16 & 16 & 16 & 16 & 16 & 16 & 16 & 16 & 16 & Custo & Médio & $\left.10^{6} \$\right)$ \\
\hline $\begin{array}{c}\text { Custo } \\
\left(10^{6} \$\right)\end{array}$ & 505 & 505 & 505 & 505 & 505 & 505 & 505 & 505 & 505 & 505 & & 505 & \\
\hline InRef & 2 & 2 & 2 & 2 & 2 & 2 & 0 & 2 & 2 & 0 & & $\overline{\text { GU }}$ & \\
\hline InCus & 88 & 88 & 88 & 88 & 88 & 88 & 32 & 88 & 88 & 0 & & 123 & \\
\hline InRefA & 5 & 8 & 7 & 8 & 7 & 7 & 7 & 8 & 8 & 7 & & & \\
\hline InCusA & 183 & 264 & 210 & 290 & 210 & 242 & 214 & 290 & 268 & 209 & & & \\
\hline
\end{tabular}




\section{8.}

\section{Comparação com planos adicionais}

Nesta seção, o plano de expansão obtido mediante a abordagem adotada, denominado por Plano 1, é comparado com outros quatro planos de expansão. Para tal, foram obtidas duas soluções intermediárias: Plano 2, resultante da superposição das soluções iniciais dos 10 cenários (presentes na Tabela 4.8); e Plano 3: formado pela superposição das soluções obtidas ao término do passo $v$ (Etapa Iterativa para a Convergência dos Planos de Expansão). Os demais planos são obtidos mediante a repetição da metodologia proposta utilizando-se duas estratégias, as quais são descritas a seguir.

\subsection{1.}

\section{Desconsideração inicial dos cenários menos prováveis}

Esta estratégia consiste em desprezar os cenários menos prováveis. No entanto, após a aplicação da metodologia proposta os cenários desconsiderados devem ser avaliados. Eventualmente, pode ser necessário inserir reforços adicionais.

Neste estudo, optou-se por desconsiderar os 4 cenários menos prováveis (6, 7, 8 e 9). Foi, então, obtida a Tabela 4.22, a qual apresenta as melhores soluções iniciais para os Cenários 1-5 e 10. Ao final da aplicação da metodologia tem-se a Tabela 4.23. 
Tabela 4.22 - Tabela Decisão Inicial - Cenários mais Prováveis.

\begin{tabular}{|c|c|c|c|c|c|c|c|c|c|}
\hline \multirow{2}{*}{ Ramo } & \multicolumn{6}{|c|}{ Plano Para Cada Cenário } & \multicolumn{3}{|c|}{ Grau de Incidência } \\
\hline & 1 & 2 & 3 & 4 & 5 & 10 & GI1 & GI2 & GI3 \\
\hline 01-02 & 1 & 0 & 0 & 0 & 0 & 0 & 1 & 0 & 0 \\
\hline 01-03 & 0 & 0 & 0 & 0 & 0 & 0 & 0 & 0 & 0 \\
\hline 01-05 & 0 & 0 & 0 & 2 & 0 & 2 & 2 & 2 & 0 \\
\hline $02-04$ & 0 & 0 & 0 & 0 & 0 & 0 & 0 & 0 & 0 \\
\hline 02-06 & 0 & 0 & 0 & 0 & 0 & 0 & 0 & 0 & 0 \\
\hline 03-09 & 1 & 1 & 1 & 1 & 1 & 1 & 6 & 0 & 0 \\
\hline $03-24$ & 0 & 0 & 0 & 0 & 0 & 0 & 0 & 0 & 0 \\
\hline 04-09 & 0 & 0 & 0 & 0 & 0 & 0 & 0 & 0 & 0 \\
\hline $05-10$ & 0 & 0 & 0 & 0 & 0 & 1 & 1 & 0 & 0 \\
\hline $06-10$ & 2 & 2 & 2 & 1 & 2 & 1 & 6 & 4 & 0 \\
\hline $07-08$ & 2 & 2 & 2 & 2 & 2 & 0 & 5 & 5 & 0 \\
\hline 08-09 & 0 & 0 & 0 & 0 & 0 & 0 & 0 & 0 & 0 \\
\hline $08-10$ & 0 & 0 & 0 & 0 & 0 & 0 & 0 & 0 & 0 \\
\hline 09-11 & 0 & 0 & 0 & 0 & 0 & 0 & 0 & 0 & 0 \\
\hline 09-12 & 0 & 0 & 0 & 0 & 0 & 0 & 0 & 0 & 0 \\
\hline $10-11$ & 0 & 0 & 1 & 0 & 1 & 0 & 2 & 0 & 0 \\
\hline $10-12$ & 1 & 1 & 0 & 0 & 0 & 0 & 2 & 0 & 0 \\
\hline $11-13$ & 0 & 1 & 1 & 0 & 1 & 0 & 3 & 0 & 0 \\
\hline $11-14$ & 0 & 0 & 0 & 0 & 0 & 0 & 0 & 0 & 0 \\
\hline $12-13$ & 1 & 0 & 0 & 0 & 0 & 0 & 1 & 0 & 0 \\
\hline $12-23$ & 0 & 0 & 0 & 0 & 0 & 0 & 0 & 0 & 0 \\
\hline $13-23$ & 0 & 0 & 0 & 0 & 0 & 0 & 0 & 0 & 0 \\
\hline $14-16$ & 1 & 0 & 1 & 0 & 1 & 0 & 3 & 0 & 0 \\
\hline $15-16$ & 1 & 0 & 0 & 0 & 0 & 0 & 1 & 0 & 0 \\
\hline $15-21$ & 0 & 0 & 0 & 0 & 0 & 0 & 0 & 0 & 0 \\
\hline $15-24$ & 0 & 0 & 0 & 0 & 0 & 0 & 0 & 0 & 0 \\
\hline $16-17$ & 0 & 0 & 0 & 0 & 0 & 0 & 0 & 0 & 0 \\
\hline 16-19 & 0 & 0 & 0 & 0 & 0 & 0 & 0 & 0 & 0 \\
\hline $17-18$ & 0 & 0 & 0 & 0 & 0 & 0 & 0 & 0 & 0 \\
\hline $17-22$ & 0 & 0 & 0 & 0 & 0 & 0 & 0 & 0 & 0 \\
\hline $18-21$ & 0 & 0 & 0 & 0 & 0 & 0 & 0 & 0 & 0 \\
\hline $19-20$ & 0 & 0 & 0 & 0 & 0 & 1 & 1 & 0 & 0 \\
\hline $20-23$ & 1 & 1 & 1 & 1 & 1 & 1 & 6 & 0 & 0 \\
\hline $21-22$ & 0 & 0 & 0 & 0 & 0 & 0 & 0 & 0 & 0 \\
\hline 01-08 & 0 & 0 & 0 & 0 & 0 & 1 & 1 & 0 & 0 \\
\hline 02-08 & 0 & 0 & 0 & 0 & 0 & 0 & 0 & 0 & 0 \\
\hline $06-07$ & 0 & 0 & 0 & 0 & 0 & 0 & 0 & 0 & 0 \\
\hline 13-14 & 0 & 0 & 0 & 1 & 0 & 1 & 2 & 0 & 0 \\
\hline $14-23$ & 0 & 0 & 0 & 0 & 0 & 0 & 0 & 0 & 0 \\
\hline $16-23$ & 0 & 0 & 0 & 0 & 0 & 0 & 0 & 0 & 0 \\
\hline $19-23$ & 0 & 0 & 0 & 0 & 0 & 0 & 0 & 0 & 0 \\
\hline Reforços & 11 & 8 & 9 & 8 & 9 & 9 & Custo & Médio & $\overline{\left(10^{6} \$\right)}$ \\
\hline $\begin{array}{c}\text { Custo } \\
\left(10^{6} \$\right)\end{array}$ & 322 & 241 & 295 & 215 & 295 & 296 & & 277,33 & \\
\hline
\end{tabular}


Tabela 4.23 - Plano Final - Cenários mais Prováveis.

\begin{tabular}{|c|c|c|c|c|c|c|c|c|c|}
\hline \multirow{2}{*}{ Ramo } & \multicolumn{6}{|c|}{ Plano Para Cada Cenário } & \multicolumn{3}{|c|}{ Grau de Incidência } \\
\hline & 1 & 2 & 3 & 4 & 5 & 10 & GI1 & GI2 & GI3 \\
\hline 01-02 & 0 & 0 & 0 & 0 & 0 & 0 & 0 & 0 & 0 \\
\hline 01-03 & 1 & 1 & 1 & 1 & 1 & 1 & 6 & 0 & 0 \\
\hline 01-05 & 2 & 2 & 2 & 2 & 2 & 2 & 6 & 6 & 0 \\
\hline $02-04$ & 0 & 0 & 0 & 0 & 0 & 0 & 0 & 0 & 0 \\
\hline $02-06$ & 0 & 0 & 0 & 0 & 0 & 0 & 0 & 0 & 0 \\
\hline 03-09 & 1 & 1 & 1 & 1 & 1 & 1 & 6 & 0 & 0 \\
\hline 03-24 & 0 & 0 & 0 & 0 & 0 & 0 & 0 & 0 & 0 \\
\hline 04-09 & 0 & 0 & 0 & 0 & 0 & 0 & 0 & 0 & 0 \\
\hline $05-10$ & 0 & 0 & 0 & 0 & 0 & 0 & 0 & 0 & 0 \\
\hline $06-10$ & 2 & 2 & 2 & 2 & 2 & 2 & 6 & 6 & 0 \\
\hline 07-08 & 2 & 2 & 2 & 2 & 2 & 2 & 6 & 6 & 0 \\
\hline 08-09 & 0 & 0 & 0 & 0 & 0 & 0 & 0 & 0 & 0 \\
\hline 08-10 & 0 & 0 & 0 & 0 & 0 & 0 & 0 & 0 & 0 \\
\hline $09-11$ & 0 & 0 & 0 & 0 & 0 & 0 & 0 & 0 & 0 \\
\hline $09-12$ & 0 & 0 & 0 & 0 & 0 & 0 & 0 & 0 & 0 \\
\hline $10-11$ & 1 & 1 & 1 & 1 & 1 & 1 & 6 & 0 & 0 \\
\hline $10-12$ & 0 & 0 & 0 & 0 & 0 & 0 & 0 & 0 & 0 \\
\hline $11-13$ & 1 & 1 & 1 & 1 & 1 & 1 & 6 & 0 & 0 \\
\hline 11-14 & 0 & 0 & 0 & 0 & 0 & 0 & 0 & 0 & 0 \\
\hline $12-13$ & 0 & 0 & 0 & 0 & 0 & 0 & 0 & 0 & 0 \\
\hline $12-23$ & 0 & 0 & 0 & 0 & 0 & 0 & 0 & 0 & 0 \\
\hline $13-23$ & 0 & 0 & 0 & 0 & 0 & 0 & 0 & 0 & 0 \\
\hline $14-16$ & 1 & 1 & 1 & 1 & 1 & 1 & 6 & 0 & 0 \\
\hline $15-16$ & 0 & 0 & 0 & 0 & 0 & 0 & 0 & 0 & 0 \\
\hline $15-21$ & 0 & 0 & 0 & 0 & 0 & 0 & 0 & 0 & 0 \\
\hline $15-24$ & 0 & 0 & 0 & 0 & 0 & 0 & 0 & 0 & 0 \\
\hline $16-17$ & 0 & 0 & 0 & 0 & 0 & 0 & 0 & 0 & 0 \\
\hline $16-19$ & 0 & 0 & 0 & 0 & 0 & 0 & 0 & 0 & 0 \\
\hline $17-18$ & 1 & 1 & 1 & 1 & 1 & 1 & 6 & 0 & 0 \\
\hline $17-22$ & 0 & 0 & 0 & 0 & 0 & 0 & 0 & 0 & 0 \\
\hline $18-21$ & 0 & 0 & 0 & 0 & 0 & 0 & 0 & 0 & 0 \\
\hline $19-20$ & 1 & 1 & 1 & 1 & 1 & 1 & 6 & 0 & 0 \\
\hline $20-23$ & 1 & 1 & 1 & 1 & 1 & 1 & 6 & 0 & 0 \\
\hline $21-22$ & 0 & 0 & 0 & 0 & 0 & 0 & 0 & 0 & 0 \\
\hline 01-08 & 1 & 1 & 1 & 1 & 1 & 1 & 6 & 0 & 0 \\
\hline $02-08$ & 0 & 0 & 0 & 0 & 0 & 0 & 0 & 0 & 0 \\
\hline 06-07 & 0 & 0 & 0 & 0 & 0 & 0 & 0 & 0 & 0 \\
\hline $13-14$ & 0 & 0 & 0 & 0 & 0 & 0 & 0 & 0 & 0 \\
\hline $14-23$ & 0 & 0 & 0 & 0 & 0 & 0 & 0 & 0 & 0 \\
\hline $16-23$ & 0 & 0 & 0 & 0 & 0 & 0 & 0 & 0 & 0 \\
\hline $19-23$ & 0 & 0 & 0 & 0 & 0 & 0 & 0 & 0 & 0 \\
\hline Reforços & 15 & 15 & 15 & 15 & 15 & 15 & Custo & Médio & $\left.10^{6} \$\right)$ \\
\hline $\begin{array}{c}\text { Custo } \\
\left(10^{6} \$\right)\end{array}$ & 504 & 504 & 504 & 504 & 504 & 504 & & 504 & \\
\hline InRef & 4 & 7 & 6 & 7 & 6 & 6 & & & \\
\hline InCt & 182 & 263 & 209 & 289 & 209 & 208 & & & \\
\hline
\end{tabular}


Capítulo 4

É importante salientar, que neste caso, o plano de expansão resultante além de funcionar para os 6 cenários considerados, funciona também para os outros 4 cenários descartados para assumir a análise. Cabe esclarecer que isto não é normal no geral, e que para outro sistema de estudo pode-se não acontecer a mesma situação.

\subsection{2.}

\section{Relaxamento na análise de contingências "N-1"}

Nesta segunda estratégia, permitiu-se uma sobrecarga de 30\% para todos os elementos de transmissão em situações de emergência, ou seja, na análise "N-1". No entanto, todos os cenários foram considerados. Com a aplicação da metodologia proposta foram obtidas as Tabelas 4.24 (com as melhores soluções iniciais para os 10 cenários) e 4.25 (com a solução final). 
Tabela 4.24 - Tabela Decisão Inicial - Relaxamento no "N-1".

\begin{tabular}{|c|c|c|c|c|c|c|c|c|c|c|c|c|c|}
\hline \multirow{2}{*}{ Ramo } & \multicolumn{10}{|c|}{ Plano Para Cada Cenário } & \multicolumn{3}{|c|}{ Graus de Incidência } \\
\hline & 1 & 2 & 3 & 4 & 5 & 6 & 7 & 8 & 9 & 10 & GI1 & GI2 & GI3 \\
\hline 01-02 & 0 & 0 & 0 & 0 & 0 & 0 & 0 & 0 & 0 & 0 & 0 & 0 & 0 \\
\hline 01-03 & 0 & 0 & 0 & 0 & 0 & 0 & 0 & 0 & 0 & 0 & 0 & 0 & 0 \\
\hline 01-05 & 0 & 0 & 0 & 0 & 0 & 0 & 1 & 0 & 0 & 1 & 2 & 0 & 0 \\
\hline $02-04$ & 0 & 0 & 0 & 0 & 0 & 0 & 0 & 0 & 0 & 0 & 0 & 0 & 0 \\
\hline $02-06$ & 0 & 0 & 0 & 0 & 0 & 0 & 0 & 0 & 0 & 0 & 0 & 0 & 0 \\
\hline 03-09 & 1 & 0 & 1 & 0 & 1 & 0 & 0 & 0 & 0 & 0 & 3 & 0 & 0 \\
\hline 03-24 & 0 & 0 & 0 & 0 & 0 & 0 & 0 & 0 & 0 & 0 & 0 & 0 & 0 \\
\hline 04-09 & 0 & 0 & 0 & 0 & 0 & 0 & 0 & 0 & 0 & 0 & 0 & 0 & 0 \\
\hline 05-10 & 0 & 0 & 0 & 0 & 0 & 1 & 0 & 0 & 0 & 0 & 1 & 0 & 0 \\
\hline $06-10$ & 1 & 1 & 1 & 1 & 1 & 1 & 1 & 2 & 1 & 1 & 10 & 1 & 0 \\
\hline 07-08 & 2 & 0 & 0 & 2 & 0 & 0 & 0 & 0 & 0 & 0 & 2 & 2 & 0 \\
\hline 08-09 & 0 & 0 & 0 & 0 & 0 & 0 & 0 & 0 & 0 & 0 & 0 & 0 & 0 \\
\hline 08-10 & 0 & 0 & 0 & 0 & 0 & 0 & 0 & 0 & 0 & 0 & 0 & 0 & 0 \\
\hline 09-11 & 0 & 0 & 0 & 0 & 0 & 0 & 0 & 0 & 0 & 0 & 0 & 0 & 0 \\
\hline 09-12 & 0 & 0 & 0 & 0 & 0 & 0 & 0 & 0 & 0 & 0 & 0 & 0 & 0 \\
\hline $10-11$ & 0 & 0 & 0 & 0 & 0 & 0 & 0 & 0 & 0 & 0 & 0 & 0 & 0 \\
\hline $10-12$ & 1 & 1 & 1 & 0 & 1 & 1 & 0 & 0 & 0 & 0 & 5 & 0 & 0 \\
\hline $11-13$ & 0 & 0 & 1 & 0 & 0 & 0 & 0 & 0 & 0 & 0 & 1 & 0 & 0 \\
\hline $11-14$ & 0 & 0 & 0 & 0 & 0 & 0 & 0 & 0 & 0 & 0 & 0 & 0 & 0 \\
\hline $12-13$ & 0 & 0 & 0 & 0 & 0 & 0 & 0 & 0 & 0 & 0 & 0 & 0 & 0 \\
\hline $12-23$ & 0 & 0 & 0 & 0 & 0 & 0 & 0 & 0 & 0 & 0 & 0 & 0 & 0 \\
\hline $13-23$ & 0 & 0 & 0 & 0 & 0 & 0 & 0 & 0 & 0 & 0 & 0 & 0 & 0 \\
\hline 14-16 & 0 & 0 & 0 & 0 & 0 & 0 & 0 & 0 & 0 & 0 & 0 & 0 & 0 \\
\hline 15-16 & 0 & 0 & 0 & 0 & 0 & 0 & 0 & 0 & 0 & 0 & 0 & 0 & 0 \\
\hline $15-21$ & 0 & 0 & 0 & 0 & 0 & 0 & 0 & 0 & 0 & 0 & 0 & 0 & 0 \\
\hline $15-24$ & 0 & 0 & 0 & 0 & 0 & 0 & 0 & 0 & 0 & 0 & 0 & 0 & 0 \\
\hline 16-17 & 0 & 0 & 0 & 0 & 0 & 0 & 0 & 0 & 0 & 0 & 0 & 0 & 0 \\
\hline 16-19 & 0 & 0 & 0 & 1 & 0 & 0 & 0 & 0 & 0 & 0 & 1 & 0 & 0 \\
\hline $17-18$ & 0 & 0 & 0 & 0 & 0 & 0 & 0 & 0 & 0 & 0 & 0 & 0 & 0 \\
\hline $17-22$ & 0 & 0 & 0 & 0 & 0 & 0 & 0 & 0 & 0 & 0 & 0 & 0 & 0 \\
\hline 18-21 & 0 & 0 & 0 & 0 & 0 & 0 & 0 & 0 & 0 & 0 & 0 & 0 & 0 \\
\hline $19-20$ & 0 & 0 & 0 & 0 & 0 & 0 & 0 & 0 & 0 & 0 & 0 & 0 & 0 \\
\hline $20-23$ & 0 & 0 & 0 & 1 & 0 & 0 & 1 & 0 & 0 & 1 & 3 & 0 & 0 \\
\hline $21-22$ & 0 & 0 & 0 & 0 & 0 & 0 & 0 & 0 & 0 & 0 & 0 & 0 & 0 \\
\hline 01-08 & 0 & 0 & 0 & 0 & 0 & 0 & 1 & 0 & 0 & 1 & 2 & 0 & 0 \\
\hline $02-08$ & 0 & 0 & 0 & 0 & 0 & 0 & 0 & 0 & 0 & 0 & 0 & 0 & 0 \\
\hline 06-07 & 0 & 0 & 0 & 0 & 0 & 0 & 0 & 0 & 0 & 0 & 0 & 0 & 0 \\
\hline $13-14$ & 1 & 1 & 0 & 0 & 1 & 1 & 0 & 0 & 0 & 0 & 4 & 0 & 0 \\
\hline $14-23$ & 0 & 0 & 0 & 0 & 0 & 0 & 0 & 1 & 1 & 0 & 2 & 0 & 0 \\
\hline $16-23$ & 0 & 0 & 0 & 0 & 0 & 0 & 0 & 0 & 0 & 0 & 0 & 0 & 0 \\
\hline $19-23$ & 0 & 0 & 0 & 0 & 0 & 0 & 0 & 0 & 0 & 0 & 0 & 0 & 0 \\
\hline Reforços & 6 & 3 & 4 & 5 & 4 & 4 & 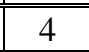 & 3 & 2 & 4 & Custo & Médio & $\left.10^{6} \$\right)$ \\
\hline $\begin{array}{c}\text { Custo } \\
\left(\mathbf{1 0}^{6} \$\right)\end{array}$ & 191 & 128 & 163 & 110 & 159 & 151 & 103 & 118 & 102 & 103 & & 132,8 & \\
\hline
\end{tabular}


Capítulo 4

Tabela 4.25 - Plano Final - Relaxamento no "N-1".

\begin{tabular}{|c|c|c|c|c|c|c|c|c|c|c|c|c|c|}
\hline \multirow{2}{*}{ Ramo } & \multicolumn{10}{|c|}{ Plano Para Cada Cenário } & \multicolumn{3}{|c|}{ | Graus de Incidência } \\
\hline & 1 & 2 & 3 & 4 & 5 & 6 & 7 & 8 & 9 & 10 & GI1 & GI2 & GI3 \\
\hline 01-02 & 2 & 2 & 2 & 2 & 2 & 2 & 2 & 2 & 2 & 2 & 10 & 10 & 0 \\
\hline 01-03 & 0 & 0 & 0 & 0 & 0 & 0 & 0 & 0 & 0 & 0 & 0 & 0 & 0 \\
\hline 01-05 & 0 & 0 & 0 & 0 & 0 & 0 & 0 & 0 & 0 & 0 & 0 & 0 & 0 \\
\hline $02-04$ & 0 & 0 & 0 & 0 & 0 & 0 & 0 & 0 & 0 & 0 & 0 & 0 & 0 \\
\hline $02-06$ & 0 & 0 & 0 & 0 & 0 & 0 & 0 & 0 & 0 & 0 & 0 & 0 & 0 \\
\hline 03-09 & 1 & 1 & 1 & 1 & 1 & 1 & 1 & 1 & 1 & 1 & 10 & 0 & 0 \\
\hline $03-24$ & 0 & 0 & 0 & 0 & 0 & 0 & 0 & 0 & 0 & 0 & 0 & 0 & 0 \\
\hline 04-09 & 0 & 0 & 0 & 0 & 0 & 0 & 0 & 0 & 0 & 0 & 0 & 0 & 0 \\
\hline 05-10 & 0 & 0 & 0 & 0 & 0 & 0 & 0 & 0 & 0 & 0 & 0 & 0 & 0 \\
\hline 06-10 & 2 & 2 & 2 & 2 & 2 & 2 & 2 & 2 & 2 & 2 & 10 & 10 & 0 \\
\hline 07-08 & 2 & 2 & 2 & 2 & 2 & 2 & 2 & 2 & 2 & 2 & 10 & 10 & 0 \\
\hline 08-09 & 0 & 0 & 0 & 0 & 0 & 0 & 0 & 0 & 0 & 0 & 0 & 0 & 0 \\
\hline 08-10 & 0 & 0 & 0 & 0 & 0 & 0 & 0 & 0 & 0 & 0 & 0 & 0 & 0 \\
\hline 09-11 & 0 & 0 & 0 & 0 & 0 & 0 & 0 & 0 & 0 & 0 & 0 & 0 & 0 \\
\hline 09-12 & 0 & 0 & 0 & 0 & 0 & 0 & 0 & 0 & 0 & 0 & 0 & 0 & 0 \\
\hline 10-11 & 0 & 0 & 0 & 0 & 0 & 0 & 0 & 0 & 0 & 0 & 0 & 0 & 0 \\
\hline $10-12$ & 1 & 1 & 1 & 1 & 1 & 1 & 1 & 1 & 1 & 1 & 10 & 0 & 0 \\
\hline $11-13$ & 0 & 0 & 0 & 0 & 0 & 0 & 0 & 0 & 0 & 0 & 0 & 0 & 0 \\
\hline 11-14 & 0 & 0 & 0 & 0 & 0 & 0 & 0 & 0 & 0 & 0 & 0 & 0 & 0 \\
\hline $12-13$ & 0 & 0 & 0 & 0 & 0 & 0 & 0 & 0 & 0 & 0 & 0 & 0 & 0 \\
\hline $12-23$ & 0 & 0 & 0 & 0 & 0 & 0 & 0 & 0 & 0 & 0 & 0 & 0 & 0 \\
\hline $13-23$ & 0 & 0 & 0 & 0 & 0 & 0 & 0 & 0 & 0 & 0 & 0 & 0 & 0 \\
\hline $14-16$ & 0 & 0 & 0 & 0 & 0 & 0 & 0 & 0 & 0 & 0 & 0 & 0 & 0 \\
\hline $15-16$ & 0 & 0 & 0 & 0 & 0 & 0 & 0 & 0 & 0 & 0 & 0 & 0 & 0 \\
\hline $15-21$ & 0 & 0 & 0 & 0 & 0 & 0 & 0 & 0 & 0 & 0 & 0 & 0 & 0 \\
\hline $15-24$ & 0 & 0 & 0 & 0 & 0 & 0 & 0 & 0 & 0 & 0 & 0 & 0 & 0 \\
\hline $16-17$ & 0 & 0 & 0 & 0 & 0 & 0 & 0 & 0 & 0 & 0 & 0 & 0 & 0 \\
\hline $\begin{array}{l}16-19 \\
\end{array}$ & 0 & 0 & 0 & 0 & 0 & 0 & 0 & 0 & 0 & 0 & 0 & 0 & 0 \\
\hline $17-18$ & 0 & 0 & 0 & 0 & 0 & 0 & 0 & 0 & 0 & 0 & 0 & 0 & 0 \\
\hline $17-22$ & 0 & 0 & 0 & 0 & 0 & 0 & 0 & 0 & 0 & 0 & 0 & 0 & 0 \\
\hline $18-21$ & 0 & 0 & 0 & 0 & 0 & 0 & 0 & 0 & 0 & 0 & 0 & 0 & 0 \\
\hline $19-20$ & 0 & 0 & 0 & 0 & 0 & 0 & 0 & 0 & 0 & 0 & 0 & 0 & 0 \\
\hline $20-23$ & 1 & 1 & 1 & 1 & 1 & 1 & 1 & 1 & 1 & 1 & 10 & 0 & 0 \\
\hline $21-22$ & 0 & 0 & 0 & 0 & 0 & 0 & 0 & 0 & 0 & 0 & 0 & 0 & 0 \\
\hline 01-08 & 0 & 0 & 0 & 0 & 0 & 0 & 0 & 0 & 0 & 0 & 0 & 0 & 0 \\
\hline 02-08 & 0 & 0 & 0 & 0 & 0 & 0 & 0 & 0 & 0 & 0 & 0 & 0 & 0 \\
\hline $\begin{array}{l}06-07 \\
\end{array}$ & 0 & 0 & 0 & 0 & 0 & 0 & 0 & 0 & 0 & 0 & 0 & 0 & 0 \\
\hline $13-14$ & 1 & 1 & 1 & 1 & 1 & 1 & 1 & 1 & 1 & 1 & 10 & 0 & 0 \\
\hline $14-23$ & 0 & 0 & 0 & 0 & 0 & 0 & 0 & 0 & 0 & 0 & 0 & 0 & 0 \\
\hline $16-23$ & 0 & 0 & 0 & 0 & 0 & 0 & 0 & 0 & 0 & 0 & 0 & 0 & 0 \\
\hline $19-23$ & 0 & 0 & 0 & 0 & 0 & 0 & 0 & 0 & 0 & 0 & 0 & 0 & 0 \\
\hline Reforços & 10 & 10 & 10 & 10 & 10 & 10 & 10 & 10 & 10 & 10 & \multicolumn{3}{|c|}{ Custo Médio $\left(10^{6} \$\right)$} \\
\hline $\begin{array}{c}\text { Custo } \\
\left(10^{6} \$\right) \\
\end{array}$ & 243 & 243 & 243 & 243 & 243 & 243 & 243 & 243 & 243 & 243 & \multicolumn{3}{|c|}{243} \\
\hline InRef & 4 & 7 & 6 & 5 & 6 & 6 & 6 & 7 & 8 & 6 & \\
\hline InCus & 52 & 115 & 80 & 133 & 84 & 92 & 140 & 125 & 141 & 140 & & & \\
\hline
\end{tabular}




\subsection{3.}

Análise comparativa dos planos obtidos

A Tabela 4.26 faz um resumo dos 5 planos de expansão obtidos.

Tabela 4.26 - Comparação entre os planos obtidos.

\begin{tabular}{|c|c|c|c|c|c|}
\hline \multirow{2}{*}{ Ramo } & \multicolumn{5}{|c|}{ Planos } \\
\cline { 2 - 6 } & $\mathbf{1}$ & $\mathbf{2}$ & $\mathbf{3}$ & $\mathbf{4}$ & $\mathbf{5}$ \\
\hline $01-02$ & 1 & 1 & 1 & 0 & 2 \\
\hline $01-03$ & 1 & 0 & 1 & 1 & 0 \\
\hline $01-05$ & 2 & 2 & 2 & 2 & 0 \\
\hline $02-04$ & 0 & 0 & 1 & 0 & 0 \\
\hline $02-06$ & 0 & 0 & 0 & 0 & 0 \\
\hline $03-09$ & 1 & 1 & 1 & 1 & 1 \\
\hline $03-24$ & 0 & 0 & 0 & 0 & 0 \\
\hline $04-09$ & 0 & 0 & 0 & 0 & 0 \\
\hline $05-10$ & 0 & 1 & 1 & 0 & 0 \\
\hline $06-10$ & 2 & 2 & 2 & 2 & 2 \\
\hline $07-08$ & 2 & 2 & 2 & 2 & 2 \\
\hline $08-09$ & 0 & 0 & 0 & 0 & 0 \\
\hline $08-10$ & 0 & 0 & 0 & 0 & 0 \\
\hline $09-11$ & 0 & 0 & 0 & 0 & 0 \\
\hline $09-12$ & 0 & 1 & 0 & 0 & 0 \\
\hline $10-11$ & 1 & 1 & 1 & 1 & 0 \\
\hline $10-12$ & 0 & 1 & 0 & 0 & 1 \\
\hline $11-13$ & 1 & 1 & 1 & 1 & 0 \\
\hline $11-14$ & 0 & 0 & 0 & 0 & 0 \\
\hline $12-13$ & 0 & 1 & 0 & 0 & 0 \\
\hline $12-23$ & 0 & 0 & 0 & 0 & 0 \\
\hline $13-23$ & 0 & 0 & 0 & 0 & 0 \\
\hline $14-16$ & 1 & 1 & 1 & 1 & 0 \\
\hline $15-16$ & 0 & 1 & 0 & 0 & 0 \\
\hline $15-21$ & 0 & 0 & 0 & 0 & 0 \\
\hline $15-24$ & 0 & 0 & 0 & 0 & 0 \\
\hline $16-17$ & 0 & 0 & 0 & 0 & 0 \\
\hline $16-19$ & 0 & 0 & 0 & 0 & 0 \\
\hline $17-18$ & 1 & 0 & 1 & 1 & 0 \\
\hline $17-22$ & 0 & 0 & 0 & 0 & 0 \\
\hline $18-21$ & 0 & 0 & 0 & 0 & 0 \\
\hline $19-20$ & 1 & 1 & 1 & 1 & 0 \\
\hline $20-23$ & 1 & 1 & 1 & 1 & 1 \\
\hline $21-22$ & 0 & 0 & 0 & 0 & 0 \\
\hline $01-08$ & 0 & 1 & 0 & 1 & 0 \\
\hline $02-08$ & 1 & 0 & 1 & 0 & 0 \\
\hline $06-07$ & 0 & 0 & 0 & 0 & 0 \\
\hline $13-14$ & 0 & 1 & 0 & 0 & 1 \\
\hline $14-23$ & 0 & 0 & 0 & 0 & 0 \\
\hline $16-23$ & 0 & 0 & 0 & 0 & 0 \\
\hline $19-23$ & 0 & 0 & 0 & 0 & 0 \\
\hline Reforços & $\mathbf{1 6}$ & $\mathbf{2 0}$ & $\mathbf{1 8}$ & $\mathbf{1 5}$ & $\mathbf{1 0}$ \\
\hline Custo & $\mathbf{5 0 5}$ & $\mathbf{7 0 7}$ & $\mathbf{5 6 1}$ & $\mathbf{5 0 4}$ & $\mathbf{2 4 3}$ \\
\hline $\mathbf{1 0}$ (10) & & & & & \\
\hline
\end{tabular}


Fazendo uma comparação entre o Plano 1 (obtido da abordagem principal do presente trabalho), com os Planos 2 e 3 (obtidos por superposição das soluções de cada cenário em etapas intermediárias da aplicação realizada), tem-se uma medida do ganho produzido pela metodologia proposta. Os Planos 2 e 3 são, respectivamente, $40 \%$ e $11 \%$ mais caros que o Plano 1.

Ao comparar o Plano 1 com o Plano 4, pode-se observar de forma clara que são soluções muito semelhantes, com custos praticamente idênticos. No entanto, por inserir um circuito a mais, o Plano 1 pode ser considerado mais atraente. Embora, no presente estudo, o plano obtido através da desconsideração dos cenários menos prováveis tenha se mostrado um pouco pior, é possível que esta estratégia seja interessante para sistemas reais (com maior porte e número bem superior de centrais eólicas).

Da análise do Plano 5 conclui-se que, como esperado, permitir um relaxamento nos elementos de transmissão na análise de contingências “ $\mathrm{N}-1$ ”, produz uma resposta com um número bem reduzido de reforços. Portanto, um montante de investimento significativamente menor é requerido para implementar este plano de expansão. Como argumento para se adotar o Plano 5 pode-se citar que a adoção de limites de emergência em situações de contingência é prática comum da operação. Adicionalmente, vale lembrar que, na solução do problema PET de longo prazo, o processo é realizado para uma configuração que considera o pico anual de demanda. Contudo esta situação ocorre em pouquíssimos momentos (horas) do ano, justificando ainda mais a adoção do Plano 5 ou de outro plano que considere limites menores para as sobrecargas dos circuitos. Em [48], por exemplo, é proposta uma metodologia para resolver o problema PET baseada no critério “N-1" relaxado, onde tal relaxamento consiste em permitir níveis previamente especificados de sobrecarga em certos equipamentos.

\section{9.}

\section{Esforço Computacional}

A ferramenta AMC-PET, base desta dissertação está programada em C\# principalmente, e conta com duas bibliotecas principais. Uma dessas bibliotecas está programada em $\mathrm{C}++$, sendo empregada para o cálculo do despacho no fluxo de potência ótimo com o método simplex. A segunda biblioteca escrita em Fortran, realiza os cálculos dos fluxos de potência pelo modelo DC com perdas. 
Os testes foram realizados em um processador Intel core I7 -3770 $3.40 \mathrm{GHz}$, e, para automatizar a maior parte da metodologia, foi utilizada a plataforma MATLAB 2016b. Os processos que demandaram mais tempo computacional, para a obtenção do Plano 1, são detalhados a seguir.

Primeiramente, a etapa para obter o melhor plano para cada cenário estabelecido conforme o passo iv (Construção da Tabela Decisão, Subseção 3.4.6) levou 29 minutos, com 114 chamadas da ferramenta AMC-PET. Subsequentemente, foi executada a etapa iterativa para a convergência dos planos de expansão, a qual requereu 125 minutos com 1362 execuções do AMC-PET.

É importante salientar que, cada cenário tem um nível de complexidade que influencia diretamente o tempo computacional. No entanto, a despeito deste aspecto, à medida em que se avança o procedimento para obtenção da solução final, o tempo gasto pelas execuções do AMC-PET diminui, pois haverá uma quantidade cada vez menor de reforços a "planejar”.

A última etapa, que corresponde à exploração por combinações, foi realizada através de planilhas, sendo a obtenção do resultado para cada combinação praticamente imediato. Nesta fase, o objetivo é comprovar se o plano testado respeitava o critério de segurança N-1. No futuro, esta etapa também poderá fazer parte do procedimento automático de avaliação.

\subsection{0. \\ Conclusão}

Neste capítulo, apresentou-se a aplicação da metodologia proposta nesta dissertação, junto com uma descrição previa, de como foram estabelecidos os parâmetros necessários para a abordagem adotada.

Foram apresentadas algumas iterações da primeira etapa, seguido das considerações da segunda etapa combinatória. Exibindo deste modo, como foi evoluindo o procedimento, até conseguir a convergência com o resultado do plano de expansão final. Este resultado final foi comparado com duas possíveis soluções obtidas ao longo do procedimento, através da superposição dos planos dos cenários estabelecidos, na Tabela Decisão inicial e no final da primeira fase (Etapa Iterativa para a Convergência dos Plano de Expansão). Outras duas soluções, obtidas por meio da repetição da metodologia utilizando-se duas estratégias (descon- 
sideração de cenários menos prováveis e relaxamento na análise “N-1”), também foram inseridas na comparação.

Observaram-se resultados interessantes, que podem vislumbrar a exploração de novas estratégias. Por exemplo, implementar um refinamento na solução final, identificando reforços iniciais/intermediários que podem ser removidos sem comprometer o critério de segurança. Outro exemplo, ao observar a queda significativa no custo de investimento, ao permitir sobrecarga nos elementos de transmissão para condição de emergência, percebe-se a viabilidade de investigar o relaxamento do critério "N-1", assim como adotado em [48].

Por fim, pode-se dizer que a metodologia implementada obteve um bom resultado, empregando a ferramenta AMC-PET proposta em [1]. Isto, considerando o objetivo inicial, de conseguir um plano flexível que garanta um pleno aproveitamento da possível energia que pode ser fornecida pelo vento, respeitando sempre o critério de segurança “ $\mathrm{N}-1$ ”. 


\section{5 \\ CONCLUSÃO}

Atualmente têm-se muitas maneiras para resolver o problema PET de acordo com as características intrínsecas do sistema o que inclui sua dimensão, o horizonte de planejamento, erros nas previsões de carga e fontes de energia renovável, entre outras. Contudo cada uma das alternativas metodológicas disponíveis para tratar o problema PET tem o mesmo objetivo: realizar um planejamento adequado da rede de transmissão sob critérios de segurança, qualidade e confiabilidade, de modo a garantir o suprimento contínuo da energia requerida, pelos blocos de demanda distribuídos pelo sistema.

O uso de técnicas metaheurísticas têm provado ser um excelente caminho para abordar o problema de planejamento da expansão da rede de transmissão, tendo em vista as enormes vantagens em relação ao custo computacional e à diversidade e qualidade das soluções que pode fornecer.

Nesta dissertação de mestrado foi proposta uma nova metodologia para solução do problema de planejamento da expansão da transmissão (PET) considerando a intermitência de fontes renováveis de energia. A variabilidade das fontes renováveis foi representada por meio de cenários, obtidos a partir do algoritmo de classificação K-Means, o qual permite preservar a correlação entre as centrais geradoras. A identificação do melhor plano de expansão para cada cenário definido foi inicialmente realizada com base no emprego de um algoritmo metaheurístico construtivo (AMC-PET). Em seguida, por meio de duas etapas heurísticas, uma interativa e outra combinatória, as soluções obtidas para cada cenário são convergidas para uma única solução, capaz de atender a todos os cenários de geração eólica considerados. O desempenho da metodologia proposta foi comprovado por meio do sistema IEEE-RTS, adaptado para incluir uma significativa participação de energia eólica. O modelo linear DC com perdas foi utilizado para representação da rede do sistema e o critério de segurança “N-1" foi considerado para solução do problema. 
Por fim, pode-se dizer que a metodologia implementada obteve um bom desempenho, através da ferramenta AMC-PET, considerando o objetivo inicial de se obter um plano flexível que garanta um pleno aproveitamento da provável energia que pode ser fornecida pelo vento, ou outra fonte intermitente, respeitando sempre o critério de segurança “N-1". Além disso, com os resultados obtidos, pode-se dizer que ainda existem muitas alternativas e considerações para se explorar, ao adotar esta metodologia ou similar.

\section{Trabalhos futuros}

Futuramente, pode-se construir uma metodologia mais robusta, aplicando cenários de geração e de carga com outros parâmetros ou diferentes considerações em lugar do grau de uniformidade adotado nesta abordagem heurística.

Outra alternativa seria a execução em árvore para gerar mais planos finais. Para isto, considerar-se-ia uma paralelização no modo de execução para reduzir expressivamente o tempo de computacional.

Poder-se-ia considerar também uma abordagem não determinística, e por exemplo, incluir critérios de confiabilidade com base probabilística em lugar do critério determinístico "N-1".

Como mencionado no capítulo anterior, ao observar a queda significativa no custo de investimento, ao permitir sobrecarga nos elementos de transmissão para condição de emergência, percebe-se a viabilidade de investigar o relaxamento do critério “N-1" e/ou da utilização de medidas remediadoras específicas, como já admitidas em alguns países.

Conhecendo a natureza intermitente das fontes eólicas e a possibilidade de usar sistemas de armazenamento de energia (baterias, etc.), para mitigar o problema da alta intermitência do vento, outro trabalho interessante seria abordar o problema PET com inserção destes dispositivos, estabelecendo cenários de modo semelhante à metodologia exposta neste trabalho.

Outras fontes renováveis de energia intermitente (e.g., solar, etc.) poderiam também ser utilizadas considerando a metodologia proposta.

Uma outra possibilidade seria aplicar a metodologia proposta em um sistema real considerando a variação no número de cenários gerados pelo K-means. Seria então realizada uma análise de sensibilidade para verificar se existe uma 
Capítulo 5

faixa ideal (restrita), para a qual o desempenho da metodologia não se altera; verificando o impacto de utilizar um número elevado ou baixo de cenários. Poderia se incluir também o desperdício na condução do processo de uniformização das soluções.

Por fim, técnicas de programação matemática via otimização estocástica poderiam ainda ser utilizadas para confrontar as soluções obtidas por técnicas heurísticas e metaheurísticas. 


\section{REFERÊNCIAS BIBLIOGRÁFICAS}

[1] F. A. DE ASSIS, “Algoritmo Metaheurístico Construtivo Para Solução do Problema de Planejamento da Expansão da Transmissão”, Proposta de Tese de Doutorado, Pontifícia Universidade Católica do Rio de Janeiro (PUC-Rio), Julho/2016.

[2] G. LATORRE; D. R. CRUZ; J. M. AREIZA e A. VILLEGAS, "Classification of Publications and Models on Transmission Planning", IEEE Transactions on Power Systems, Vol. 18, pp. 938-946, May 2003.

[3] P. E. ABREU; L. A. F. MANSO; L. C. RESENDE; A. M. LEITE DA SILVA e C. E. SACRAMENTO, "Planejamento da Expansão de Redes de Transmissão Considerando o Custo da Confiabilidade", Anais do XXI SNPTEE, Florianópolis, pp. 1-9, 2011.

[4] REN21 (RENEWABLE ENERGY POLICY NETWORK FOR THE 21ST CENTURY), “Renewables 2017 - Global Status Report”, edition 2017.

[5] NIHARIKA, et al., "Transmission expansion planning: A review", 2016 International Conference on Energy Efficient Technologies for Sustainability (ICEETS), pp. 350-355, Nagercoil, 2016.

[6] E. E. COSTA, "Elementos de programação matemática: aplicações ao problema do fluxo de potência ótimo linearizado”, Dissertação de Mestrado, Pontifícia Universidade Católica de Minas Gerais, 2006.

[7] L. L. GARVER, "Transmission Network Estimation Using Liner Programming", IEEE Transaction on Power Apparatus and Systems, Vol. PAS89, pp. 1688- 1697, Sept. 1970.

[8] Y. P. DUSONCHET e A.H. EL-ABIAD, "Discrete Optimization and the Planning of Electric Power Networks", IEEE Transactions on Circuit Theory, Vol. CT-20, pp. 230-238, May 1973.

[9] M. J. RIDER; A. V. GARCIA e R. ROMERO, "Power System Transmission Network Expansion Planning Using AC Model", IET Gener. Transm. Distrib., Vol. 1, pp. 731-742, 2007. 
[10] N. ALGUACIL; A. L. MOTTO e A. J. CONEJO, "Transmission Expansion Planning: A Mixed-Integer LP Approach", IEEE Transactions on Power Systems, Vol. 18, pp. 1070-1077, Aug. 2003.

[11] R. ROMERO e A. MONTICELLI, "A Hierarchical Decomposition Approach for Transmission Network Expansion Planning", IEEE Transactions on Power Systems, Vol. 9, pp. 373-380, Feb. 1994.

[12] K. SÖRENSEN e F. GLOVER, "Metaheuristics," Encyclopedia of Operations Research and Management Science, S. I. Gass and M. C. Fu, Eds. New York: Springer US, pp. 960-970, 2013.

[13] E. G. TALBI, “Metaheuristics: From Design to Implementation”. New Jersey: John Wiley \& Son, 2009.

[14] H. MORI e Y. SONE, "A Parallel Tabu Search Based Approach to Transmission Network Expansion Planning", IEEE Porto Power Tech Conference, Porto, 2001.

[15] T. A. FEO e M. G. C. RESENDE, "Greedy Randomized Adaptive Search Procedures", Journal of Global Optimization, Vol. 6, pp. 109-133, 1995.

[16] R. HEMMATI; R. HOOSHMAND e A. KHODABAKHSHIAN, "State-ofthe-art of transmission expansion planning: Comprehensive review”, Renewable and Sustainable Energy Reviews, Vol. 23, pp. 312-319, Jul. 2013.

[17] J. W. BIALEK, "Transmission Charging and Growth of Renewable in the UK", IEEE Power \& Energy Society General Meeting, Stockholm, Sweden, 2007.

[18] M. B. JACOBS, "Transmission Recommendations for High Wind Penetration", IEEE Power \& Energy Society General Meeting, pp. 1-6, Stockholm, Sweden, 2007.

[19] L. FAN; D. OSBORN; J. MILAND e Z. MIAO, "Regional Transmission Planning for Large-Scale Wind Power", IEEE Power \& Energy Society General Meeting, Calgary, Alberta, Canadá, 2009.

[20] A. M. LEITE DA SILVA; W. S. SALES; L. A. F. MANSO e R. BILLINTON, "Long-Term Probabilistic Evaluation of Operating Reserve Requirements with Renewable Sources", IEEE Transactions on Power Systems, Vol. 25, N 1, pp. 106-116, Feb. 2010. 
[21] A. M. LEITE DA SILVA; L. A. F. MANSO; W. S. SALES; S. A. FLÁVIO; G. J. ANDERS e L. C. RESENDE, "Chronological Power Flow for Planning Transmission Systems Considering Intermittent Sources", IEEE Transactions on Power Systems, Vol. 27, $N^{\circ} 4$, pp. 2314- 2322, Nov. 2012.

[22] M. JADIDOLESLAM; A. EBRAHIMI e M. A. LATIFY, "Probabilistic transmission expansion planning to maximize the integration of wind power”, Renewable Energy, Vol. 114, Part B, pp 866-878, Dec. 2017.

[23] G. A. ORFANOS; P. S. GEORGILAKIS e N. D. HATZIARGYRIOU, “Transmission Expansion Planning of Systems With Increasing Wind Power Integration”, IEEE Transactions on Power Systems, Vol. 28, Issue: 2, May 2013.

[24] J. QIU; J. ZHAO e Z. Y. DONG, 'Probabilistic transmission expansion planning for increasing wind power penetration”, IET Renewable Power Generation, Vol. 11, Issue: 6, pp. 837-845, May 2017.

[25] F. UGRANLI e E. KARATEPE, "Multi-objective transmission expansion planning considering minimization of curtailed wind energy”, International Journal of Electrical Power \& Energy Systems, Vol. 65, pp. 348-356, Feb. 2015.

[26] A. ARABALI; M. GHOFRANI; M. ETEZADI-AMOLI; M. S. FADALI e M. MOEINI-AGHTAIE, “A Multi-Objective Transmission Expansion Planning Framework in Deregulated Power Systems With Wind Generation”, IEEE Transactions on Power Systems, Vol. 29, Issue: 6, pp. 30033011, Nov. 2014.

[27] C. ROLDÁN; A. A. SÁNCHEZ; R. GARCÍA-BERTRAND e R. MÍNGUEZ, "Robust dynamic transmission and renewable generation expansion planning: Walking towards sustainable systems”, International Journal of Electrical Power \& Energy Systems, Vol. 96, pp. 52-63, Mar. 2018.

[28] F. PORRUA; R. CHABAR; L.M. THOME; L.M. BARROSO e M.V.F. PEREIRA, "Incorporating Large-Scale Renewable to the Transmission Grid: Technical and Regulatory Issues", IEEE Power \& Energy Society General Meeting, Calgary, Alberta, Canada, 2009. 
[29] R. HEMMATI; R. A. HOOSHMAND e A. KHODABAKHSHIAN, "Market based transmission expansion and reactive power planning with consideration of wind and load uncertainties”, Renewable and Sustainable Energy Reviews, Vol. 29, pp. 1-10, Jan. 2014.

[30] G. W. AULT; K. R. W. BELL e S. J. GALLOWAY, "Calculation of Economic Transmission Connection Capacity for Wind Power Generation", IET Procedures Renewable Power Generation, Vol. 1, № 1, pp. 61-69, Mar. 2007.

[31] R. HEMMATI; R. A. HOOSHMAND e AMIN KHODABAKHSHIAN, "Coordinated generation and transmission expansion planning in deregulated electricity market considering wind farms”, Renewable Energy, Volume 85, pp. 620-630, Jan. 2016.

[32] A. MOREIRA; D. POZO; A. STREET e E. SAUMA, "Reliable Renewable Generation and Transmission Expansion Planning: Co-Optimizing System's Resources for Meeting Renewable Targets”, IEEE Transactions on Power Systems, Vol. 32, Issue: 4, pp. 3246-3257 Jul. 2017.

[33] Y. GU; J. D. MCCALLEY e M. NI, “Coordinating Large-Scale Wind Integration and Transmission Planning”, IEEE Transactions on Sustainable Energy, Vol. 3, Issue: 4, pp. 652-659, Oct. 2012.

[34] M. MOEINI-AGHTAIE; A. ABBASPOUR e M. FOTUHI-FIRUZABAD, “Incorporating Large-Scale Distant Wind Farms in Probabilistic Transmission Expansion Planning-Part I: Theory and Algorithm”, IEEE Transactions on Power Systems, Vol. 27, Issue 3, Aug. 2012.

[35] M. MOEINI-AGHTAIE; A. ABBASPOUR e M. FOTUHI-FIRUZABAD, “Incorporating Large-Scale Distant Wind Farms in Probabilistic Transmission Expansion Planning-Part II: Case Studies”, IEEE Transactions on Power Systems, Vol. 27, Issue 3, Aug. 2012.

[36] S. DEHGHAN e N. AMJADY, "Robust Transmission and Energy Storage Expansion Planning in Wind Farm-Integrated Power Systems Considering Transmission Switching”, IEEE Transactions on Sustainable Energy, Vol. 7, Issue: 2, pp. 765-774, Apr. 2016.

[37] S. A. FLÁVIO, "Planejamento da Expansão de Sistemas de Transmissão com Elevada Participação de Fontes Renováveis”, Tese de Doutorado, Universidade Federal de Itajubá (UNIFEI), Outubro/2015. 
[38] A. M. LEITE DA SILVA; L. S. REZENDE; L. M. HONÓRIO e L. A. F. MANSO, "Performance Comparison of Metaheuristics to Solve the Multistage Transmission Expansion Planning Problem", IET Gener. Transm. Distrib., Vol. 5, pp. 360-367, 2011.

[39] A. M. LEITE DA SILVA; L. A. F. MANSO; L. C. RESENDE e L. S. REZENDE, “Tabu Search Applied to transmission Expansion Planning Considering Losses and Interruption Costs”, Proceedings of 10th PMAPS, pp. 25-29, Rincón, 2008.

[40] P. C. BERBERT, “Sistema Imunológico Artificial para Otimização Multiobjetivo”, Dissertação de Mestrado, Universidade Estadual de Campinas, 2008.

[41] H. FARIA JR.; S. BINATO; M. G. C. RESENDE; D. M. FALCÃO, “Power Transmission Network Design by Greedy Randomized Adaptive Path Relinking”, IEEE Trans. Power Syst., Vol. 20, Issue 1, pp. 43-49, Feb. 2005.

[42] A. M. LEITE DA SILVA; M. R. FREIRE e L. M. Honório, “Transmission expansion planning optimization by adaptive multi-operator evolutionary algorithms,” Elect. Power Syst. Res., Vol. 133, pp. 173-191, April 2016

[43] A. M. LEITE DA SILVA; L. S. REZENDE; L. A. F. MANSO e G. J. ANDERS, "Transmission Expansion Planning: A Discussion on Reliability and "N-1" Security Criteria", Proceedings of the 11th PMAPS, Singapore, 2010 .

[44] A. M. LeITE DA SILVA; F. A. DE ASSIS; L. A. F. MANSO; M. R. FREIRE e S. A. FÁVIO, "Constructive Metaheuristics Applied to Transmission Expansion Planning with Security Constraints,” 19th International Conference on Intelligent System Applications to Power Systems - ISAP, San Antonio, Texas, USA, September 2017.

[45] A.K. JAIN, “Data clustering: 50 years beyond K-means”, Pattern Recognition Letters, Vol. 31, Issue 8, pp. 651-666, June 2010.

[46] IEEE APM SUBCOMMITTEE, "IEEE Reliability Test System", IEEE Trans. on PAS, Vol. PAS-99, pp. 2047-2054, Nov/Dec. 1979.

[47] KONINKLIJK NETHERLANDS METEOROLOGICAL INSTITUTE (KNMI). - Climate and Services, Oct. 2010. Disponível em: $<$ http://www.knmi.nl/klimatologie/onderzoeksgegevens/potentiele_wind/ind ex.cgi?language $=$ eng $>$, 
[48] A. M. LEITE DA SILVA; M. R. FREIRE; F. A. ASSIS e L. A. F. MANSO, "Transmission Expansion Planning Based on Relaxed "N-1" Criteria and Reliability Indices”, 14th PMAPS - Probabilistic Methods Applied to Power Systems, Beijing, China, Oct. 2016. 


\section{APÊNDICE A - "Tabelas Decisão" Complementares}

Neste apêndice são apresentadas as Tabelas Decisão obtidas ao longo das Iterações 4 a 10, correspondentes à continuação da etapa iterativa aplicada ao caso com os 10 cenários de geração eólica (Plano 1). 
Tabela A.1 - Tabela Decisão da Iteração 4 - Alternativa 1.

\begin{tabular}{|c|c|c|c|c|c|c|c|c|c|c|c|c|c|}
\hline \multirow{2}{*}{ Ramo } & \multicolumn{10}{|c|}{ Plano Para Cada Cenário } & \multicolumn{3}{|c|}{ Graus de Incidência } \\
\hline & 1 & 2 & 3 & 4 & 5 & 6 & 7 & 8 & 9 & 10 & GI1 & GI2 & GI3 \\
\hline $01-02$ & 1 & 0 & 0 & 0 & 0 & 0 & 1 & 0 & 0 & 1 & 3 & 0 & 0 \\
\hline $01-03$ & 0 & 0 & 0 & 0 & 0 & 0 & 0 & 0 & 0 & 0 & 0 & 0 & 0 \\
\hline $01-05$ & 1 & 1 & 1 & 2 & 1 & 1 & 2 & 2 & 1 & 2 & 10 & 4 & 0 \\
\hline $02-04$ & 0 & 0 & 0 & 0 & 0 & 0 & 1 & 0 & 0 & 1 & 2 & 0 & 0 \\
\hline $02-06$ & 0 & 0 & 0 & 0 & 0 & 0 & 0 & 0 & 0 & 0 & 0 & 0 & 0 \\
\hline $03-09$ & 1 & 1 & 1 & 1 & 1 & 1 & 1 & 1 & 1 & 1 & 10 & 0 & 0 \\
\hline $03-24$ & 0 & 0 & 0 & 0 & 0 & 0 & 0 & 0 & 0 & 0 & 0 & 0 & 0 \\
\hline 04-09 & 0 & 0 & 0 & 0 & 0 & 0 & 0 & 0 & 0 & 0 & 0 & 0 & 0 \\
\hline $\begin{array}{l}05-10 \\
\end{array}$ & 0 & 0 & 0 & 0 & 0 & 0 & 1 & 0 & 0 & 1 & 2 & 0 & 0 \\
\hline 06-10 & 2 & 2 & 2 & 2 & 2 & 2 & 2 & 2 & 2 & 2 & 10 & 10 & 0 \\
\hline $\begin{array}{l}07-08 \\
\end{array}$ & 2 & 2 & 2 & 2 & 2 & 2 & 2 & 2 & 2 & 2 & 10 & 10 & 0 \\
\hline 08-09 & 0 & 0 & 0 & 0 & 0 & 0 & 0 & 0 & 0 & 0 & 0 & 0 & 0 \\
\hline 08-10 & 0 & 0 & 0 & 0 & 0 & 0 & 0 & 0 & 0 & 0 & 0 & 0 & 0 \\
\hline 09-11 & 0 & 0 & 0 & 0 & 0 & 0 & 0 & 0 & 0 & 0 & 0 & 0 & 0 \\
\hline 09-12 & 0 & 0 & 0 & 0 & 0 & 0 & 0 & 0 & 0 & 0 & 0 & 0 & 0 \\
\hline $10-11$ & 1 & 0 & 1 & 0 & 1 & 0 & 0 & 0 & 0 & 0 & 3 & 0 & 0 \\
\hline $10-12$ & 0 & 1 & 0 & 0 & 0 & 1 & 0 & 0 & 1 & 0 & 3 & 0 & 0 \\
\hline $11-13$ & 1 & 1 & 1 & 1 & 1 & 1 & 1 & 1 & 1 & 1 & 10 & 0 & 0 \\
\hline 11-14 & 0 & 0 & 0 & 0 & 0 & 0 & 0 & 0 & 0 & 0 & 0 & 0 & 0 \\
\hline $12-13$ & 0 & 0 & 0 & 0 & 0 & 0 & 0 & 0 & 0 & 0 & 0 & 0 & 0 \\
\hline $12-23$ & 0 & 0 & 0 & 0 & 0 & 0 & 0 & 0 & 0 & 0 & 0 & 0 & 0 \\
\hline $13-23$ & 0 & 0 & 0 & 0 & 0 & 0 & 0 & 0 & 0 & 0 & 0 & 0 & 0 \\
\hline 14-16 & 1 & 0 & 1 & 0 & 1 & 0 & 0 & 0 & 0 & 0 & 3 & 0 & 0 \\
\hline $15-16$ & 1 & 0 & 0 & 0 & 0 & 0 & 0 & 0 & 0 & 0 & 1 & 0 & 0 \\
\hline 15-21 & 0 & 0 & 0 & 0 & 0 & 0 & 0 & 0 & 0 & 0 & 0 & 0 & 0 \\
\hline $15-24$ & 0 & 0 & 0 & 0 & 0 & 0 & 0 & 0 & 0 & 0 & 0 & 0 & 0 \\
\hline $16-17$ & 0 & 0 & 0 & 0 & 0 & 0 & 0 & 0 & 0 & 0 & 0 & 0 & 0 \\
\hline 16-19 & 0 & 0 & 0 & 0 & 0 & 0 & 0 & 0 & 0 & 0 & 0 & 0 & 0 \\
\hline $17-18$ & 0 & 0 & 0 & 0 & 0 & 0 & 0 & 0 & 1 & 0 & 1 & 0 & 0 \\
\hline $17-22$ & 0 & 0 & 0 & 0 & 0 & 0 & 0 & 0 & 0 & 0 & 0 & 0 & 0 \\
\hline $18-21$ & 0 & 0 & 0 & 0 & 0 & 0 & 0 & 0 & 0 & 0 & 0 & 0 & 0 \\
\hline $19-20$ & 0 & 0 & 0 & 1 & 0 & 0 & 1 & 1 & 0 & 0 & 3 & 0 & 0 \\
\hline $20-23$ & 1 & 1 & 1 & 1 & 1 & 1 & 1 & 1 & 1 & 1 & 10 & 0 & 0 \\
\hline $21-22$ & 0 & 0 & 0 & 0 & 0 & 0 & 0 & 0 & 0 & 0 & 0 & 0 & 0 \\
\hline 01-08 & 0 & 0 & 0 & 0 & 0 & 0 & 0 & 0 & 0 & 0 & 0 & 0 & 0 \\
\hline $02-08$ & 0 & 0 & 0 & 0 & 0 & 0 & 0 & 0 & 0 & 0 & 0 & 0 & 0 \\
\hline 06-07 & 0 & 0 & 0 & 0 & 0 & 0 & 0 & 0 & 0 & 0 & 0 & 0 & 0 \\
\hline $13-14$ & 0 & 0 & 0 & 0 & 0 & 0 & 0 & 0 & 0 & 0 & 0 & 0 & 0 \\
\hline $14-23$ & 0 & 0 & 0 & 0 & 0 & 0 & 0 & 0 & 0 & 1 & 1 & 0 & 0 \\
\hline $16-23$ & 0 & 0 & 0 & 0 & 0 & 0 & 0 & 0 & 0 & 0 & 0 & 0 & 0 \\
\hline $19-23$ & 0 & 0 & 0 & 0 & 0 & 0 & 0 & 0 & 0 & 0 & 0 & 0 & 0 \\
\hline Reforços & 12 & 9 & 10 & 10 & 10 & 9 & 13 & 10 & 10 & 13 & \multicolumn{3}{|c|}{ Custo Médio } \\
\hline $\begin{array}{c}\text { Custo } \\
\left(10^{6} \$\right)\end{array}$ & 344 & 263 & 317 & 290 & 317 & 263 & 349 & 290 & 283 & 380 & \multicolumn{3}{|c|}{309,6} \\
\hline InRef & 0 & 0 & 0 & 1 & 0 & 0 & 0 & 1 & 1 & 0 & \multicolumn{3}{|c|}{ GU } \\
\hline InCus & 0 & 0 & 0 & 59 & 0 & 0 & 4 & 59 & 24 & 35 & \multicolumn{3}{|c|}{111,4} \\
\hline InRefA & 1 & 1 & 1 & 2 & 1 & 0 & 4 & 2 & 2 & 4 & & & \\
\hline InCusA & 22 & 22 & 22 & 75 & 22 & 0 & 58 & 75 & 46 & 84 & & & \\
\hline
\end{tabular}


Tabela A.2 - Tabela Decisão da Iteração 4 - Alternativa 2.

\begin{tabular}{|c|c|c|c|c|c|c|c|c|c|c|c|c|c|}
\hline \multirow{2}{*}{ Ramo } & \multicolumn{10}{|c|}{ Plano Para Cada Cenário } & \multicolumn{3}{|c|}{ || Graus de Incidência } \\
\hline & 1 & 2 & 3 & 4 & 5 & 6 & 7 & 8 & 9 & 10 & GI1 & GI2 & GI3 \\
\hline $01-02$ & 1 & 0 & 0 & 0 & 0 & 0 & 1 & 0 & 0 & 1 & 3 & 0 & 0 \\
\hline $01-03$ & 0 & 0 & 0 & 0 & 0 & 0 & 0 & 0 & 0 & 0 & 0 & 0 & 0 \\
\hline $01-05$ & 1 & 1 & 1 & 2 & 1 & 1 & 2 & 2 & 1 & 2 & 10 & 4 & 0 \\
\hline $02-04$ & 0 & 0 & 0 & 0 & 0 & 0 & 1 & 0 & 0 & 1 & 2 & 0 & 0 \\
\hline $02-06$ & 0 & 0 & 0 & 0 & 0 & 0 & 0 & 0 & 0 & 0 & 0 & 0 & 0 \\
\hline $03-09$ & 1 & 1 & 1 & 1 & 1 & 1 & 1 & 1 & 1 & 1 & 10 & 0 & 0 \\
\hline $03-24$ & 0 & 1 & 0 & 0 & 0 & 0 & 0 & 0 & 0 & 0 & 1 & 0 & 0 \\
\hline $\begin{array}{l}04-09 \\
\end{array}$ & 0 & 0 & 0 & 0 & 0 & 0 & 0 & 0 & 0 & 0 & 0 & 0 & 0 \\
\hline 05-10 & 0 & 0 & 0 & 0 & 0 & 0 & 1 & 0 & 0 & 1 & 2 & 0 & 0 \\
\hline $06-10$ & 2 & 2 & 2 & 2 & 2 & 2 & 2 & 2 & 2 & 2 & 10 & 10 & 0 \\
\hline $07-08$ & 2 & 2 & 2 & 2 & 2 & 2 & 2 & 2 & 2 & 2 & 10 & 10 & 0 \\
\hline $\begin{array}{l}08-09 \\
\end{array}$ & 0 & 0 & 0 & 0 & 0 & 0 & 0 & 0 & 0 & 0 & 0 & 0 & 0 \\
\hline 08-10 & 0 & 0 & 0 & 0 & 0 & 0 & 0 & 0 & 0 & 0 & 0 & 0 & 0 \\
\hline 09-11 & 0 & 0 & 0 & 0 & 0 & 1 & 0 & 0 & 0 & 0 & 1 & 0 & 0 \\
\hline 09-12 & 0 & 0 & 0 & 0 & 0 & 0 & 0 & 0 & 0 & 0 & 0 & 0 & 0 \\
\hline $10-11$ & 0 & 0 & 1 & 0 & 0 & 0 & 0 & 0 & 0 & 0 & 1 & 0 & 0 \\
\hline $10-12$ & 1 & 1 & 0 & 0 & 1 & 1 & 0 & 0 & 1 & 0 & 5 & 0 & 0 \\
\hline $11-13$ & 0 & 0 & 0 & 0 & 1 & 0 & 0 & 0 & 0 & 0 & 1 & 0 & 0 \\
\hline 11-14 & 0 & 0 & 1 & 0 & 0 & 0 & 0 & 0 & 0 & 0 & 1 & 0 & 0 \\
\hline $12-13$ & 1 & 0 & 0 & 0 & 0 & 0 & 0 & 0 & 0 & 0 & 1 & 0 & 0 \\
\hline $12-23$ & 0 & 0 & 0 & 0 & 0 & 0 & 0 & 0 & 0 & 0 & 0 & 0 & 0 \\
\hline $13-23$ & 0 & 0 & 0 & 0 & 0 & 0 & 0 & 0 & 0 & 0 & 0 & 0 & 0 \\
\hline 14-16 & 1 & 0 & 1 & 0 & 0 & 0 & 0 & 0 & 0 & 0 & 2 & 0 & 0 \\
\hline $15-16$ & 0 & 0 & 0 & 0 & 0 & 0 & 0 & 0 & 0 & 0 & 0 & 0 & 0 \\
\hline $15-21$ & 0 & 0 & 0 & 0 & 0 & 0 & 0 & 0 & 0 & 0 & 0 & 0 & 0 \\
\hline $15-24$ & 0 & 0 & 0 & 0 & 0 & 0 & 0 & 0 & 0 & 0 & 0 & 0 & 0 \\
\hline 16-17 & 0 & 0 & 0 & 0 & 0 & 0 & 0 & 0 & 0 & 0 & 0 & 0 & 0 \\
\hline $16-19$ & 0 & 0 & 0 & 0 & 0 & 0 & 0 & 0 & 0 & 0 & 0 & 0 & 0 \\
\hline $17-18$ & 1 & 0 & 0 & 0 & 0 & 0 & 0 & 0 & 0 & 0 & 1 & 0 & 0 \\
\hline $17-22$ & 0 & 0 & 0 & 0 & 0 & 0 & 0 & 0 & 0 & 0 & 0 & 0 & 0 \\
\hline $18-21$ & 0 & 0 & 0 & 0 & 0 & 0 & 0 & 0 & 0 & 0 & 0 & 0 & 0 \\
\hline $19-20$ & 0 & 0 & 0 & 0 & 0 & 0 & 1 & 0 & 0 & 1 & 2 & 0 & 0 \\
\hline $20-23$ & 1 & 1 & 1 & 1 & 1 & 1 & 1 & 1 & 1 & 1 & 10 & 0 & 0 \\
\hline $21-22$ & 0 & 0 & 0 & 0 & 0 & 0 & 0 & 0 & 0 & 0 & 0 & 0 & 0 \\
\hline $\begin{array}{l}01-08 \\
\end{array}$ & 0 & 0 & 0 & 0 & 0 & 0 & 0 & 0 & 0 & 0 & 0 & 0 & 0 \\
\hline 02-08 & 0 & 0 & 0 & 0 & 0 & 0 & 0 & 0 & 0 & 0 & 0 & 0 & 0 \\
\hline $\begin{array}{l}06-07 \\
\end{array}$ & 0 & 0 & 0 & 0 & 0 & 0 & 0 & 0 & 0 & 0 & 0 & 0 & 0 \\
\hline 13-14 & 1 & 1 & 1 & 1 & 1 & 1 & 1 & 1 & 1 & 1 & 10 & 0 & 0 \\
\hline $14-23$ & 0 & 0 & 0 & 0 & 0 & 0 & 0 & 0 & 0 & 0 & 0 & 0 & 0 \\
\hline $16-23$ & 0 & 0 & 0 & 0 & 0 & 0 & 0 & 0 & 0 & 0 & 0 & 0 & 0 \\
\hline $19-23$ & 0 & 0 & 0 & 0 & 0 & 0 & 0 & 0 & 0 & 0 & 0 & 0 & 0 \\
\hline Reforços & 13 & 10 & 11 & 9 & 10 & 10 & 13 & 9 & 9 & 13 & & sto $M$ & \\
\hline $\begin{array}{c}\text { Custo } \\
\left(10^{6} \$\right)\end{array}$ & 402 & 309 & 371 & 231 & 325 & 309 & 345 & 231 & 259 & 345 & & 312,7 & \\
\hline InRef & 1 & 1 & 1 & 0 & 0 & 1 & 0 & 0 & 0 & 0 & & GU & \\
\hline InCus & 58 & 46 & 54 & 0 & 8 & 46 & 0 & 0 & 0 & 0 & & 107,9 & \\
\hline
\end{tabular}

\begin{tabular}{|c|c|c|c|c|c|c|c|c|c|c|}
\hline InRefA & 2 & 2 & 2 & 1 & 1 & 1 & 4 & 1 & 1 & 4 \\
\hline
\end{tabular}

\begin{tabular}{l|c|c|c|c|c|c|c|c|c|c|} 
InCusA & 80 & 68 & 76 & 16 & 30 & 46 & 54 & 16 & 22 & 49 \\
\hline
\end{tabular} 
Tabela A.3 - Reforços consolidados até a Tabela Decisão da Iteração 4.

\begin{tabular}{|c|c|c|}
\hline Ramo Candidato & Quantidade de Reforços & \multirow{2}{*}{ Tabela Decisão } \\
\hline $03-09$ & 1 & \multirow{2}{*}{ Inicial } \\
\cline { 1 - 2 } $06-10$ & 1 & \\
\hline $20-23$ & 1 & Iteração 1 \\
\hline $07-08$ & 2 & Iteração 2 \\
\hline $06-10$ & 2 & Iteração 3 \\
\hline $01-05$ & 1 & Iteração 4 \\
\hline $11-13$ & 1 & \\
\hline
\end{tabular}


Tabela A.4 - Tabela Decisão da Iteração 5.

\begin{tabular}{|c|c|c|c|c|c|c|c|c|c|c|c|c|c|}
\hline \multirow{2}{*}{ Ramo } & \multicolumn{10}{|c|}{ Plano Para Cada Cenário } & \multicolumn{3}{|c|}{ Graus de Incidência } \\
\hline & 1 & 2 & 3 & 4 & 5 & 6 & 7 & 8 & 9 & 10 & GI1 & GI2 & GI3 \\
\hline $01-02$ & 1 & 0 & 0 & 0 & 0 & 0 & 1 & 0 & 0 & 1 & 3 & 0 & 0 \\
\hline $01-03$ & 0 & 0 & 0 & 0 & 0 & 0 & 0 & 0 & 0 & 0 & 0 & 0 & 0 \\
\hline $01-05$ & 2 & 2 & 2 & 2 & 2 & 2 & 2 & 2 & 2 & 2 & 10 & 10 & 0 \\
\hline $02-04$ & 0 & 0 & 0 & 0 & 0 & 0 & 1 & 0 & 0 & 1 & 2 & 0 & 0 \\
\hline $02-06$ & 0 & 0 & 0 & 0 & 0 & 0 & 0 & 0 & 0 & 0 & 0 & 0 & 0 \\
\hline 03-09 & 1 & 1 & 1 & 1 & 1 & 1 & 1 & 1 & 1 & 1 & 10 & 0 & 0 \\
\hline $03-24$ & 0 & 0 & 0 & 0 & 0 & 0 & 0 & 0 & 0 & 0 & 0 & 0 & 0 \\
\hline $04-09$ & 0 & 0 & 0 & 0 & 0 & 0 & 0 & 0 & 0 & 0 & 0 & 0 & 0 \\
\hline 05-10 & 0 & 0 & 0 & 0 & 0 & 0 & 1 & 0 & 0 & 1 & 2 & 0 & 0 \\
\hline 06-10 & 2 & 2 & 2 & 2 & 2 & 2 & 2 & 2 & 2 & 2 & 10 & 10 & 0 \\
\hline $\begin{array}{l}07-08 \\
\end{array}$ & 2 & 2 & 2 & 2 & 2 & 2 & 2 & 2 & 2 & 2 & 10 & 10 & 0 \\
\hline $\begin{array}{l}08-09 \\
\end{array}$ & 0 & 0 & 0 & 0 & 0 & 0 & 0 & 0 & 0 & 0 & 0 & 0 & 0 \\
\hline 08-10 & 0 & 0 & 0 & 0 & 0 & 0 & 0 & 0 & 0 & 0 & 0 & 0 & 0 \\
\hline 09-11 & 0 & 0 & 0 & 0 & 0 & 0 & 0 & 0 & 0 & 0 & 0 & 0 & 0 \\
\hline 09-12 & 0 & 0 & 0 & 0 & 0 & 0 & 0 & 0 & 0 & 0 & 0 & 0 & 0 \\
\hline $10-11$ & 1 & 0 & 1 & 0 & 1 & 0 & 0 & 0 & 0 & 0 & 3 & 0 & 0 \\
\hline $10-12$ & 0 & 1 & 0 & 0 & 0 & 1 & 0 & 0 & 1 & 0 & 3 & 0 & 0 \\
\hline $11-13$ & 1 & 1 & 1 & 1 & 1 & 1 & 1 & 1 & 1 & 1 & 10 & 0 & 0 \\
\hline 11-14 & 0 & 0 & 0 & 0 & 0 & 0 & 0 & 0 & 0 & 0 & 0 & 0 & 0 \\
\hline $12-13$ & 0 & 0 & 0 & 0 & 0 & 0 & 0 & 0 & 0 & 0 & 0 & 0 & 0 \\
\hline $12-23$ & 0 & 0 & 0 & 0 & 0 & 0 & 0 & 0 & 0 & 0 & 0 & 0 & 0 \\
\hline $13-23$ & 0 & 0 & 0 & 0 & 0 & 0 & 0 & 0 & 0 & 0 & 0 & 0 & 0 \\
\hline $\begin{array}{l}14-16 \\
\end{array}$ & 1 & 0 & 1 & 0 & 1 & 0 & 0 & 0 & 0 & 0 & 3 & 0 & 0 \\
\hline $15-16$ & 1 & 0 & 0 & 0 & 0 & 0 & 0 & 0 & 0 & 0 & 1 & 0 & 0 \\
\hline 15-21 & 0 & 0 & 0 & 0 & 0 & 0 & 0 & 0 & 0 & 0 & 0 & 0 & 0 \\
\hline $15-24$ & 0 & 0 & 0 & 0 & 0 & 0 & 0 & 0 & 0 & 0 & 0 & 0 & 0 \\
\hline 16-17 & 0 & 0 & 0 & 0 & 0 & 0 & 0 & 0 & 0 & 0 & 0 & 0 & 0 \\
\hline 16-19 & 0 & 0 & 0 & 0 & 0 & 0 & 0 & 0 & 0 & 0 & 0 & 0 & 0 \\
\hline $17-18$ & 0 & 0 & 0 & 0 & 0 & 0 & 0 & 0 & 1 & 0 & 1 & 0 & 0 \\
\hline $17-22$ & 0 & 0 & 0 & 0 & 0 & 0 & 0 & 0 & 0 & 0 & 0 & 0 & 0 \\
\hline $18-21$ & 0 & 0 & 0 & 0 & 0 & 0 & 0 & 0 & 0 & 0 & 0 & 0 & 0 \\
\hline $19-20$ & 0 & 0 & 0 & 1 & 0 & 0 & 1 & 1 & 0 & 0 & 3 & 0 & 0 \\
\hline $20-23$ & 1 & 1 & 1 & 1 & 1 & 1 & 1 & 1 & 1 & 1 & 10 & 0 & 0 \\
\hline $21-22$ & 0 & 0 & 0 & 0 & 0 & 0 & 0 & 0 & 0 & 0 & 0 & 0 & 0 \\
\hline 01-08 & 0 & 0 & 0 & 0 & 0 & 0 & 0 & 0 & 0 & 0 & 0 & 0 & 0 \\
\hline $02-08$ & 0 & 0 & 0 & 0 & 0 & 0 & 0 & 0 & 0 & 0 & 0 & 0 & 0 \\
\hline 06-07 & 0 & 0 & 0 & 0 & 0 & 0 & 0 & 0 & 0 & 0 & 0 & 0 & 0 \\
\hline $13-14$ & 0 & 0 & 0 & 0 & 0 & 0 & 0 & 0 & 0 & 0 & 0 & 0 & 0 \\
\hline $14-23$ & 0 & 0 & 0 & 0 & 0 & 0 & 0 & 0 & 0 & 1 & 1 & 0 & 0 \\
\hline $16-23$ & 0 & 0 & 0 & 0 & 0 & 0 & 0 & 0 & 0 & 0 & 0 & 0 & 0 \\
\hline $19-23$ & 0 & 0 & 0 & 0 & 0 & 0 & 0 & 0 & 0 & 0 & 0 & 0 & 0 \\
\hline \begin{tabular}{|l} 
Reforços \\
\end{tabular} & 13 & 10 & 11 & 10 & 11 & 10 & 13 & 10 & 11 & 13 & & Isto $M$ & \\
\hline $\begin{array}{c}\text { Custo } \\
\left(10^{6} \$\right)\end{array}$ & 366 & 285 & 339 & 290 & 339 & 285 & 349 & 290 & 305 & 380 & & 322,8 & \\
\hline InRef & 1 & 1 & 1 & 0 & 1 & 1 & 0 & 0 & 1 & 0 & & $\overline{\text { GU }}$ & \\
\hline InCus & 22 & 22 & 22 & 0 & 22 & 22 & 0 & 0 & 22 & 0 & & 113 & \\
\hline \begin{tabular}{|l|} 
InRefA \\
\end{tabular} & 2 & 2 & 2 & 2 & 2 & 1 & 4 & 2 & 3 & 4 & & & \\
\hline \begin{tabular}{|l|} 
InCusA \\
\end{tabular} & 44 & 44 & 44 & 75 & 44 & 22 & 58 & 75 & 68 & 84 & & & \\
\hline
\end{tabular}


Tabela A.5 - Reforços consolidados até a Tabela Decisão da Iteração 5.

\begin{tabular}{|c|c|c|}
\hline Ramo Candidato & Quantidade de Reforços & \multirow{2}{*}{ Tabela Decisão } \\
\cline { 1 - 2 } $03-09$ & 1 & \multirow{2}{*}{ Inicial } \\
\hline $06-10$ & 1 & \\
\hline $20-23$ & 1 & Iteração 1 \\
\hline $07-08$ & 2 & Iteração 2 \\
\hline $06-10$ & 2 & Iteração 3 \\
\hline $01-05$ & 1 & Iteração 4 \\
\hline $11-13$ & 1 & Iteração 5 \\
\hline $01-05$ & 2 & \\
\hline
\end{tabular}


Tabela A.6 - Tabela Decisão da Iteração 6 - Alternativa 1.

\begin{tabular}{|c|c|c|c|c|c|c|c|c|c|c|c|c|c|}
\hline \multirow{2}{*}{ Ramo } & \multicolumn{10}{|c|}{ Plano Para Cada Cenário } & \multicolumn{3}{|c|}{ Graus de Incidência } \\
\hline & 1 & 2 & 3 & 4 & 5 & 6 & 7 & 8 & 9 & 10 & GI1 & GI2 & GI3 \\
\hline $01-02$ & 1 & 1 & 1 & 1 & 1 & 1 & 1 & 1 & 1 & 1 & 10 & 0 & 0 \\
\hline $01-03$ & 0 & 0 & 0 & 0 & 0 & 0 & 0 & 0 & 0 & 0 & 0 & 0 & 0 \\
\hline $01-05$ & 2 & 2 & 2 & 2 & 2 & 2 & 2 & 2 & 2 & 2 & 10 & 10 & 0 \\
\hline $02-04$ & 0 & 0 & 0 & 0 & 0 & 0 & 1 & 0 & 0 & 1 & 2 & 0 & 0 \\
\hline $02-06$ & 0 & 0 & 0 & 0 & 0 & 0 & 0 & 0 & 0 & 0 & 0 & 0 & 0 \\
\hline 03-09 & 1 & 1 & 1 & 1 & 1 & 1 & 1 & 1 & 1 & 1 & 10 & 0 & 0 \\
\hline $03-24$ & 0 & 0 & 0 & 0 & 0 & 0 & 0 & 0 & 0 & 0 & 0 & 0 & 0 \\
\hline $04-09$ & 0 & 0 & 0 & 0 & 0 & 0 & 0 & 0 & 0 & 0 & 0 & 0 & 0 \\
\hline $05-10$ & 0 & 0 & 0 & 0 & 0 & 0 & 1 & 0 & 0 & 1 & 2 & 0 & 0 \\
\hline 06-10 & 2 & 2 & 2 & 2 & 2 & 2 & 2 & 2 & 2 & 2 & 10 & 10 & 0 \\
\hline $\begin{array}{l}07-08 \\
\end{array}$ & 2 & 2 & 2 & 2 & 2 & 2 & 2 & 2 & 2 & 2 & 10 & 10 & 0 \\
\hline 08-09 & 0 & 0 & 0 & 0 & 0 & 0 & 0 & 0 & 0 & 0 & 0 & 0 & 0 \\
\hline 08-10 & 0 & 0 & 0 & 0 & 0 & 0 & 0 & 0 & 0 & 0 & 0 & 0 & 0 \\
\hline 09-11 & 0 & 0 & 0 & 0 & 0 & 0 & 0 & 0 & 0 & 0 & 0 & 0 & 0 \\
\hline 09-12 & 0 & 0 & 0 & 0 & 0 & 0 & 0 & 0 & 0 & 0 & 0 & 0 & 0 \\
\hline $10-11$ & 1 & 0 & 1 & 0 & 1 & 0 & 0 & 0 & 0 & 0 & 3 & 0 & 0 \\
\hline $10-12$ & 0 & 1 & 0 & 0 & 0 & 1 & 0 & 0 & 1 & 0 & 3 & 0 & 0 \\
\hline 11-13 & 1 & 1 & 1 & 1 & 1 & 1 & 1 & 1 & 1 & 1 & 10 & 0 & 0 \\
\hline 11-14 & 0 & 0 & 0 & 0 & 0 & 0 & 0 & 0 & 0 & 0 & 0 & 0 & 0 \\
\hline $12-13$ & 0 & 0 & 0 & 0 & 0 & 0 & 0 & 0 & 0 & 0 & 0 & 0 & 0 \\
\hline $12-23$ & 0 & 0 & 0 & 0 & 0 & 0 & 0 & 0 & 0 & 0 & 0 & 0 & 0 \\
\hline 13-23 & 0 & 0 & 0 & 0 & 0 & 0 & 0 & 0 & 0 & 0 & 0 & 0 & 0 \\
\hline $14-16$ & 1 & 0 & 1 & 0 & 1 & 0 & 0 & 0 & 0 & 0 & 3 & 0 & 0 \\
\hline $15-16$ & 1 & 0 & 0 & 0 & 0 & 0 & 0 & 0 & 0 & 0 & 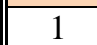 & 0 & 0 \\
\hline $15-21$ & 0 & 0 & 0 & 0 & 0 & 0 & 0 & 0 & 0 & 0 & 0 & 0 & 0 \\
\hline $15-24$ & 0 & 0 & 0 & 0 & 0 & 0 & 0 & 0 & 0 & 0 & 0 & 0 & 0 \\
\hline 16-17 & 0 & 0 & 0 & 0 & 0 & 0 & 0 & 0 & 0 & 0 & 0 & 0 & 0 \\
\hline 16-19 & 0 & 0 & 0 & 0 & 0 & 0 & 0 & 0 & 0 & 0 & 0 & 0 & 0 \\
\hline 17-18 & 0 & 0 & 0 & 0 & 0 & 0 & 0 & 0 & 1 & 0 & 1 & 0 & 0 \\
\hline $17-22$ & 0 & 0 & 0 & 0 & 0 & 0 & 0 & 0 & 0 & 0 & 0 & 0 & 0 \\
\hline $18-21$ & 0 & 0 & 0 & 0 & 0 & 0 & 0 & 0 & 0 & 0 & 0 & 0 & 0 \\
\hline $19-20$ & 0 & 0 & 0 & 1 & 0 & 0 & 1 & 1 & 0 & 0 & 3 & 0 & 0 \\
\hline $20-23$ & 1 & 1 & 1 & 1 & 1 & 1 & 1 & 1 & 1 & 1 & 10 & 0 & 0 \\
\hline $21-22$ & 0 & 0 & 0 & 0 & 0 & 0 & 0 & 0 & 0 & 0 & 0 & 0 & 0 \\
\hline 01-08 & 0 & 0 & 0 & 0 & 0 & 0 & 0 & 0 & 0 & 0 & 0 & 0 & 0 \\
\hline $\begin{array}{l}02-08 \\
\end{array}$ & 0 & 0 & 0 & 0 & 0 & 0 & 0 & 0 & 0 & 0 & 0 & 0 & 0 \\
\hline 06-07 & 0 & 0 & 0 & 0 & 0 & 0 & 0 & 0 & 0 & 0 & 0 & 0 & 0 \\
\hline 13-14 & 0 & 0 & 0 & 0 & 0 & 0 & 0 & 0 & 0 & 0 & 0 & 0 & 0 \\
\hline $14-23$ & 0 & 0 & 0 & 0 & 0 & 0 & 0 & 0 & 0 & 1 & 1 & 0 & 0 \\
\hline $16-23$ & 0 & 0 & 0 & 0 & 0 & 0 & 0 & 0 & 0 & 0 & 0 & 0 & 0 \\
\hline $19-23$ & 0 & 0 & 0 & 0 & 0 & 0 & 0 & 0 & 0 & 0 & 0 & 0 & 0 \\
\hline Reforços & 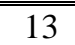 & 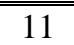 & $\begin{array}{l}12 \\
12\end{array}$ & 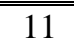 & $\begin{array}{l}12 \\
\end{array}$ & $\begin{array}{l}11 \\
\end{array}$ & $\begin{array}{l}13 \\
\end{array}$ & \begin{tabular}{l|l}
11 \\
\end{tabular} & 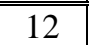 & 213 & & sto Mé & \\
\hline $\begin{array}{c}\text { Custo } \\
\left(10^{6} \$\right)\end{array}$ & 366 & 288 & 342 & 293 & 342 & 288 & 349 & 293 & 308 & 380 & & 324,9 & \\
\hline InRef & 0 & 1 & 1 & 1 & 1 & 1 & 0 & 1 & 1 & 0 & & GU & \\
\hline InCus & 0 & 3 & 3 & 3 & 3 & 3 & 0 & 3 & 3 & 0 & & 114 & \\
\hline InRefA & 2 & 3 & 3 & 3 & 3 & 2 & 4 & 3 & 4 & 4 & & & \\
\hline InCusA & 44 & 47 & 47 & 78 & 47 & 25 & 58 & 78 & 71 & 84 & & & \\
\hline
\end{tabular}


Tabela A.7 - Tabela Decisão da Iteração 6 - Alternativa 2.

\begin{tabular}{|c|c|c|c|c|c|c|c|c|c|c|c|c|c|}
\hline \multirow{2}{*}{ Ramo } & \multicolumn{10}{|c|}{ Plano Para Cada Cenário } & \multicolumn{3}{|c|}{ Graus de Incidência } \\
\hline & 1 & 2 & 3 & 4 & 5 & 6 & 7 & 8 & 9 & 10 & GI1 & GI2 & GI3 \\
\hline 01-02 & 1 & 0 & 0 & 0 & 0 & 0 & 1 & 0 & 0 & 0 & 2 & 0 & 0 \\
\hline $01-03$ & 0 & 0 & 0 & 0 & 0 & 0 & 0 & 0 & 0 & 1 & 1 & 0 & 0 \\
\hline $01-05$ & 2 & 2 & 2 & 2 & 2 & 2 & 2 & 2 & 2 & 2 & 10 & 10 & 0 \\
\hline $02-04$ & 0 & 0 & 0 & 0 & 0 & 0 & 1 & 0 & 0 & 0 & 1 & 0 & 0 \\
\hline $02-06$ & 0 & 0 & 0 & 0 & 0 & 0 & 0 & 0 & 0 & 0 & 0 & 0 & 0 \\
\hline 03-09 & 1 & 1 & 1 & 1 & 1 & 1 & 1 & 1 & 1 & 1 & 10 & 0 & 0 \\
\hline $03-24$ & 0 & 0 & 0 & 0 & 0 & 0 & 0 & 0 & 0 & 0 & 0 & 0 & 0 \\
\hline 04-09 & 0 & 0 & 0 & 0 & 0 & 0 & 0 & 0 & 0 & 0 & 0 & 0 & 0 \\
\hline 05-10 & 0 & 0 & 0 & 0 & 0 & 0 & 1 & 0 & 0 & 0 & 1 & 0 & 0 \\
\hline $06-10$ & 2 & 2 & 2 & 2 & 2 & 2 & 2 & 2 & 2 & 2 & 10 & 10 & 0 \\
\hline 07-08 & 2 & 2 & 2 & 2 & 2 & 2 & 2 & 2 & 2 & 2 & 10 & 10 & 0 \\
\hline $08-09$ & 0 & 0 & 0 & 0 & 0 & 0 & 0 & 0 & 0 & 0 & 0 & 0 & 0 \\
\hline 08-10 & 0 & 0 & 0 & 0 & 0 & 0 & 0 & 0 & 0 & 0 & 0 & 0 & 0 \\
\hline 09-11 & 0 & 0 & 0 & 0 & 0 & 0 & 0 & 0 & 0 & 0 & 0 & 0 & 0 \\
\hline 09-12 & 0 & 1 & 0 & 0 & 0 & 0 & 0 & 0 & 0 & 0 & 1 & 0 & 0 \\
\hline 10-11 & 1 & 1 & 1 & 1 & 1 & 1 & 1 & 1 & 1 & 1 & 10 & 0 & 0 \\
\hline 10-12 & 0 & 0 & 0 & 0 & 0 & 0 & 0 & 0 & 0 & 0 & 0 & 0 & 0 \\
\hline 11-13 & 1 & 1 & 1 & 1 & 1 & 1 & 1 & 1 & 1 & 1 & 10 & 0 & 0 \\
\hline 11-14 & 0 & 0 & 0 & 0 & 0 & 0 & 0 & 0 & 0 & 0 & 0 & 0 & 0 \\
\hline $12-13$ & 0 & 0 & 0 & 0 & 0 & 0 & 0 & 0 & 0 & 0 & 0 & 0 & 0 \\
\hline $12-23$ & 0 & 0 & 0 & 0 & 0 & 0 & 0 & 0 & 0 & 0 & 0 & 0 & 0 \\
\hline 13-23 & 0 & 0 & 0 & 0 & 0 & 0 & 0 & 0 & 0 & 0 & 0 & 0 & 0 \\
\hline 14-16 & 1 & 0 & 1 & 0 & 1 & 1 & 0 & 0 & 0 & 0 & 4 & 0 & 0 \\
\hline 15-16 & 1 & 0 & 0 & 0 & 0 & 0 & 0 & 0 & 0 & 0 & 1 & 0 & 0 \\
\hline $15-21$ & 0 & 0 & 0 & 0 & 0 & 0 & 0 & 0 & 0 & 0 & 0 & 0 & 0 \\
\hline 15-24 & 0 & 0 & 0 & 0 & 0 & 0 & 0 & 0 & 0 & 0 & 0 & 0 & 0 \\
\hline $\begin{array}{l}16-17 \\
\end{array}$ & 0 & 0 & 0 & 0 & 0 & 0 & 0 & 0 & 0 & 0 & 0 & 0 & 0 \\
\hline 16-19 & 0 & 0 & 0 & 0 & 0 & 0 & 0 & 0 & 0 & 0 & 0 & 0 & 0 \\
\hline 17-18 & 0 & 0 & 0 & 0 & 0 & 0 & 0 & 0 & 0 & 0 & 0 & 0 & 0 \\
\hline $17-22$ & 0 & 0 & 0 & 0 & 0 & 0 & 0 & 0 & 0 & 0 & 0 & 0 & 0 \\
\hline $18-21$ & 0 & 0 & 0 & 0 & 0 & 0 & 0 & 0 & 0 & 0 & 0 & 0 & 0 \\
\hline 19-20 & 0 & 0 & 0 & 1 & 0 & 0 & 1 & 1 & 0 & 1 & 4 & 0 & 0 \\
\hline $20-23$ & 1 & 1 & 1 & 1 & 1 & 1 & 1 & 1 & 1 & 1 & 10 & 0 & 0 \\
\hline $21-22$ & 0 & 0 & 0 & 0 & 0 & 0 & 0 & 0 & 0 & 0 & 0 & 0 & 0 \\
\hline 01-08 & 0 & 0 & 0 & 0 & 0 & 0 & 0 & 0 & 0 & 1 & 1 & 0 & 0 \\
\hline 02-08 & 0 & 0 & 0 & 0 & 0 & 0 & 0 & 0 & 0 & 0 & 0 & 0 & 0 \\
\hline $06-07$ & 0 & 0 & 0 & 0 & 0 & 0 & 0 & 0 & 0 & 0 & 0 & 0 & 0 \\
\hline 13-14 & 0 & 0 & 0 & 0 & 0 & 0 & 0 & 0 & 1 & 0 & 1 & 0 & 0 \\
\hline $14-23$ & 0 & 0 & 0 & 0 & 0 & 0 & 0 & 0 & 0 & 0 & 0 & 0 & 0 \\
\hline $16-23$ & 0 & 0 & 0 & 0 & 0 & 0 & 0 & 0 & 0 & 0 & 0 & 0 & 0 \\
\hline $19-23$ & 0 & 0 & 0 & 0 & 0 & 0 & 0 & 0 & 0 & 0 & 0 & 0 & 0 \\
\hline Reforços & 13 & 11 & 11 & 11 & 11 & 11 & 14 & 11 & 11 & 13 & \multicolumn{3}{|c|}{ Custo Médio } \\
\hline $\begin{array}{c}\text { Custo } \\
\left(10^{6} \$\right)\end{array}$ & 366 & 335 & 339 & 340 & 339 & 339 & 399 & 340 & 347 & 430 & \multicolumn{3}{|c|}{357,4} \\
\hline InRef & 0 & 1 & 0 & 1 & 0 & 1 & 1 & 1 & 0 & 0 & \multicolumn{3}{|c|}{ GU } \\
\hline InCus & 0 & 50 & 0 & 50 & 0 & 54 & 50 & 50 & 42 & 50 & \multicolumn{3}{|c|}{111,8} \\
\hline InRefA & 2 & 3 & 2 & 3 & 2 & 2 & 5 & 3 & 3 & 4 & & & \\
\hline InCusA & 44 & 94 & 44 & 125 & 44 & 76 & 108 & 125 & 110 & 134 & & & \\
\hline
\end{tabular}


Tabela A.8 - Tabela Decisão da Iteração 6 - Alternativa 3.

\begin{tabular}{|c|c|c|c|c|c|c|c|c|c|c|c|c|c|}
\hline \multirow{2}{*}{ Ramo } & \multicolumn{10}{|c|}{ Plano Para Cada Cenário } & \multicolumn{3}{|c|}{ Graus de Incidência } \\
\hline & 1 & 2 & 3 & 4 & 5 & 6 & 7 & 8 & 9 & 10 & GI1 & GI2 & GI3 \\
\hline 01-02 & 1 & 0 & 0 & 0 & 0 & 0 & 1 & 0 & 0 & 0 & 2 & 0 & 0 \\
\hline $01-03$ & 0 & 0 & 0 & 0 & 0 & 0 & 0 & 0 & 0 & 1 & 1 & 0 & 0 \\
\hline $01-05$ & 2 & 2 & 2 & 2 & 2 & 2 & 2 & 2 & 2 & 2 & 10 & 10 & 0 \\
\hline $02-04$ & 0 & 0 & 0 & 0 & 0 & 0 & 1 & 0 & 0 & 0 & 1 & 0 & 0 \\
\hline $02-06$ & 0 & 0 & 0 & 0 & 0 & 0 & 0 & 0 & 0 & 0 & 0 & 0 & 0 \\
\hline 03-09 & 1 & 1 & 1 & 1 & 1 & 1 & 1 & 1 & 1 & 1 & 10 & 0 & 0 \\
\hline $03-24$ & 0 & 0 & 0 & 0 & 0 & 0 & 0 & 0 & 0 & 0 & 0 & 0 & 0 \\
\hline $04-09$ & 0 & 0 & 0 & 0 & 0 & 0 & 0 & 0 & 0 & 0 & 0 & 0 & 0 \\
\hline $05-10$ & 0 & 0 & 0 & 0 & 0 & 0 & 1 & 0 & 0 & 0 & 1 & 0 & 0 \\
\hline $06-10$ & 2 & 2 & 2 & 2 & 2 & 2 & 2 & 2 & 2 & 2 & 10 & 10 & 0 \\
\hline 07-08 & 2 & 2 & 2 & 2 & 2 & 2 & 2 & 2 & 2 & 2 & 10 & 10 & 0 \\
\hline $08-09$ & 0 & 0 & 0 & 0 & 0 & 0 & 0 & 0 & 0 & 0 & 0 & 0 & 0 \\
\hline 08-10 & 0 & 0 & 0 & 0 & 0 & 0 & 0 & 0 & 0 & 0 & 0 & 0 & 0 \\
\hline 09-11 & 1 & 0 & 1 & 0 & 0 & 0 & 0 & 0 & 0 & 0 & 2 & 0 & 0 \\
\hline 09-12 & 0 & 0 & 0 & 0 & 0 & 0 & 0 & 0 & 0 & 0 & 0 & 0 & 0 \\
\hline 10-11 & 0 & 0 & 0 & 0 & 0 & 0 & 0 & 0 & 0 & 0 & 0 & 0 & 0 \\
\hline $10-12$ & 1 & 1 & 1 & 1 & 1 & 1 & 1 & 1 & 1 & 1 & 10 & 0 & 0 \\
\hline 11-13 & 1 & 1 & 1 & 1 & 1 & 1 & 1 & 1 & 1 & 1 & 10 & 0 & 0 \\
\hline 11-14 & 0 & 0 & 0 & 0 & 0 & 0 & 0 & 0 & 0 & 0 & 0 & 0 & 0 \\
\hline $12-13$ & 0 & 0 & 0 & 0 & 0 & 0 & 0 & 0 & 0 & 0 & 0 & 0 & 0 \\
\hline $12-23$ & 0 & 0 & 0 & 0 & 0 & 0 & 0 & 0 & 0 & 0 & 0 & 0 & 0 \\
\hline $13-23$ & 0 & 0 & 0 & 0 & 0 & 0 & 0 & 0 & 0 & 0 & 0 & 0 & 0 \\
\hline 14-16 & 1 & 0 & 1 & 0 & 0 & 0 & 0 & 0 & 0 & 0 & 2 & 0 & 0 \\
\hline 15-16 & 1 & 0 & 0 & 0 & 0 & 0 & 0 & 0 & 0 & 0 & 1 & 0 & 0 \\
\hline $15-21$ & 0 & 0 & 0 & 0 & 0 & 0 & 0 & 0 & 0 & 0 & 0 & 0 & 0 \\
\hline 15-24 & 0 & 0 & 0 & 0 & 0 & 0 & 0 & 0 & 0 & 0 & 0 & 0 & 0 \\
\hline $\begin{array}{l}16-17 \\
\end{array}$ & 0 & 0 & 0 & 0 & 0 & 0 & 0 & 0 & 0 & 0 & 0 & 0 & 0 \\
\hline 16-19 & 0 & 0 & 0 & 0 & 0 & 0 & 0 & 0 & 0 & 0 & 0 & 0 & 0 \\
\hline 17-18 & 0 & 0 & 0 & 0 & 0 & 0 & 0 & 0 & 1 & 0 & 1 & 0 & 0 \\
\hline $17-22$ & 0 & 0 & 0 & 0 & 0 & 0 & 0 & 0 & 0 & 0 & 0 & 0 & 0 \\
\hline $18-21$ & 0 & 0 & 0 & 0 & 0 & 0 & 0 & 0 & 0 & 0 & 0 & 0 & 0 \\
\hline 19-20 & 0 & 0 & 0 & 1 & 0 & 0 & 1 & 1 & 0 & 1 & 4 & 0 & 0 \\
\hline $20-23$ & 1 & 1 & 1 & 1 & 1 & 1 & 1 & 1 & 1 & 1 & 10 & 0 & 0 \\
\hline $21-22$ & 0 & 0 & 0 & 0 & 0 & 0 & 0 & 0 & 0 & 0 & 0 & 0 & 0 \\
\hline 01-08 & 0 & 0 & 0 & 0 & 0 & 0 & 0 & 0 & 0 & 1 & 1 & 0 & 0 \\
\hline 02-08 & 0 & 0 & 0 & 0 & 0 & 0 & 0 & 0 & 0 & 0 & 0 & 0 & 0 \\
\hline $06-07$ & 0 & 0 & 0 & 0 & 0 & 0 & 0 & 0 & 0 & 0 & 0 & 0 & 0 \\
\hline 13-14 & 0 & 0 & 0 & 0 & 1 & 0 & 0 & 0 & 0 & 0 & 1 & 0 & 0 \\
\hline $14-23$ & 0 & 0 & 0 & 0 & 0 & 0 & 0 & 0 & 0 & 0 & 0 & 0 & 0 \\
\hline 16-23 & 0 & 0 & 0 & 0 & 0 & 0 & 0 & 0 & 0 & 0 & 0 & 0 & 0 \\
\hline $19-23$ & 0 & 0 & 0 & 0 & 0 & 0 & 0 & 0 & 0 & 0 & 0 & 0 & 0 \\
\hline Reforços & 14 & 10 & 12 & 11 & 11 & 10 & 14 & 11 & 11 & 13 & \multicolumn{3}{|c|}{ Custo Médio } \\
\hline $\begin{array}{c}\text { Custo } \\
\left(10^{6} \$\right)\end{array}$ & 416 & 285 & 389 & 340 & 347 & 285 & 399 & 340 & 305 & 430 & \multicolumn{3}{|c|}{353,6} \\
\hline InRef & 1 & 0 & 1 & 1 & 0 & 0 & 1 & 1 & 0 & 0 & \multicolumn{3}{|c|}{ GU } \\
\hline InCus & 50 & 0 & 50 & 50 & 8 & 0 & 50 & 50 & 0 & 50 & \multicolumn{3}{|c|}{111,4} \\
\hline
\end{tabular}

\begin{tabular}{|c|c|c|c|c|c|c|c|c|c|c|}
\hline InRefA & 3 & 2 & 3 & 3 & 2 & 1 & 5 & 3 & 3 & 4 \\
\hline
\end{tabular}

\begin{tabular}{|l|l|l|l|l|l|l|r|r|r|r|}
\hline InCusA & 94 & 44 & 94 & 125 & 52 & 22 & 108 & 125 & 68 & 134 \\
\hline
\end{tabular} 
Tabela A.9 - Tabela Decisão da Iteração 6 - Alternativa 4.

\begin{tabular}{|c|c|c|c|c|c|c|c|c|c|c|c|c|c|}
\hline \multirow{2}{*}{ Ramo } & \multicolumn{10}{|c|}{ Plano Para Cada Cenário } & \multicolumn{3}{|c|}{ Graus de Incidência } \\
\hline & 1 & 2 & 3 & 4 & 5 & 6 & 7 & 8 & 9 & 10 & GI1 & GI2 & GI3 \\
\hline 01-02 & 1 & 0 & 0 & 0 & 0 & 0 & 1 & 0 & 0 & 1 & 3 & 0 & 0 \\
\hline $01-03$ & 0 & 0 & 0 & 0 & 0 & 0 & 0 & 0 & 0 & 0 & 0 & 0 & 0 \\
\hline $01-05$ & 2 & 2 & 2 & 2 & 2 & 2 & 2 & 2 & 2 & 2 & 10 & 10 & 0 \\
\hline $02-04$ & 0 & 0 & 0 & 0 & 0 & 0 & 1 & 0 & 0 & 1 & 2 & 0 & 0 \\
\hline $02-06$ & 0 & 0 & 0 & 0 & 0 & 0 & 0 & 0 & 0 & 0 & 0 & 0 & 0 \\
\hline 03-09 & 1 & 1 & 1 & 1 & 1 & 1 & 1 & 1 & 1 & 1 & 10 & 0 & 0 \\
\hline $03-24$ & 0 & 0 & 0 & 0 & 0 & 0 & 0 & 0 & 0 & 0 & 0 & 0 & 0 \\
\hline 04-09 & 0 & 0 & 0 & 0 & 0 & 0 & 0 & 0 & 0 & 0 & 0 & 0 & 0 \\
\hline 05-10 & 0 & 0 & 0 & 0 & 0 & 0 & 1 & 0 & 0 & 1 & 2 & 0 & 0 \\
\hline $06-10$ & 2 & 2 & 2 & 2 & 2 & 2 & 2 & 2 & 2 & 2 & 10 & 10 & 0 \\
\hline 07-08 & 2 & 2 & 2 & 2 & 2 & 2 & 2 & 2 & 2 & 2 & 10 & 10 & 0 \\
\hline $08-09$ & 0 & 0 & 0 & 0 & 0 & 0 & 0 & 0 & 0 & 0 & 0 & 0 & 0 \\
\hline 08-10 & 0 & 0 & 0 & 0 & 0 & 0 & 0 & 0 & 0 & 0 & 0 & 0 & 0 \\
\hline 09-11 & 0 & 0 & 0 & 0 & 0 & 0 & 0 & 0 & 0 & 0 & 0 & 0 & 0 \\
\hline 09-12 & 0 & 0 & 0 & 0 & 0 & 0 & 0 & 0 & 1 & 0 & 1 & 0 & 0 \\
\hline 10-11 & 1 & 0 & 1 & 0 & 1 & 0 & 0 & 0 & 0 & 0 & 3 & 0 & 0 \\
\hline 10-12 & 0 & 1 & 0 & 0 & 0 & 1 & 0 & 0 & 1 & 0 & 3 & 0 & 0 \\
\hline 11-13 & 1 & 1 & 1 & 1 & 1 & 1 & 1 & 1 & 1 & 1 & 10 & 0 & 0 \\
\hline 11-14 & 0 & 0 & 0 & 0 & 0 & 0 & 0 & 0 & 0 & 0 & 0 & 0 & 0 \\
\hline $12-13$ & 0 & 0 & 0 & 0 & 0 & 0 & 0 & 0 & 0 & 0 & 0 & 0 & 0 \\
\hline $12-23$ & 0 & 0 & 0 & 0 & 0 & 0 & 0 & 0 & 0 & 0 & 0 & 0 & 0 \\
\hline 13-23 & 0 & 0 & 0 & 0 & 0 & 0 & 0 & 0 & 0 & 0 & 0 & 0 & 0 \\
\hline 14-16 & 1 & 1 & 1 & 1 & 1 & 1 & 1 & 1 & 1 & 1 & 10 & 0 & 0 \\
\hline 15-16 & 1 & 0 & 0 & 0 & 0 & 0 & 0 & 0 & 0 & 0 & 1 & 0 & 0 \\
\hline $15-21$ & 0 & 0 & 0 & 0 & 0 & 0 & 0 & 0 & 0 & 0 & 0 & 0 & 0 \\
\hline 15-24 & 0 & 0 & 0 & 0 & 0 & 0 & 0 & 0 & 0 & 0 & 0 & 0 & 0 \\
\hline $\begin{array}{l}16-17 \\
\end{array}$ & 0 & 0 & 0 & 0 & 0 & 0 & 0 & 0 & 0 & 0 & 0 & 0 & 0 \\
\hline 16-19 & 0 & 0 & 0 & 0 & 0 & 0 & 0 & 0 & 0 & 0 & 0 & 0 & 0 \\
\hline 17-18 & 0 & 0 & 0 & 0 & 0 & 0 & 0 & 0 & 1 & 0 & 1 & 0 & 0 \\
\hline $17-22$ & 0 & 0 & 0 & 0 & 0 & 0 & 0 & 0 & 0 & 0 & 0 & 0 & 0 \\
\hline $18-21$ & 0 & 0 & 0 & 0 & 0 & 0 & 0 & 0 & 0 & 0 & 0 & 0 & 0 \\
\hline 19-20 & 0 & 0 & 0 & 1 & 0 & 0 & 1 & 1 & 0 & 0 & 3 & 0 & 0 \\
\hline $20-23$ & 1 & 1 & 1 & 1 & 1 & 1 & 1 & 1 & 1 & 1 & 10 & 0 & 0 \\
\hline $21-22$ & 0 & 0 & 0 & 0 & 0 & 0 & 0 & 0 & 0 & 0 & 0 & 0 & 0 \\
\hline 01-08 & 0 & 0 & 0 & 0 & 0 & 0 & 0 & 0 & 0 & 0 & 0 & 0 & 0 \\
\hline 02-08 & 0 & 0 & 0 & 0 & 0 & 0 & 0 & 0 & 0 & 0 & 0 & 0 & 0 \\
\hline $06-07$ & 0 & 0 & 0 & 0 & 0 & 0 & 0 & 0 & 0 & 0 & 0 & 0 & 0 \\
\hline 13-14 & 0 & 0 & 0 & 0 & 0 & 0 & 0 & 0 & 0 & 0 & 0 & 0 & 0 \\
\hline $14-23$ & 0 & 0 & 0 & 0 & 0 & 0 & 0 & 0 & 0 & 1 & 1 & 0 & 0 \\
\hline $16-23$ & 0 & 0 & 0 & 0 & 0 & 0 & 0 & 0 & 0 & 0 & 0 & 0 & 0 \\
\hline $19-23$ & 0 & 0 & 0 & 0 & 0 & 0 & 0 & 0 & 0 & 0 & 0 & 0 & 0 \\
\hline Reforços & 13 & 11 & 11 & 11 & 11 & 11 & 14 & 11 & 13 & 14 & \multicolumn{3}{|c|}{ Custo Médio } \\
\hline $\begin{array}{c}\text { Custo } \\
\left(10^{6} \$\right)\end{array}$ & 366 & 339 & 339 & 344 & 339 & 339 & 403 & 344 & 409 & 434 & \multicolumn{3}{|c|}{365,6} \\
\hline InRef & 0 & 1 & 0 & 1 & 0 & 1 & 1 & 1 & 2 & 1 & \multicolumn{3}{|c|}{ GU } \\
\hline InCus & 0 & 54 & 0 & 54 & 0 & 54 & 54 & 54 & 104 & 54 & \multicolumn{3}{|c|}{113} \\
\hline InRefA & 2 & 3 & 2 & 3 & 2 & 2 & 5 & 3 & 5 & 5 & & & \\
\hline InCusA & 44 & 98 & 44 & 129 & 44 & 76 & 112 & 129 & 172 & 138 & & & \\
\hline
\end{tabular}


Tabela A.10 - Tabela Decisão da Iteração 6 - Alternativa 5.

\begin{tabular}{|c|c|c|c|c|c|c|c|c|c|c|c|c|c|}
\hline \multirow{2}{*}{ Ramo } & \multicolumn{10}{|c|}{ Plano Para Cada Cenário } & \multicolumn{3}{|c|}{ Graus de Incidência } \\
\hline & 1 & 2 & 3 & 4 & 5 & 6 & 7 & 8 & 9 & 10 & GI1 & GI2 & GI3 \\
\hline $01-02$ & 1 & 0 & 0 & 0 & 0 & 0 & 1 & 0 & 0 & 0 & 2 & 0 & 0 \\
\hline $01-03$ & 0 & 0 & 0 & 0 & 0 & 0 & 0 & 0 & 0 & 1 & 1 & 0 & 0 \\
\hline $01-05$ & 2 & 2 & 2 & 2 & 2 & 2 & 2 & 2 & 2 & 3 & 10 & 10 & 1 \\
\hline $02-04$ & 0 & 0 & 0 & 0 & 0 & 0 & 1 & 0 & 0 & 0 & 1 & 0 & 0 \\
\hline $02-06$ & 0 & 0 & 0 & 0 & 0 & 0 & 0 & 0 & 0 & 0 & 0 & 0 & 0 \\
\hline $03-09$ & 1 & 1 & 1 & 1 & 1 & 1 & 1 & 1 & 1 & 1 & 10 & 0 & 0 \\
\hline $03-24$ & 0 & 0 & 0 & 0 & 0 & 0 & 0 & 0 & 0 & 0 & 0 & 0 & 0 \\
\hline $04-09$ & 0 & 0 & 0 & 0 & 0 & 0 & 0 & 0 & 0 & 0 & 0 & 0 & 0 \\
\hline $05-10$ & 0 & 0 & 0 & 0 & 0 & 0 & 1 & 0 & 0 & 1 & 2 & 0 & 0 \\
\hline 06-10 & 2 & 2 & 2 & 2 & 2 & 2 & 2 & 2 & 2 & 2 & 10 & 10 & 0 \\
\hline $\begin{array}{l}07-08 \\
\end{array}$ & 2 & 2 & 2 & 2 & 2 & 2 & 2 & 2 & 2 & 2 & 10 & 10 & 0 \\
\hline $\begin{array}{l}08-09 \\
\end{array}$ & 0 & 0 & 0 & 0 & 0 & 0 & 0 & 0 & 0 & 0 & 0 & 0 & 0 \\
\hline 08-10 & 0 & 0 & 0 & 0 & 0 & 0 & 0 & 0 & 0 & 0 & 0 & 0 & 0 \\
\hline 09-11 & 0 & 0 & 0 & 0 & 0 & 0 & 0 & 0 & 0 & 0 & 0 & 0 & 0 \\
\hline 09-12 & 0 & 0 & 0 & 0 & 0 & 0 & 0 & 0 & 0 & 0 & 0 & 0 & 0 \\
\hline $10-11$ & 1 & 0 & 1 & 0 & 1 & 0 & 0 & 0 & 0 & 0 & 3 & 0 & 0 \\
\hline $10-12$ & 0 & 1 & 0 & 0 & 0 & 1 & 0 & 0 & 1 & 0 & 3 & 0 & 0 \\
\hline $11-13$ & 1 & 1 & 1 & 1 & 1 & 1 & 1 & 1 & 1 & 1 & 10 & 0 & 0 \\
\hline $11-14$ & 0 & 0 & 0 & 0 & 0 & 0 & 0 & 0 & 0 & 0 & 0 & 0 & 0 \\
\hline $12-13$ & 0 & 0 & 0 & 0 & 0 & 0 & 0 & 0 & 0 & 0 & 0 & 0 & 0 \\
\hline $12-23$ & 0 & 0 & 0 & 0 & 0 & 0 & 0 & 0 & 0 & 0 & 0 & 0 & 0 \\
\hline $13-23$ & 0 & 0 & 0 & 0 & 0 & 0 & 0 & 0 & 0 & 0 & 0 & 0 & 0 \\
\hline $14-16$ & 1 & 0 & 1 & 0 & 1 & 1 & 0 & 0 & 0 & 0 & 4 & 0 & 0 \\
\hline $15-16$ & 0 & 0 & 0 & 0 & 0 & 0 & 0 & 0 & 0 & 0 & 0 & 0 & 0 \\
\hline $15-21$ & 0 & 0 & 0 & 0 & 0 & 0 & 0 & 0 & 0 & 0 & 0 & 0 & 0 \\
\hline $15-24$ & 0 & 0 & 0 & 0 & 0 & 0 & 0 & 0 & 0 & 0 & 0 & 0 & 0 \\
\hline $16-17$ & 0 & 0 & 0 & 0 & 0 & 0 & 0 & 0 & 0 & 0 & 0 & 0 & 0 \\
\hline $\begin{array}{l}16-19 \\
\end{array}$ & 0 & 0 & 0 & 0 & 0 & 0 & 0 & 0 & 0 & 0 & 0 & 0 & 0 \\
\hline $17-18$ & 1 & 0 & 0 & 0 & 0 & 0 & 0 & 0 & 1 & 0 & 2 & 0 & 0 \\
\hline $17-22$ & 0 & 0 & 0 & 0 & 0 & 0 & 0 & 0 & 0 & 0 & 0 & 0 & 0 \\
\hline $18-21$ & 0 & 0 & 0 & 0 & 0 & 0 & 0 & 0 & 0 & 0 & 0 & 0 & 0 \\
\hline $19-20$ & 1 & 1 & 1 & 1 & 1 & 1 & 1 & 1 & 1 & 1 & 10 & 0 & 0 \\
\hline $20-23$ & 1 & 1 & 1 & 1 & 1 & 1 & 1 & 1 & 1 & 1 & 10 & 0 & 0 \\
\hline $21-22$ & 0 & 0 & 0 & 0 & 0 & 0 & 0 & 0 & 0 & 0 & 0 & 0 & 0 \\
\hline 01-08 & 0 & 0 & 0 & 0 & 0 & 0 & 0 & 0 & 0 & 0 & 0 & 0 & 0 \\
\hline $02-08$ & 0 & 0 & 0 & 0 & 0 & 0 & 0 & 0 & 0 & 0 & 0 & 0 & 0 \\
\hline $06-07$ & 0 & 0 & 0 & 0 & 0 & 0 & 0 & 0 & 0 & 0 & 0 & 0 & 0 \\
\hline $13-14$ & 0 & 0 & 0 & 0 & 0 & 0 & 0 & 0 & 0 & 0 & 0 & 0 & 0 \\
\hline $14-23$ & 0 & 0 & 0 & 0 & 0 & 0 & 0 & 0 & 0 & 0 & 0 & 0 & 0 \\
\hline $16-23$ & 0 & 0 & 0 & 0 & 0 & 0 & 0 & 0 & 0 & 0 & 0 & 0 & 0 \\
\hline $19-23$ & 0 & 0 & 0 & 0 & 0 & 0 & 0 & 0 & 0 & 0 & 0 & 0 & 0 \\
\hline Reforços & 14 & 11 & 12 & 10 & 12 & 12 & 13 & 10 & 12 & 13 & \multicolumn{3}{|c|}{ Custo Médio } \\
\hline $\begin{array}{c}\text { Custo } \\
\left(10^{6} \$\right)\end{array}$ & 417 & 340 & 394 & 290 & 394 & 394 & 349 & 290 & 360 & 390 & \multicolumn{3}{|c|}{361,8} \\
\hline InRef & 1 & 1 & 1 & 0 & 1 & 2 & 0 & 0 & 1 & 0 & \multicolumn{3}{|c|}{ GU } \\
\hline InCus & 51 & 55 & 55 & 0 & 55 & 109 & 0 & 0 & 55 & 10 & \multicolumn{3}{|c|}{113,4} \\
\hline InRefA & 3 & 3 & 3 & 2 & 3 & 3 & 4 & 2 & 4 & 4 & & & \\
\hline InCusA & 95 & 99 & 99 & 75 & 99 & 131 & 58 & 75 & 123 & 94 & & & \\
\hline
\end{tabular}


Apêndice

Tabela A.11 - Reforços consolidados até a Tabela Decisão da Iteração 6.

\begin{tabular}{|c|c|c|}
\hline Ramo Candidato & Quantidade de Reforços & \multirow{2}{*}{ Tabela Decisão } \\
\cline { 1 - 2 } $03-09$ & 1 & \multirow{2}{*}{ Inicial } \\
\hline $06-10$ & 1 & \\
\hline $20-23$ & 1 & Iteração 1 \\
\hline $07-08$ & 2 & Iteração 2 \\
\hline $06-10$ & 2 & Iteração 3 \\
\hline $01-05$ & 1 & Iteração 4 \\
\hline $11-13$ & 1 & Iteração 5 \\
\hline $01-05$ & 2 & Iteração 6 \\
\hline $01-02$ & 1 &
\end{tabular}


Tabela A.12 - Tabela Decisão da Iteração 7 - Alternativa 1.

\begin{tabular}{|c|c|c|c|c|c|c|c|c|c|c|c|c|c|}
\hline \multirow{2}{*}{ Ramo } & \multicolumn{10}{|c|}{ Plano Para Cada Cenário } & \multicolumn{3}{|c|}{ Graus de Incidência } \\
\hline & 1 & 2 & 3 & 4 & 5 & 6 & 7 & 8 & 9 & 10 & GI1 & GI2 & GI3 \\
\hline 01-02 & 1 & 1 & 1 & 1 & 1 & 1 & 1 & 1 & 1 & 1 & 10 & 0 & 0 \\
\hline $01-03$ & 0 & 0 & 0 & 0 & 0 & 0 & 0 & 0 & 0 & 1 & 1 & 0 & 0 \\
\hline $01-05$ & 2 & 2 & 2 & 2 & 2 & 2 & 2 & 2 & 2 & 2 & 10 & 10 & 0 \\
\hline $02-04$ & 0 & 0 & 0 & 0 & 0 & 0 & 1 & 0 & 0 & 0 & 1 & 0 & 0 \\
\hline $02-06$ & 0 & 0 & 0 & 0 & 0 & 0 & 0 & 0 & 0 & 0 & 0 & 0 & 0 \\
\hline 03-09 & 1 & 1 & 1 & 1 & 1 & 1 & 1 & 1 & 1 & 1 & 10 & 0 & 0 \\
\hline $03-24$ & 0 & 0 & 0 & 0 & 0 & 0 & 0 & 0 & 0 & 0 & 0 & 0 & 0 \\
\hline 04-09 & 0 & 0 & 0 & 0 & 0 & 0 & 0 & 0 & 0 & 0 & 0 & 0 & 0 \\
\hline 05-10 & 0 & 0 & 0 & 0 & 0 & 0 & 1 & 0 & 0 & 0 & 1 & 0 & 0 \\
\hline $06-10$ & 2 & 2 & 2 & 2 & 2 & 2 & 2 & 2 & 2 & 2 & 10 & 10 & 0 \\
\hline 07-08 & 2 & 2 & 2 & 2 & 2 & 2 & 2 & 2 & 2 & 2 & 10 & 10 & 0 \\
\hline $08-09$ & 0 & 0 & 0 & 0 & 0 & 0 & 0 & 0 & 0 & 0 & 0 & 0 & 0 \\
\hline 08-10 & 0 & 0 & 0 & 0 & 0 & 0 & 0 & 0 & 0 & 0 & 0 & 0 & 0 \\
\hline 09-11 & 0 & 0 & 0 & 0 & 0 & 0 & 0 & 0 & 0 & 0 & 0 & 0 & 0 \\
\hline 09-12 & 0 & 1 & 0 & 0 & 0 & 0 & 0 & 0 & 0 & 0 & 1 & 0 & 0 \\
\hline 10-11 & 1 & 1 & 1 & 1 & 1 & 1 & 1 & 1 & 1 & 1 & 10 & 0 & 0 \\
\hline 10-12 & 0 & 0 & 0 & 0 & 0 & 0 & 0 & 0 & 0 & 0 & 0 & 0 & 0 \\
\hline 11-13 & 1 & 1 & 1 & 1 & 1 & 1 & 1 & 1 & 1 & 1 & 10 & 0 & 0 \\
\hline 11-14 & 0 & 0 & 0 & 0 & 0 & 0 & 0 & 0 & 0 & 0 & 0 & 0 & 0 \\
\hline $12-13$ & 0 & 0 & 0 & 0 & 0 & 0 & 0 & 0 & 0 & 0 & 0 & 0 & 0 \\
\hline $12-23$ & 0 & 0 & 0 & 0 & 0 & 0 & 0 & 0 & 0 & 0 & 0 & 0 & 0 \\
\hline 13-23 & 0 & 0 & 0 & 0 & 0 & 0 & 0 & 0 & 0 & 0 & 0 & 0 & 0 \\
\hline 14-16 & 1 & 0 & 1 & 0 & 1 & 1 & 0 & 0 & 0 & 0 & 4 & 0 & 0 \\
\hline 15-16 & 1 & 0 & 0 & 0 & 0 & 0 & 0 & 0 & 0 & 0 & 1 & 0 & 0 \\
\hline $15-21$ & 0 & 0 & 0 & 0 & 0 & 0 & 0 & 0 & 0 & 0 & 0 & 0 & 0 \\
\hline 15-24 & 0 & 0 & 0 & 0 & 0 & 0 & 0 & 0 & 0 & 0 & 0 & 0 & 0 \\
\hline $\begin{array}{l}16-17 \\
\end{array}$ & 0 & 0 & 0 & 0 & 0 & 0 & 0 & 0 & 0 & 0 & 0 & 0 & 0 \\
\hline 16-19 & 0 & 0 & 0 & 0 & 0 & 0 & 0 & 0 & 0 & 0 & 0 & 0 & 0 \\
\hline 17-18 & 0 & 0 & 0 & 0 & 0 & 0 & 0 & 0 & 0 & 0 & 0 & 0 & 0 \\
\hline $17-22$ & 0 & 0 & 0 & 0 & 0 & 0 & 0 & 0 & 0 & 0 & 0 & 0 & 0 \\
\hline $18-21$ & 0 & 0 & 0 & 0 & 0 & 0 & 0 & 0 & 0 & 0 & 0 & 0 & 0 \\
\hline 19-20 & 0 & 0 & 0 & 1 & 0 & 0 & 1 & 1 & 0 & 1 & 4 & 0 & 0 \\
\hline $20-23$ & 1 & 1 & 1 & 1 & 1 & 1 & 1 & 1 & 1 & 1 & 10 & 0 & 0 \\
\hline $21-22$ & 0 & 0 & 0 & 0 & 0 & 0 & 0 & 0 & 0 & 0 & 0 & 0 & 0 \\
\hline 01-08 & 0 & 0 & 0 & 0 & 0 & 0 & 0 & 0 & 0 & 0 & 0 & 0 & 0 \\
\hline 02-08 & 0 & 0 & 0 & 0 & 0 & 0 & 0 & 0 & 0 & 1 & 1 & 0 & 0 \\
\hline $06-07$ & 0 & 0 & 0 & 0 & 0 & 0 & 0 & 0 & 0 & 0 & 0 & 0 & 0 \\
\hline 13-14 & 0 & 0 & 0 & 0 & 0 & 0 & 0 & 0 & 1 & 0 & 1 & 0 & 0 \\
\hline $14-23$ & 0 & 0 & 0 & 0 & 0 & 0 & 0 & 0 & 0 & 0 & 0 & 0 & 0 \\
\hline $16-23$ & 0 & 0 & 0 & 0 & 0 & 0 & 0 & 0 & 0 & 0 & 0 & 0 & 0 \\
\hline $19-23$ & 0 & 0 & 0 & 0 & 0 & 0 & 0 & 0 & 0 & 0 & 0 & 0 & 0 \\
\hline Reforços & 13 & 12 & 12 & 12 & 12 & 12 & 14 & 12 & 12 & 14 & \multicolumn{3}{|c|}{ Custo Médio } \\
\hline $\begin{array}{c}\text { Custo } \\
\left(10^{6} \$\right)\end{array}$ & 366 & 338 & 342 & 343 & 342 & 342 & 399 & 343 & 350 & 431 & \multicolumn{3}{|c|}{359,6} \\
\hline InRef & 0 & 1 & 0 & 1 & 0 & 1 & 1 & 1 & 0 & 1 & \multicolumn{3}{|c|}{ GU } \\
\hline InCus & 0 & 50 & 0 & 50 & 0 & 54 & 50 & 50 & 42 & 51 & \multicolumn{3}{|c|}{112,8} \\
\hline InRefA & 2 & 4 & 3 & 4 & 3 & 3 & 5 & 4 & 4 & 5 & & & \\
\hline InCusA & 44 & 97 & 47 & 128 & 47 & 79 & 108 & 128 & 113 & 135 & & & \\
\hline
\end{tabular}


Tabela A.13 - Tabela Decisão da Iteração 7 - Alternativa 2.

\begin{tabular}{|c|c|c|c|c|c|c|c|c|c|c|c|c|c|}
\hline \multirow{2}{*}{ Ramo } & \multicolumn{10}{|c|}{ Plano Para Cada Cenário } & \multicolumn{3}{|c|}{ Graus de Incidência } \\
\hline & 1 & 2 & 3 & 4 & 5 & 6 & 7 & 8 & 9 & 10 & GI1 & GI2 & GI3 \\
\hline $01-02$ & 1 & 1 & 1 & 1 & 1 & 1 & 1 & 1 & 1 & 1 & 10 & 0 & 0 \\
\hline $01-03$ & 0 & 0 & 0 & 0 & 0 & 0 & 0 & 0 & 0 & 1 & 1 & 0 & 0 \\
\hline 01-05 & 2 & 2 & 2 & 2 & 2 & 2 & 2 & 2 & 2 & 2 & 10 & 10 & 0 \\
\hline $02-04$ & 0 & 0 & 0 & 0 & 0 & 0 & 1 & 0 & 0 & 0 & 1 & 0 & 0 \\
\hline $02-06$ & 0 & 0 & 0 & 0 & 0 & 0 & 0 & 0 & 0 & 0 & 0 & 0 & 0 \\
\hline 03-09 & 1 & 1 & 1 & 1 & 1 & 1 & 1 & 1 & 1 & 1 & 10 & 0 & 0 \\
\hline $03-24$ & 0 & 0 & 0 & 0 & 0 & 0 & 0 & 0 & 0 & 0 & 0 & 0 & 0 \\
\hline $04-09$ & 0 & 0 & 0 & 0 & 0 & 0 & 0 & 0 & 0 & 0 & 0 & 0 & 0 \\
\hline $05-10$ & 0 & 0 & 0 & 0 & 0 & 0 & 1 & 0 & 0 & 0 & 1 & 0 & 0 \\
\hline 06-10 & 2 & 2 & 2 & 2 & 2 & 2 & 2 & 2 & 2 & 2 & 10 & 10 & 0 \\
\hline $07-08$ & 2 & 2 & 2 & 2 & 2 & 2 & 2 & 2 & 2 & 2 & 10 & 10 & 0 \\
\hline $08-09$ & 0 & 0 & 0 & 0 & 0 & 0 & 0 & 0 & 0 & 0 & 0 & 0 & 0 \\
\hline 08-10 & 0 & 0 & 0 & 0 & 0 & 0 & 0 & 0 & 0 & 0 & 0 & 0 & 0 \\
\hline $09-11$ & 0 & 0 & 1 & 0 & 0 & 0 & 0 & 0 & 0 & 0 & 1 & 0 & 0 \\
\hline $09-12$ & 0 & 0 & 0 & 0 & 0 & 0 & 0 & 0 & 0 & 0 & 0 & 0 & 0 \\
\hline $10-11$ & 1 & 0 & 0 & 0 & 0 & 0 & 0 & 0 & 0 & 0 & 1 & 0 & 0 \\
\hline $10-12$ & 1 & 1 & 1 & 1 & 1 & 1 & 1 & 1 & 1 & 1 & 10 & 0 & 0 \\
\hline $11-13$ & 1 & 1 & 1 & 1 & 1 & 1 & 1 & 1 & 1 & 1 & 10 & 0 & 0 \\
\hline $11-14$ & 0 & 0 & 0 & 0 & 0 & 0 & 0 & 0 & 0 & 0 & 0 & 0 & 0 \\
\hline $12-13$ & 0 & 0 & 0 & 0 & 0 & 0 & 0 & 0 & 0 & 0 & 0 & 0 & 0 \\
\hline $12-23$ & 0 & 0 & 0 & 0 & 0 & 0 & 0 & 0 & 0 & 0 & 0 & 0 & 0 \\
\hline $13-23$ & 0 & 0 & 0 & 0 & 0 & 0 & 0 & 0 & 0 & 0 & 0 & 0 & 0 \\
\hline $14-16$ & 1 & 0 & 1 & 0 & 0 & 0 & 0 & 0 & 0 & 0 & 2 & 0 & 0 \\
\hline $15-16$ & 1 & 0 & 0 & 0 & 0 & 0 & 0 & 0 & 0 & 0 & 1 & 0 & 0 \\
\hline $15-21$ & 0 & 0 & 0 & 0 & 0 & 0 & 0 & 0 & 0 & 0 & 0 & 0 & 0 \\
\hline $15-24$ & 0 & 0 & 0 & 0 & 0 & 0 & 0 & 0 & 0 & 0 & 0 & 0 & 0 \\
\hline $16-17$ & 0 & 0 & 0 & 0 & 0 & 0 & 0 & 0 & 0 & 0 & 0 & 0 & 0 \\
\hline $16-19$ & 0 & 0 & 0 & 0 & 0 & 0 & 0 & 0 & 0 & 0 & 0 & 0 & 0 \\
\hline $\begin{array}{ll}17-18 \\
\end{array}$ & 0 & 0 & 0 & 0 & 0 & 0 & 0 & 0 & 1 & 0 & 1 & 0 & 0 \\
\hline $17-22$ & 0 & 0 & 0 & 0 & 0 & 0 & 0 & 0 & 0 & 0 & 0 & 0 & 0 \\
\hline $18-21$ & 0 & 0 & 0 & 0 & 0 & 0 & 0 & 0 & 0 & 0 & 0 & 0 & 0 \\
\hline $19-20$ & 0 & 0 & 0 & 1 & 0 & 0 & 1 & 1 & 0 & 1 & 4 & 0 & 0 \\
\hline $20-23$ & 1 & 1 & 1 & 1 & 1 & 1 & 1 & 1 & 1 & 1 & 10 & 0 & 0 \\
\hline 21-22 & 0 & 0 & 0 & 0 & 0 & 0 & 0 & 0 & 0 & 0 & 0 & 0 & 0 \\
\hline 01-08 & 0 & 0 & 0 & 0 & 0 & 0 & 0 & 0 & 0 & 0 & 0 & 0 & 0 \\
\hline $02-08$ & 0 & 0 & 0 & 0 & 0 & 0 & 0 & 0 & 0 & 1 & 1 & 0 & 0 \\
\hline $06-07$ & 0 & 0 & 0 & 0 & 0 & 0 & 0 & 0 & 0 & 0 & 0 & 0 & 0 \\
\hline 13-14 & 0 & 0 & 0 & 0 & 1 & 0 & 0 & 0 & 0 & 0 & 1 & 0 & 0 \\
\hline $14-23$ & 0 & 0 & 0 & 0 & 0 & 0 & 0 & 0 & 0 & 0 & 0 & 0 & 0 \\
\hline $16-23$ & 0 & 0 & 0 & 0 & 0 & 0 & 0 & 0 & 0 & 0 & 0 & 0 & 0 \\
\hline $19-23$ & 0 & 0 & 0 & 0 & 0 & 0 & 0 & 0 & 0 & 0 & 0 & 0 & 0 \\
\hline Reforços & 14 & 11 & 13 & 12 & 12 & 11 & 14 & 12 & 12 & 14 & & sto $M_{t}$ & \\
\hline $\begin{array}{c}\text { Custo } \\
\left(1^{6} \$\right)\end{array}$ & 416 & 288 & 392 & 343 & 350 & 288 & 399 & 343 & 308 & 431 & & 355,8 & \\
\hline InRef & 1 & 0 & 1 & 1 & 0 & 0 & 1 & 1 & 0 & 1 & & GU & \\
\hline InCus & 50 & 0 & 50 & 50 & 8 & 0 & 50 & 50 & 0 & 51 & & 111,4 & \\
\hline InRefA & 3 & 3 & 4 & 4 & 3 & 2 & 5 & 4 & 4 & 5 & & & \\
\hline InCusA & 94 & 47 & 97 & 128 & 55 & 25 & 108 & 128 & 71 & 135 & & & \\
\hline
\end{tabular}


Tabela A.14 - Tabela Decisão da Iteração 7 - Alternativa 3.

\begin{tabular}{|c|c|c|c|c|c|c|c|c|c|c|c|c|c|}
\hline \multirow{2}{*}{ Ramo } & \multicolumn{10}{|c|}{ Plano Para Cada Cenário } & \multicolumn{3}{|c|}{ Graus de Incidência } \\
\hline & 1 & 2 & 3 & 4 & 5 & 6 & 7 & 8 & 9 & 10 & GI1 & GI2 & GI3 \\
\hline $01-02$ & 1 & 1 & 1 & 1 & 1 & 1 & 1 & 1 & 1 & 1 & 10 & 0 & 0 \\
\hline 01-03 & 0 & 0 & 0 & 0 & 0 & 0 & 0 & 0 & 0 & 0 & 0 & 0 & 0 \\
\hline $01-05$ & 2 & 2 & 2 & 2 & 2 & 2 & 2 & 2 & 2 & 2 & 10 & 10 & 0 \\
\hline $02-04$ & 0 & 0 & 0 & 0 & 0 & 0 & 1 & 0 & 0 & 1 & 2 & 0 & 0 \\
\hline $02-06$ & 0 & 0 & 0 & 0 & 0 & 0 & 0 & 0 & 0 & 0 & 0 & 0 & 0 \\
\hline 03-09 & 1 & 1 & 1 & 1 & 1 & 1 & 1 & 1 & 1 & 1 & 10 & 0 & 0 \\
\hline $03-24$ & 0 & 0 & 0 & 0 & 0 & 0 & 0 & 0 & 0 & 0 & 0 & 0 & 0 \\
\hline $\begin{array}{c}04-09 \\
\end{array}$ & 0 & 0 & 0 & 0 & 0 & 0 & 0 & 0 & 0 & 0 & 0 & 0 & 0 \\
\hline $05-10$ & 0 & 0 & 0 & 0 & 0 & 0 & 1 & 0 & 0 & 1 & 2 & 0 & 0 \\
\hline 06-10 & 2 & 2 & 2 & 2 & 2 & 2 & 2 & 2 & 2 & 2 & 10 & 10 & 0 \\
\hline $07-08$ & 2 & 2 & 2 & 2 & 2 & 2 & 2 & 2 & 2 & 2 & 10 & 10 & 0 \\
\hline $\begin{array}{l}08-09 \\
\end{array}$ & 0 & 0 & 0 & 0 & 0 & 0 & 0 & 0 & 0 & 0 & 0 & 0 & 0 \\
\hline 08-10 & 0 & 0 & 0 & 0 & 0 & 0 & 0 & 0 & 0 & 0 & 0 & 0 & 0 \\
\hline $09-11$ & 0 & 0 & 0 & 0 & 0 & 0 & 0 & 0 & 0 & 0 & 0 & 0 & 0 \\
\hline $09-12$ & 0 & 0 & 0 & 0 & 0 & 0 & 0 & 0 & 0 & 0 & 0 & 0 & 0 \\
\hline $10-11$ & 1 & 0 & 1 & 0 & 1 & 0 & 0 & 0 & 0 & 0 & 3 & 0 & 0 \\
\hline $10-12$ & 0 & 1 & 0 & 0 & 0 & 1 & 0 & 0 & 2 & 0 & 3 & 1 & 0 \\
\hline $11-13$ & 1 & 1 & 1 & 1 & 1 & 1 & 1 & 1 & 1 & 1 & 10 & 0 & 0 \\
\hline $11-14$ & 0 & 0 & 0 & 0 & 0 & 0 & 0 & 0 & 0 & 0 & 0 & 0 & 0 \\
\hline $12-13$ & 0 & 0 & 0 & 0 & 0 & 0 & 0 & 0 & 0 & 0 & 0 & 0 & 0 \\
\hline $12-23$ & 0 & 0 & 0 & 0 & 0 & 0 & 0 & 0 & 0 & 0 & 0 & 0 & 0 \\
\hline $13-23$ & 0 & 0 & 0 & 0 & 0 & 0 & 0 & 0 & 0 & 0 & 0 & 0 & 0 \\
\hline $14-16$ & 1 & 1 & 1 & 1 & 1 & 1 & 1 & 1 & 1 & 1 & 10 & 0 & 0 \\
\hline $15-16$ & 1 & 0 & 0 & 0 & 0 & 0 & 0 & 0 & 0 & 0 & 1 & 0 & 0 \\
\hline $15-21$ & 0 & 0 & 0 & 0 & 0 & 0 & 0 & 0 & 0 & 0 & 0 & 0 & 0 \\
\hline $15-24$ & 0 & 0 & 0 & 0 & 0 & 0 & 0 & 0 & 0 & 0 & 0 & 0 & 0 \\
\hline $16-17$ & 0 & 0 & 0 & 0 & 0 & 0 & 0 & 0 & 0 & 0 & 0 & 0 & 0 \\
\hline $16-19$ & 0 & 0 & 0 & 0 & 0 & 0 & 0 & 0 & 0 & 0 & 0 & 0 & 0 \\
\hline $\begin{array}{ll}17-18 \\
\end{array}$ & 0 & 0 & 0 & 0 & 0 & 0 & 0 & 0 & 1 & 0 & 1 & 0 & 0 \\
\hline $17-22$ & 0 & 0 & 0 & 0 & 0 & 0 & 0 & 0 & 0 & 0 & 0 & 0 & 0 \\
\hline $18-21$ & 0 & 0 & 0 & 0 & 0 & 0 & 0 & 0 & 0 & 0 & 0 & 0 & 0 \\
\hline $19-20$ & 0 & 0 & 0 & 1 & 0 & 0 & 1 & 1 & 0 & 0 & 3 & 0 & 0 \\
\hline $20-23$ & 1 & 1 & 1 & 1 & 1 & 1 & 1 & 1 & 1 & 1 & 10 & 0 & 0 \\
\hline $21-22$ & 0 & 0 & 0 & 0 & 0 & 0 & 0 & 0 & 0 & 0 & 0 & 0 & 0 \\
\hline 01-08 & 0 & 0 & 0 & 0 & 0 & 0 & 0 & 0 & 0 & 0 & 0 & 0 & 0 \\
\hline $\begin{array}{l}02-08 \\
\end{array}$ & 0 & 0 & 0 & 0 & 0 & 0 & 0 & 0 & 0 & 0 & 0 & 0 & 0 \\
\hline 06-07 & 0 & 0 & 0 & 0 & 0 & 0 & 0 & 0 & 0 & 0 & 0 & 0 & 0 \\
\hline $13-14$ & 0 & 0 & 0 & 0 & 0 & 0 & 0 & 0 & 0 & 0 & 0 & 0 & 0 \\
\hline $14-23$ & 0 & 0 & 0 & 0 & 0 & 0 & 0 & 0 & 0 & 1 & 1 & 0 & 0 \\
\hline $16-23$ & 0 & 0 & 0 & 0 & 0 & 0 & 0 & 0 & 0 & 0 & 0 & 0 & 0 \\
\hline $19-23$ & 0 & 0 & 0 & 0 & 0 & 0 & 0 & 0 & 0 & 0 & 0 & 0 & 0 \\
\hline Reforços & 13 & 12 & 12 & 12 & 12 & 12 & 14 & 12 & 14 & 14 & \multicolumn{3}{|c|}{ "Custo Médio } \\
\hline $\begin{array}{c}\text { Custo } \\
\left(10^{6} \$\right)\end{array}$ & 366 & 342 & 342 & 347 & 342 & 342 & 403 & 347 & 412 & 434 & \multicolumn{3}{|c|}{367,7} \\
\hline InRef & 0 & 1 & 0 & 1 & 0 & 1 & 1 & 1 & 2 & 1 & \multicolumn{3}{|c|}{ GU } \\
\hline InCus & 0 & 54 & 0 & 54 & 0 & 54 & 54 & 54 & 104 & 54 & \multicolumn{3}{|c|}{114} \\
\hline InRefA & 2 & 4 & 3 & 4 & 3 & 3 & 5 & 4 & 6 & 5 & & & \\
\hline InCusA & 44 & 101 & 47 & 132 & 47 & 79 & 112 & 132 & 175 & 138 & & & \\
\hline
\end{tabular}


Tabela A.15 - Tabela Decisão da Iteração 7 - Alternativa 4.

\begin{tabular}{|c|c|c|c|c|c|c|c|c|c|c|c|c|c|}
\hline \multirow{2}{*}{ Ramo } & \multicolumn{10}{|c|}{ Plano Para Cada Cenário } & \multicolumn{3}{|c|}{ Graus de Incidência } \\
\hline & 1 & 2 & 3 & 4 & 5 & 6 & 7 & 8 & 9 & 10 & GI1 & GI2 & GI3 \\
\hline $01-02$ & 1 & 1 & 1 & 1 & 1 & 1 & 1 & 1 & 1 & 1 & 10 & 0 & 0 \\
\hline $01-03$ & 0 & 0 & 0 & 0 & 0 & 0 & 0 & 0 & 0 & 0 & 0 & 0 & 0 \\
\hline $01-05$ & 2 & 2 & 2 & 2 & 2 & 2 & 2 & 2 & 2 & 2 & 10 & 10 & 0 \\
\hline $02-04$ & 0 & 0 & 0 & 0 & 0 & 0 & 1 & 0 & 0 & 1 & 2 & 0 & 0 \\
\hline $02-06$ & 0 & 0 & 0 & 0 & 0 & 0 & 0 & 0 & 0 & 0 & 0 & 0 & 0 \\
\hline 03-09 & 1 & 1 & 1 & 1 & 1 & 1 & 1 & 1 & 1 & 1 & 10 & 0 & 0 \\
\hline $03-24$ & 0 & 0 & 0 & 0 & 0 & 0 & 0 & 0 & 0 & 0 & 0 & 0 & 0 \\
\hline $04-09$ & 0 & 0 & 0 & 0 & 0 & 0 & 0 & 0 & 0 & 0 & 0 & 0 & 0 \\
\hline $05-10$ & 0 & 0 & 0 & 0 & 0 & 0 & 1 & 0 & 0 & 1 & 2 & 0 & 0 \\
\hline $06-10$ & 2 & 2 & 2 & 2 & 2 & 2 & 2 & 2 & 2 & 2 & 10 & 10 & 0 \\
\hline $\begin{array}{l}07-08 \\
\end{array}$ & 2 & 2 & 2 & 2 & 2 & 2 & 2 & 2 & 2 & 2 & 10 & 10 & 0 \\
\hline 08-09 & 0 & 0 & 0 & 0 & 0 & 0 & 0 & 0 & 0 & 0 & 0 & 0 & 0 \\
\hline 08-10 & 0 & 0 & 0 & 0 & 0 & 0 & 0 & 0 & 0 & 0 & 0 & 0 & 0 \\
\hline 09-11 & 0 & 0 & 0 & 0 & 0 & 0 & 0 & 0 & 0 & 0 & 0 & 0 & 0 \\
\hline 09-12 & 0 & 0 & 0 & 0 & 0 & 0 & 0 & 0 & 0 & 0 & 0 & 0 & 0 \\
\hline $10-11$ & 1 & 0 & 1 & 0 & 1 & 0 & 0 & 0 & 0 & 0 & 3 & 0 & 0 \\
\hline $10-12$ & 0 & 1 & 0 & 0 & 0 & 1 & 0 & 0 & 1 & 0 & 3 & 0 & 0 \\
\hline 11-13 & 1 & 1 & 1 & 1 & 1 & 1 & 1 & 1 & 1 & 1 & 10 & 0 & 0 \\
\hline 11-14 & 0 & 0 & 0 & 0 & 0 & 0 & 0 & 0 & 0 & 1 & 1 & 0 & 0 \\
\hline $12-13$ & 0 & 0 & 0 & 0 & 0 & 0 & 0 & 0 & 0 & 0 & 0 & 0 & 0 \\
\hline $12-23$ & 0 & 0 & 0 & 0 & 0 & 0 & 0 & 0 & 0 & 0 & 0 & 0 & 0 \\
\hline $13-23$ & 0 & 0 & 0 & 0 & 0 & 0 & 0 & 0 & 0 & 0 & 0 & 0 & 0 \\
\hline $14-16$ & 1 & 0 & 1 & 0 & 1 & 1 & 0 & 0 & 0 & 0 & 4 & 0 & 0 \\
\hline $15-16$ & 0 & 0 & 0 & 0 & 0 & 0 & 0 & 0 & 0 & 0 & 0 & 0 & 0 \\
\hline 15-21 & 0 & 0 & 0 & 0 & 0 & 0 & 0 & 0 & 0 & 0 & 0 & 0 & 0 \\
\hline $15-24$ & 0 & 0 & 0 & 0 & 0 & 0 & 0 & 0 & 0 & 0 & 0 & 0 & 0 \\
\hline 16-17 & 0 & 0 & 0 & 0 & 0 & 0 & 0 & 0 & 0 & 0 & 0 & 0 & 0 \\
\hline 16-19 & 0 & 0 & 0 & 0 & 0 & 0 & 0 & 0 & 0 & 0 & 0 & 0 & 0 \\
\hline 17-18 & 1 & 0 & 0 & 0 & 0 & 0 & 0 & 0 & 1 & 0 & 2 & 0 & 0 \\
\hline $17-22$ & 0 & 0 & 0 & 0 & 0 & 0 & 0 & 0 & 0 & 0 & 0 & 0 & 0 \\
\hline $18-21$ & 0 & 0 & 0 & 0 & 0 & 0 & 0 & 0 & 0 & 0 & 0 & 0 & 0 \\
\hline 19-20 & 1 & 1 & 1 & 1 & 1 & 1 & 1 & 1 & 1 & 1 & 10 & 0 & 0 \\
\hline $20-23$ & 1 & 1 & 1 & 1 & 1 & 1 & 1 & 1 & 1 & 1 & 10 & 0 & 0 \\
\hline $21-22$ & 0 & 0 & 0 & 0 & 0 & 0 & 0 & 0 & 0 & 0 & 0 & 0 & 0 \\
\hline 01-08 & 0 & 0 & 0 & 0 & 0 & 0 & 0 & 0 & 0 & 0 & 0 & 0 & 0 \\
\hline 02-08 & 0 & 0 & 0 & 0 & 0 & 0 & 0 & 0 & 0 & 0 & 0 & 0 & 0 \\
\hline $06-07$ & 0 & 0 & 0 & 0 & 0 & 0 & 0 & 0 & 0 & 0 & 0 & 0 & 0 \\
\hline $13-14$ & 0 & 0 & 0 & 0 & 0 & 0 & 0 & 0 & 0 & 0 & 0 & 0 & 0 \\
\hline $14-23$ & 0 & 0 & 0 & 0 & 0 & 0 & 0 & 0 & 0 & 0 & 0 & 0 & 0 \\
\hline $16-23$ & 0 & 0 & 0 & 0 & 0 & 0 & 0 & 0 & 0 & 0 & 0 & 0 & 0 \\
\hline $19-23$ & 0 & 0 & 0 & 0 & 0 & 0 & 0 & 0 & 0 & 0 & 0 & 0 & 0 \\
\hline Reforços & 14 & 12 & 13 & 11 & 13 & 13 & 13 & 11 & 13 & 14 & \multicolumn{3}{|c|}{ Custo Médio } \\
\hline $\begin{array}{c}\text { Custo } \\
\left(10^{6} \$\right)\end{array}$ & 417 & 343 & 397 & 293 & 397 & 397 & 349 & 293 & 363 & 407 & \multicolumn{3}{|c|}{365,6} \\
\hline InRef & 1 & 1 & 1 & 0 & 1 & 2 & 0 & 0 & 1 & 1 & \multicolumn{3}{|c|}{ GU } \\
\hline InCus & 51 & 55 & 55 & 0 & 55 & 109 & 0 & 0 & 55 & 27 & \multicolumn{3}{|c|}{115,4} \\
\hline \begin{tabular}{|l|} 
InRefA \\
\end{tabular} & 3 & 4 & 4 & 3 & 4 & 4 & 4 & 3 & 5 & 5 & & & \\
\hline \begin{tabular}{|l|} 
InCusA \\
\end{tabular} & 95 & 102 & 102 & 78 & 102 & 134 & 58 & 78 & 126 & 111 & & & \\
\hline
\end{tabular}


Tabela A.16 - Reforços consolidados até a Tabela Decisão da Iteração 7.

\begin{tabular}{|c|c|c|}
\hline Ramo Candidato & Quantidade de Reforços & \multirow{2}{*}{ Tabela Decisão } \\
\cline { 1 - 2 } $03-09$ & 1 & \multirow{2}{*}{ Inicial } \\
\cline { 1 - 2 } $06-10$ & 1 & \\
\hline $20-23$ & 1 & Iteração 1 \\
\hline $07-08$ & 2 & Iteração 2 \\
\hline $06-10$ & 2 & Iteração 3 \\
\hline $01-05$ & 1 & Iteração 4 \\
\hline $11-13$ & 1 & Iteração 5 \\
\hline $01-05$ & 2 & Iteração 6 \\
\hline $01-02$ & 1 & Iteração 7 \\
\hline $19-20$ & 1 &
\end{tabular}


Tabela A.17 Tabela Decisão da Iteração 8.

\begin{tabular}{|c|c|c|c|c|c|c|c|c|c|c|c|c|c|}
\hline \multirow{2}{*}{ Ramo } & \multicolumn{10}{|c|}{ Plano Para Cada Cenário } & \multicolumn{3}{|c|}{ Graus de Incidência } \\
\hline & 1 & 2 & 3 & 4 & 5 & 6 & 7 & 8 & 9 & 10 & GI1 & GI2 & GI3 \\
\hline 01-02 & 1 & 1 & 1 & 1 & 1 & 1 & 1 & 1 & 1 & 1 & 10 & 0 & 0 \\
\hline $01-03$ & 0 & 0 & 0 & 0 & 0 & 0 & 0 & 0 & 0 & 1 & 1 & 0 & 0 \\
\hline $01-05$ & 2 & 2 & 2 & 2 & 2 & 2 & 2 & 2 & 2 & 2 & 10 & 10 & 0 \\
\hline $02-04$ & 0 & 0 & 0 & 0 & 0 & 0 & 1 & 0 & 0 & 0 & 1 & 0 & 0 \\
\hline $02-06$ & 0 & 0 & 0 & 0 & 0 & 0 & 0 & 0 & 0 & 1 & 1 & 0 & 0 \\
\hline 03-09 & 1 & 1 & 1 & 1 & 1 & 1 & 1 & 1 & 1 & 1 & 10 & 0 & 0 \\
\hline $03-24$ & 0 & 0 & 0 & 0 & 0 & 0 & 0 & 0 & 0 & 0 & 0 & 0 & 0 \\
\hline 04-09 & 0 & 0 & 0 & 0 & 0 & 0 & 0 & 0 & 0 & 0 & 0 & 0 & 0 \\
\hline 05-10 & 0 & 0 & 0 & 0 & 0 & 0 & 1 & 0 & 0 & 0 & 1 & 0 & 0 \\
\hline $06-10$ & 2 & 2 & 2 & 2 & 2 & 2 & 2 & 2 & 2 & 2 & 10 & 10 & 0 \\
\hline 07-08 & 2 & 2 & 2 & 2 & 2 & 2 & 2 & 2 & 2 & 2 & 10 & 10 & 0 \\
\hline $08-09$ & 0 & 0 & 0 & 0 & 0 & 0 & 0 & 0 & 0 & 0 & 0 & 0 & 0 \\
\hline 08-10 & 0 & 0 & 0 & 0 & 0 & 0 & 0 & 0 & 0 & 0 & 0 & 0 & 0 \\
\hline 09-11 & 0 & 0 & 0 & 0 & 0 & 0 & 0 & 0 & 0 & 0 & 0 & 0 & 0 \\
\hline 09-12 & 0 & 0 & 0 & 0 & 0 & 0 & 0 & 0 & 0 & 0 & 0 & 0 & 0 \\
\hline 10-11 & 1 & 0 & 1 & 0 & 1 & 0 & 0 & 0 & 0 & 0 & 3 & 0 & 0 \\
\hline 10-12 & 0 & 1 & 0 & 0 & 0 & 1 & 0 & 0 & 1 & 0 & 3 & 0 & 0 \\
\hline 11-13 & 1 & 1 & 1 & 1 & 1 & 1 & 1 & 1 & 1 & 1 & 10 & 0 & 0 \\
\hline 11-14 & 0 & 0 & 0 & 0 & 0 & 0 & 0 & 0 & 0 & 0 & 0 & 0 & 0 \\
\hline $12-13$ & 0 & 0 & 0 & 0 & 0 & 0 & 0 & 0 & 0 & 0 & 0 & 0 & 0 \\
\hline $12-23$ & 0 & 0 & 0 & 0 & 0 & 0 & 0 & 0 & 0 & 0 & 0 & 0 & 0 \\
\hline 13-23 & 0 & 0 & 0 & 0 & 0 & 0 & 0 & 0 & 0 & 0 & 0 & 0 & 0 \\
\hline 14-16 & 1 & 1 & 1 & 1 & 1 & 1 & 1 & 1 & 1 & 1 & 10 & 0 & 0 \\
\hline 15-16 & 0 & 0 & 0 & 0 & 0 & 0 & 0 & 0 & 0 & 0 & 0 & 0 & 0 \\
\hline $15-21$ & 0 & 0 & 0 & 0 & 0 & 0 & 0 & 0 & 0 & 0 & 0 & 0 & 0 \\
\hline 15-24 & 0 & 0 & 0 & 0 & 0 & 0 & 0 & 0 & 0 & 0 & 0 & 0 & 0 \\
\hline $\begin{array}{l}16-17 \\
\end{array}$ & 0 & 0 & 0 & 0 & 0 & 0 & 0 & 0 & 0 & 0 & 0 & 0 & 0 \\
\hline 16-19 & 0 & 0 & 0 & 0 & 0 & 0 & 0 & 0 & 0 & 0 & 0 & 0 & 0 \\
\hline 17-18 & 1 & 0 & 0 & 0 & 0 & 0 & 0 & 0 & 1 & 0 & 2 & 0 & 0 \\
\hline $17-22$ & 0 & 0 & 0 & 0 & 0 & 0 & 0 & 0 & 0 & 0 & 0 & 0 & 0 \\
\hline $18-21$ & 0 & 0 & 0 & 0 & 0 & 0 & 0 & 0 & 0 & 0 & 0 & 0 & 0 \\
\hline 19-20 & 1 & 1 & 1 & 1 & 1 & 1 & 1 & 1 & 1 & 1 & 10 & 0 & 0 \\
\hline $20-23$ & 1 & 1 & 1 & 1 & 1 & 1 & 1 & 1 & 1 & 1 & 10 & 0 & 0 \\
\hline $21-22$ & 0 & 0 & 0 & 0 & 0 & 0 & 0 & 0 & 0 & 0 & 0 & 0 & 0 \\
\hline 01-08 & 0 & 0 & 0 & 0 & 0 & 0 & 0 & 0 & 0 & 0 & 0 & 0 & 0 \\
\hline 02-08 & 0 & 0 & 0 & 0 & 0 & 0 & 0 & 0 & 0 & 0 & 0 & 0 & 0 \\
\hline $06-07$ & 0 & 0 & 0 & 0 & 0 & 0 & 0 & 0 & 0 & 0 & 0 & 0 & 0 \\
\hline 13-14 & 0 & 0 & 0 & 0 & 0 & 0 & 0 & 0 & 0 & 0 & 0 & 0 & 0 \\
\hline $14-23$ & 0 & 0 & 0 & 0 & 0 & 0 & 0 & 0 & 0 & 0 & 0 & 0 & 0 \\
\hline $16-23$ & 0 & 0 & 0 & 0 & 0 & 0 & 0 & 0 & 0 & 0 & 0 & 0 & 0 \\
\hline $19-23$ & 0 & 0 & 0 & 0 & 0 & 0 & 0 & 0 & 0 & 0 & 0 & 0 & 0 \\
\hline Reforços & 14 & 13 & 13 & 12 & 13 & 13 & 14 & 12 & 14 & 14 & \multicolumn{3}{|c|}{ Custo Médio } \\
\hline $\begin{array}{c}\text { Custo } \\
\left(10^{6} \$\right)\end{array}$ & 417 & 397 & 397 & 347 & 397 & 397 & 403 & 347 & 417 & 452 & \multicolumn{3}{|c|}{397,1} \\
\hline InRef & 0 & 1 & 0 & 1 & 0 & 0 & 1 & 1 & 1 & 0 & \multicolumn{3}{|c|}{ GU } \\
\hline InCus & 0 & 54 & 0 & 54 & 0 & 0 & 54 & 54 & 54 & 45 & \multicolumn{3}{|c|}{116} \\
\hline InRefA & 3 & 5 & 4 & 4 & 4 & 4 & 5 & 4 & 6 & 5 & & & \\
\hline InCusA & 95 & 156 & 102 & 132 & 102 & 134 & 112 & 132 & 180 & 156 & & & \\
\hline
\end{tabular}


Tabela A.18 - Reforços consolidados até a Tabela Decisão da Iteração 8.

\begin{tabular}{|c|c|c|}
\hline Ramo Candidato & Quantidade de Reforços & \multirow{2}{*}{ Tabela Decisão } \\
\cline { 1 - 2 } $03-09$ & 1 & \multirow{2}{*}{ Inicial } \\
\cline { 1 - 2 } $06-10$ & 1 & \multirow{2}{*}{ Iteração 1 } \\
\hline $20-23$ & 1 & Iteração 2 \\
\hline $07-08$ & 2 & Iteração 3 \\
\hline $06-10$ & 1 & Iteração 4 \\
\hline $01-05$ & 1 & Iteração 5 \\
\hline $11-13$ & 1 & Iteração 6 \\
\hline $01-05$ & 1 & Iteração 7 \\
\hline $01-02$ & 1 & Iteração 8 \\
\hline $19-20$ & 1 &
\end{tabular}


Tabela A.19 - Tabela Decisão da Iteração 9 - Alternativa 1.

\begin{tabular}{|c|c|c|c|c|c|c|c|c|c|c|c|c|c|}
\hline \multirow{2}{*}{ Ramo } & \multicolumn{10}{|c|}{ Plano Para Cada Cenário } & \multicolumn{3}{|c|}{ Graus de Incidência } \\
\hline & 1 & 2 & 3 & 4 & 5 & 6 & 7 & 8 & 9 & 10 & GI1 & GI2 & GI3 \\
\hline 01-02 & 1 & 1 & 1 & 1 & 1 & 1 & 1 & 1 & 1 & 1 & 10 & 0 & 0 \\
\hline $01-03$ & 0 & 0 & 0 & 0 & 0 & 0 & 0 & 0 & 0 & 1 & 1 & 0 & 0 \\
\hline $01-05$ & 2 & 2 & 2 & 2 & 2 & 2 & 2 & 2 & 2 & 2 & 10 & 10 & 0 \\
\hline $02-04$ & 0 & 0 & 0 & 0 & 0 & 0 & 1 & 0 & 0 & 0 & 1 & 0 & 0 \\
\hline $02-06$ & 0 & 0 & 0 & 0 & 0 & 0 & 0 & 0 & 0 & 0 & 0 & 0 & 0 \\
\hline 03-09 & 1 & 1 & 1 & 1 & 1 & 1 & 1 & 1 & 1 & 1 & 10 & 0 & 0 \\
\hline $03-24$ & 0 & 0 & 0 & 0 & 0 & 0 & 0 & 0 & 0 & 0 & 0 & 0 & 0 \\
\hline 04-09 & 0 & 0 & 0 & 0 & 0 & 0 & 0 & 0 & 0 & 0 & 0 & 0 & 0 \\
\hline 05-10 & 0 & 0 & 0 & 0 & 0 & 0 & 1 & 0 & 0 & 0 & 1 & 0 & 0 \\
\hline $06-10$ & 2 & 2 & 2 & 2 & 2 & 2 & 2 & 2 & 2 & 2 & 10 & 10 & 0 \\
\hline 07-08 & 2 & 2 & 2 & 2 & 2 & 2 & 2 & 2 & 2 & 2 & 10 & 10 & 0 \\
\hline $08-09$ & 0 & 0 & 0 & 0 & 0 & 0 & 0 & 0 & 0 & 0 & 0 & 0 & 0 \\
\hline 08-10 & 0 & 0 & 0 & 0 & 0 & 0 & 0 & 0 & 0 & 0 & 0 & 0 & 0 \\
\hline 09-11 & 0 & 0 & 0 & 0 & 0 & 0 & 0 & 0 & 0 & 0 & 0 & 0 & 0 \\
\hline 09-12 & 0 & 0 & 0 & 0 & 0 & 0 & 0 & 0 & 0 & 0 & 0 & 0 & 0 \\
\hline 10-11 & 1 & 1 & 1 & 1 & 1 & 1 & 1 & 1 & 1 & 1 & 10 & 0 & 0 \\
\hline 10-12 & 0 & 0 & 0 & 0 & 0 & 0 & 0 & 0 & 0 & 0 & 0 & 0 & 0 \\
\hline 11-13 & 1 & 1 & 1 & 1 & 1 & 1 & 1 & 1 & 1 & 1 & 10 & 0 & 0 \\
\hline 11-14 & 0 & 0 & 0 & 0 & 0 & 0 & 0 & 0 & 0 & 0 & 0 & 0 & 0 \\
\hline $12-13$ & 0 & 0 & 0 & 0 & 0 & 0 & 0 & 0 & 0 & 0 & 0 & 0 & 0 \\
\hline $12-23$ & 0 & 0 & 0 & 0 & 0 & 0 & 0 & 0 & 0 & 0 & 0 & 0 & 0 \\
\hline 13-23 & 0 & 0 & 0 & 0 & 0 & 0 & 0 & 0 & 0 & 0 & 0 & 0 & 0 \\
\hline 14-16 & 1 & 1 & 1 & 1 & 1 & 1 & 1 & 1 & 1 & 1 & 10 & 0 & 0 \\
\hline 15-16 & 0 & 0 & 0 & 0 & 0 & 0 & 0 & 0 & 0 & 0 & 0 & 0 & 0 \\
\hline $15-21$ & 0 & 0 & 0 & 0 & 0 & 0 & 0 & 0 & 0 & 0 & 0 & 0 & 0 \\
\hline 15-24 & 0 & 0 & 0 & 0 & 0 & 0 & 0 & 0 & 0 & 0 & 0 & 0 & 0 \\
\hline $\begin{array}{l}16-17 \\
\end{array}$ & 0 & 0 & 0 & 0 & 0 & 0 & 0 & 0 & 0 & 0 & 0 & 0 & 0 \\
\hline 16-19 & 0 & 0 & 0 & 0 & 0 & 0 & 0 & 0 & 0 & 0 & 0 & 0 & 0 \\
\hline 17-18 & 1 & 0 & 0 & 0 & 0 & 0 & 0 & 0 & 1 & 0 & 2 & 0 & 0 \\
\hline $17-22$ & 0 & 0 & 0 & 0 & 0 & 0 & 0 & 0 & 0 & 0 & 0 & 0 & 0 \\
\hline $18-21$ & 0 & 0 & 0 & 0 & 0 & 0 & 0 & 0 & 0 & 0 & 0 & 0 & 0 \\
\hline 19-20 & 1 & 1 & 1 & 1 & 1 & 1 & 1 & 1 & 1 & 1 & 10 & 0 & 0 \\
\hline $20-23$ & 1 & 1 & 1 & 1 & 1 & 1 & 1 & 1 & 1 & 1 & 10 & 0 & 0 \\
\hline $21-22$ & 0 & 0 & 0 & 0 & 0 & 0 & 0 & 0 & 0 & 0 & 0 & 0 & 0 \\
\hline 01-08 & 0 & 0 & 0 & 0 & 0 & 0 & 0 & 0 & 0 & 0 & 0 & 0 & 0 \\
\hline 02-08 & 0 & 0 & 0 & 0 & 0 & 0 & 0 & 0 & 0 & 1 & 1 & 0 & 0 \\
\hline $06-07$ & 0 & 0 & 0 & 0 & 0 & 0 & 0 & 0 & 0 & 0 & 0 & 0 & 0 \\
\hline 13-14 & 0 & 0 & 0 & 0 & 0 & 0 & 0 & 0 & 0 & 0 & 0 & 0 & 0 \\
\hline $14-23$ & 0 & 0 & 0 & 0 & 0 & 0 & 0 & 0 & 0 & 0 & 0 & 0 & 0 \\
\hline $16-23$ & 0 & 0 & 0 & 0 & 0 & 0 & 0 & 0 & 0 & 0 & 0 & 0 & 0 \\
\hline $19-23$ & 0 & 0 & 0 & 0 & 0 & 0 & 0 & 0 & 0 & 0 & 0 & 0 & 0 \\
\hline Reforços & 14 & 13 & 13 & 13 & 13 & 13 & 15 & 13 & 14 & 15 & \multicolumn{3}{|c|}{ Custo Médio } \\
\hline $\begin{array}{c}\text { Custo } \\
\left(10^{6} \$\right)\end{array}$ & 417 & 397 & 397 & 397 & 397 & 397 & 453 & 397 & 417 & 485 & \multicolumn{3}{|c|}{415,4} \\
\hline InRef & 0 & 0 & 0 & 1 & 0 & 0 & 1 & 1 & 0 & 1 & \multicolumn{3}{|c|}{ GU } \\
\hline InCus & 0 & 0 & 0 & 50 & 0 & 0 & 50 & 50 & 0 & 33 & \multicolumn{3}{|c|}{118} \\
\hline InRefA & 3 & 5 & 4 & 5 & 4 & 4 & 6 & 5 & 6 & 6 & & & \\
\hline InCusA & 95 & 156 & 102 & 182 & 102 & 134 & 162 & 182 & 180 & 189 & & & \\
\hline
\end{tabular}


Tabela A.20 - Tabela Decisão da Iteração 9 - Alternativa 2.

\begin{tabular}{|c|c|c|c|c|c|c|c|c|c|c|c|c|c|}
\hline \multirow{2}{*}{ Ramo } & \multicolumn{10}{|c|}{ Plano Para Cada Cenário } & \multicolumn{3}{|c|}{ Graus de Incidência } \\
\hline & 1 & 2 & 3 & 4 & 5 & 6 & 7 & 8 & 9 & 10 & GI1 & GI2 & GI3 \\
\hline $01-02$ & 1 & 1 & 1 & 1 & 1 & 1 & 1 & 1 & 1 & 1 & 10 & 0 & 0 \\
\hline 01-03 & 0 & 0 & 0 & 0 & 0 & 0 & 0 & 0 & 0 & 1 & 1 & 0 & 0 \\
\hline $01-05$ & 2 & 2 & 2 & 2 & 2 & 2 & 2 & 2 & 2 & 2 & 10 & 10 & 0 \\
\hline $02-04$ & 0 & 0 & 0 & 0 & 0 & 0 & 1 & 0 & 0 & 0 & 1 & 0 & 0 \\
\hline $02-06$ & 0 & 0 & 0 & 0 & 0 & 0 & 0 & 0 & 0 & 0 & 0 & 0 & 0 \\
\hline 03-09 & 1 & 1 & 1 & 1 & 1 & 1 & 1 & 1 & 1 & 1 & 10 & 0 & 0 \\
\hline $03-24$ & 0 & 0 & 0 & 0 & 1 & 0 & 0 & 0 & 0 & 0 & 1 & 0 & 0 \\
\hline $\begin{array}{c}04-09 \\
\end{array}$ & 0 & 0 & 0 & 0 & 0 & 0 & 0 & 0 & 0 & 0 & 0 & 0 & 0 \\
\hline $05-10$ & 0 & 0 & 0 & 0 & 0 & 0 & 1 & 0 & 0 & 0 & 1 & 0 & 0 \\
\hline 06-10 & 2 & 2 & 2 & 2 & 2 & 2 & 2 & 2 & 2 & 2 & 10 & 10 & 0 \\
\hline $07-08$ & 2 & 2 & 2 & 2 & 2 & 2 & 2 & 2 & 2 & 2 & 10 & 10 & 0 \\
\hline $\begin{array}{l}08-09 \\
\end{array}$ & 0 & 0 & 0 & 0 & 0 & 0 & 0 & 0 & 0 & 0 & 0 & 0 & 0 \\
\hline 08-10 & 0 & 0 & 0 & 0 & 0 & 0 & 0 & 0 & 0 & 0 & 0 & 0 & 0 \\
\hline $09-11$ & 0 & 0 & 1 & 0 & 0 & 0 & 0 & 0 & 0 & 0 & 1 & 0 & 0 \\
\hline $09-12$ & 0 & 0 & 0 & 0 & 0 & 0 & 0 & 0 & 0 & 0 & 0 & 0 & 0 \\
\hline $10-11$ & 1 & 0 & 0 & 0 & 0 & 0 & 0 & 0 & 0 & 0 & 1 & 0 & 0 \\
\hline $10-12$ & 1 & 1 & 1 & 1 & 1 & 1 & 1 & 1 & 1 & 1 & 10 & 0 & 0 \\
\hline $11-13$ & 1 & 1 & 1 & 1 & 1 & 1 & 1 & 1 & 1 & 1 & 10 & 0 & 0 \\
\hline $11-14$ & 0 & 0 & 0 & 0 & 0 & 0 & 0 & 0 & 0 & 0 & 0 & 0 & 0 \\
\hline $12-13$ & 0 & 0 & 0 & 0 & 0 & 0 & 0 & 0 & 0 & 0 & 0 & 0 & 0 \\
\hline $12-23$ & 0 & 0 & 0 & 0 & 0 & 0 & 0 & 0 & 0 & 0 & 0 & 0 & 0 \\
\hline $13-23$ & 0 & 0 & 0 & 0 & 0 & 0 & 0 & 0 & 0 & 0 & 0 & 0 & 0 \\
\hline $14-16$ & 1 & 1 & 1 & 1 & 1 & 1 & 1 & 1 & 1 & 1 & 10 & 0 & 0 \\
\hline $15-16$ & 0 & 0 & 0 & 0 & 0 & 0 & 0 & 0 & 0 & 0 & 0 & 0 & 0 \\
\hline $15-21$ & 0 & 0 & 0 & 0 & 0 & 0 & 0 & 0 & 0 & 0 & 0 & 0 & 0 \\
\hline $15-24$ & 0 & 0 & 0 & 0 & 0 & 0 & 0 & 0 & 0 & 0 & 0 & 0 & 0 \\
\hline $16-17$ & 0 & 0 & 0 & 0 & 0 & 0 & 0 & 0 & 0 & 0 & 0 & 0 & 0 \\
\hline $16-19$ & 0 & 0 & 0 & 0 & 0 & 0 & 0 & 0 & 0 & 0 & 0 & 0 & 0 \\
\hline $\begin{array}{ll}17-18 \\
\end{array}$ & 1 & 0 & 0 & 0 & 0 & 0 & 0 & 0 & 1 & 0 & 2 & 0 & 0 \\
\hline $17-22$ & 0 & 0 & 0 & 0 & 0 & 0 & 0 & 0 & 0 & 0 & 0 & 0 & 0 \\
\hline $18-21$ & 0 & 0 & 0 & 0 & 0 & 0 & 0 & 0 & 0 & 0 & 0 & 0 & 0 \\
\hline $19-20$ & 1 & 1 & 1 & 1 & 1 & 1 & 1 & 1 & 1 & 1 & 10 & 0 & 0 \\
\hline $20-23$ & 1 & 1 & 1 & 1 & 1 & 1 & 1 & 1 & 1 & 1 & 10 & 0 & 0 \\
\hline $21-22$ & 0 & 0 & 0 & 0 & 0 & 0 & 0 & 0 & 0 & 0 & 0 & 0 & 0 \\
\hline $\begin{array}{c}01-08 \\
\end{array}$ & 0 & 0 & 0 & 0 & 0 & 0 & 0 & 0 & 0 & 0 & 0 & 0 & 0 \\
\hline $\begin{array}{l}02-08 \\
\end{array}$ & 0 & 0 & 0 & 0 & 0 & 0 & 0 & 0 & 0 & 1 & 1 & 0 & 0 \\
\hline 06-07 & 0 & 0 & 0 & 0 & 0 & 0 & 0 & 0 & 0 & 0 & 0 & 0 & 0 \\
\hline $13-14$ & 0 & 0 & 0 & 0 & 0 & 0 & 0 & 0 & 0 & 0 & 0 & 0 & 0 \\
\hline $14-23$ & 0 & 0 & 0 & 0 & 0 & 0 & 0 & 0 & 0 & 0 & 0 & 0 & 0 \\
\hline $16-23$ & 0 & 0 & 0 & 0 & 0 & 0 & 0 & 0 & 0 & 0 & 0 & 0 & 0 \\
\hline $19-23$ & 0 & 0 & 0 & 0 & 0 & 0 & 0 & 0 & 0 & 0 & 0 & 0 & 0 \\
\hline Reforços & 15 & 13 & 14 & 13 & 14 & 13 & 15 & 13 & 14 & 15 & \multicolumn{3}{|c|}{ "Custo Médio } \\
\hline $\begin{array}{c}\text { Custo } \\
\left(10^{6} \$\right)\end{array}$ & 467 & 397 & 447 & 397 & 447 & 397 & 453 & 397 & 417 & 485 & \multicolumn{3}{|c|}{430,4} \\
\hline InRef & 1 & 0 & 1 & 1 & 1 & 0 & 1 & 1 & 0 & 1 & \multicolumn{3}{|c|}{ GU } \\
\hline InCus & 50 & 0 & 50 & 50 & 50 & 0 & 50 & 50 & 0 & 33 & \multirow{2}{*}{\multicolumn{3}{|c|}{115}} \\
\hline InRefA & 4 & 5 & 5 & 5 & 5 & 4 & 6 & 5 & 6 & 6 & & & \\
\hline InCusA & 145 & 156 & 152 & 182 & 152 & 134 & 162 & 182 & 180 & 189 & & & \\
\hline
\end{tabular}


Tabela A.21 - Reforços consolidados até a Tabela Decisão da Iteração 9.

\begin{tabular}{|c|c|c|}
\hline Ramo Candidato & Quantidade de Reforços & Tabela Decisão \\
\hline 03-09 & 1 & \multirow{3}{*}{ Inicial } \\
\hline $06-10$ & 1 & \\
\hline $20-23$ & 1 & \\
\hline $07-08$ & 2 & Iteração 1 \\
\hline 06-10 & 2 & Iteração 2 \\
\hline $01-05$ & 1 & Iteração 3 \\
\hline $11-13$ & 1 & Iteração 4 \\
\hline 01-05 & 2 & Iteração 5 \\
\hline 01-02 & 1 & Iteração 6 \\
\hline $19-20$ & 1 & Iteração 7 \\
\hline $14-16$ & 1 & Iteração 8 \\
\hline $10-11$ & 1 & Iteração 9 \\
\hline
\end{tabular}


Apêndice

Tabela A.22 - Tabela Decisão da Iteração 10.

\begin{tabular}{|c|c|c|c|c|c|c|c|c|c|c|c|c|c|}
\hline \multirow{2}{*}{ Ramo } & \multicolumn{10}{|c|}{ Plano Para Cada Cenário } & \multicolumn{3}{|c|}{ Graus de Incidência } \\
\hline & 1 & 2 & 3 & 4 & 5 & 6 & 7 & 8 & 9 & 10 & GI1 & GI2 & GI3 \\
\hline 01-02 & 1 & 1 & 1 & 1 & 1 & 1 & 1 & 1 & 1 & 1 & 10 & 0 & 0 \\
\hline 01-03 & 0 & 0 & 0 & 0 & 0 & 0 & 0 & 0 & 0 & 1 & 1 & 0 & 0 \\
\hline 01-05 & 2 & 2 & 2 & 2 & 2 & 2 & 2 & 2 & 2 & 2 & 10 & 10 & 0 \\
\hline $02-04$ & 0 & 0 & 0 & 0 & 0 & 0 & 1 & 0 & 0 & 0 & 1 & 0 & 0 \\
\hline $02-06$ & 0 & 0 & 0 & 0 & 0 & 0 & 0 & 0 & 0 & 0 & 0 & 0 & 0 \\
\hline 03-09 & 1 & 1 & 1 & 1 & 1 & 1 & 1 & 1 & 1 & 1 & 10 & 0 & 0 \\
\hline $03-24$ & 0 & 0 & 0 & 0 & 0 & 0 & 0 & 0 & 0 & 0 & 0 & 0 & 0 \\
\hline $\begin{array}{l}04-09 \\
\end{array}$ & 0 & 0 & 0 & 0 & 0 & 0 & 0 & 0 & 0 & 0 & 0 & 0 & 0 \\
\hline $05-10$ & 0 & 0 & 0 & 0 & 0 & 0 & 1 & 0 & 0 & 0 & 1 & 0 & 0 \\
\hline 06-10 & 2 & 2 & 2 & 2 & 2 & 2 & 2 & 2 & 2 & 2 & 10 & 10 & 0 \\
\hline 07-08 & 2 & 2 & 2 & 2 & 2 & 2 & 2 & 2 & 2 & 2 & 10 & 10 & 0 \\
\hline 08-09 & 0 & 0 & 0 & 0 & 0 & 0 & 0 & 0 & 0 & 0 & 0 & 0 & 0 \\
\hline 08-10 & 0 & 0 & 0 & 0 & 0 & 0 & 0 & 0 & 0 & 0 & 0 & 0 & 0 \\
\hline 09-11 & 0 & 0 & 0 & 0 & 0 & 0 & 0 & 0 & 0 & 0 & 0 & 0 & 0 \\
\hline 09-12 & 0 & 0 & 0 & 0 & 0 & 0 & 0 & 0 & 0 & 0 & 0 & 0 & 0 \\
\hline $10-11$ & 1 & 1 & 1 & 1 & 1 & 1 & 1 & 1 & 1 & 1 & 10 & 0 & 0 \\
\hline $10-12$ & 0 & 0 & 0 & 0 & 0 & 0 & 0 & 0 & 0 & 0 & 0 & 0 & 0 \\
\hline 11-13 & 1 & 1 & 1 & 1 & 1 & 1 & 1 & 1 & 1 & 1 & 10 & 0 & 0 \\
\hline $11-14$ & 0 & 0 & 0 & 0 & 0 & 0 & 0 & 0 & 0 & 0 & 0 & 0 & 0 \\
\hline $12-13$ & 0 & 0 & 0 & 0 & 0 & 0 & 0 & 0 & 0 & 0 & 0 & 0 & 0 \\
\hline $12-23$ & 0 & 0 & 0 & 0 & 0 & 0 & 0 & 0 & 0 & 0 & 0 & 0 & 0 \\
\hline $13-23$ & 0 & 0 & 0 & 0 & 0 & 0 & 0 & 0 & 0 & 0 & 0 & 0 & 0 \\
\hline $14-16$ & 1 & 1 & 1 & 1 & 1 & 1 & 1 & 1 & 1 & 1 & 10 & 0 & 0 \\
\hline $15-16$ & 0 & 0 & 0 & 0 & 0 & 0 & 0 & 0 & 0 & 0 & 0 & 0 & 0 \\
\hline $15-21$ & 0 & 0 & 0 & 0 & 0 & 0 & 0 & 0 & 0 & 0 & 0 & 0 & 0 \\
\hline $15-24$ & 0 & 0 & 0 & 0 & 0 & 0 & 0 & 0 & 0 & 0 & 0 & 0 & 0 \\
\hline 16-17 & 0 & 0 & 0 & 0 & 0 & 0 & 0 & 0 & 0 & 0 & 0 & 0 & 0 \\
\hline 16-19 & 0 & 0 & 0 & 0 & 0 & 0 & 0 & 0 & 0 & 0 & 0 & 0 & 0 \\
\hline $17-18$ & 1 & 1 & 1 & 1 & 1 & 1 & 1 & 1 & 1 & 1 & 10 & 0 & 0 \\
\hline $17-22$ & 0 & 0 & 0 & 0 & 0 & 0 & 0 & 0 & 0 & 0 & 0 & 0 & 0 \\
\hline $18-21$ & 0 & 0 & 0 & 0 & 0 & 0 & 0 & 0 & 0 & 0 & 0 & 0 & 0 \\
\hline $19-20$ & 1 & 1 & 1 & 1 & 1 & 1 & 1 & 1 & 1 & 1 & 10 & 0 & 0 \\
\hline $20-23$ & 1 & 1 & 1 & 1 & 1 & 1 & 1 & 1 & 1 & 1 & 10 & 0 & 0 \\
\hline $21-22$ & 0 & 0 & 0 & 0 & 0 & 0 & 0 & 0 & 0 & 0 & 0 & 0 & 0 \\
\hline 01-08 & 0 & 0 & 0 & 0 & 0 & 0 & 0 & 0 & 0 & 0 & 0 & 0 & 0 \\
\hline $02-08$ & 0 & 0 & 0 & 0 & 0 & 0 & 0 & 0 & 0 & 1 & 1 & 0 & 0 \\
\hline 06-07 & 0 & 0 & 0 & 0 & 0 & 0 & 0 & 0 & 0 & 0 & 0 & 0 & 0 \\
\hline $13-14$ & 0 & 0 & 0 & 0 & 0 & 0 & 0 & 0 & 0 & 0 & 0 & 0 & 0 \\
\hline $14-23$ & 0 & 0 & 0 & 0 & 0 & 0 & 0 & 0 & 0 & 0 & 0 & 0 & 0 \\
\hline $16-23$ & 0 & 0 & 0 & 0 & 0 & 0 & 0 & 0 & 0 & 0 & 0 & 0 & 0 \\
\hline $19-23$ & 0 & 0 & 0 & 0 & 0 & 0 & 0 & 0 & 0 & 0 & 0 & 0 & 0 \\
\hline Reforços & 14 & 14 & 14 & 14 & 14 & 14 & 16 & 14 & 14 & 16 & & sto $M$ & \\
\hline $\begin{array}{c}\text { Custo } \\
\left(10^{6} \$\right)\end{array}$ & 417 & 417 & 417 & 417 & 417 & 417 & 473 & 417 & 417 & 505 & & 431,4 & \\
\hline InRef & 0 & 1 & 1 & 1 & 1 & 1 & 1 & 1 & 0 & 1 & & GU & \\
\hline InCus & 0 & 20 & 20 & 20 & 20 & 20 & 20 & 20 & 0 & 20 & & 119 & \\
\hline InRefA & 3 & 6 & 5 & 6 & 5 & 5 & 7 & 6 & 6 & 7 & & & \\
\hline InCusA & 95 & 176 & 122 & 202 & 122 & 154 & 182 & 202 & 180 & 209 & & & \\
\hline
\end{tabular}


Apêndice

Tabela A.23 - Reforços consolidados até a Tabela Decisão da Iteração 10.

\begin{tabular}{|c|c|c|}
\hline Ramo Candidato & Quantidade de Reforços & \multirow{2}{*}{ Tabela Decisão } \\
\cline { 1 - 2 } $03-09$ & 1 & \multirow{2}{*}{ Inicial } \\
\cline { 1 - 2 } $06-10$ & 1 & \multirow{2}{*}{ Iteração 1 } \\
\hline $20-23$ & 2 & Iteração 2 \\
\hline $07-08$ & 2 & Iteração 3 \\
\hline $06-10$ & 1 & Iteração 4 \\
\hline $01-05$ & 1 & Iteração 5 \\
\hline $11-13$ & 2 & Iteração 6 \\
\hline $01-05$ & 1 & Iteração 7 \\
\hline $01-02$ & 1 & Iteração 8 \\
\hline $19-20$ & 1 & Iteração 9 \\
\hline $14-16$ & 1 & Iteração 10 \\
\hline $10-11$ & 1 & \\
\hline $17-18$ & & \\
\hline
\end{tabular}

